\title{
INVESTIGATION OF THE EFFECTS OF DYNAMIC LOADS ON REINFORCED CONCRETE FLAT-PLATE BUILDINGS UNDER COLLAPSE SCENARIOS
}

A Dissertation

Presented to

The Faculty of the Graduate School

At the University of Missouri-Columbia

In Partial Fulfillment

Of the Requirements for the Degree

Doctor of Philosophy

by

Aamer H. Jawdhari

July 2018 



\section{INVESTIGATION OF THE EFFECTS OF DYNAMIC LOADS ON REINFORCED CONCRETE FLAT-PLATE BUILDINGS UNDER COLLAPSE SCENARIOS}

Presented by Aamer Jawdhari,

Candidate for the degree of doctor of philosophy

And hereby certify that, in their opinion, it is worthy of acceptance.

Sarah L. Orton, Supervisor

Zhen Chen

Hani A. Salim

Sherif El-Gizawy 



\section{DEDICATION}

This work is proudly dedicated to ....

The memory of my mother, a loved woman whom I still miss

every day,

And all my beloved family

(my father, my wife, my kids, my brothers and friends)

Thank you for your endless love, supports, prayers and

advices. 


\section{ACKNOWLEDGEMENTS}

I would not have been possible to write this dissertation without help and support of the kind people around me, to only some of whom it is possible to give mention here. First, I would like to express my gratitude to my supervisor Dr. Sarah Orton for her guidance, encouragement, and patience. The good advice, support and friendship has been invaluable on both an academic and a personal level, for which I am extremely grateful. I would also like to acknowledge my dissertation committee: Dr. Zhen Chen, Dr. Hani Salim, and Dr. Sherif El-Gizawy.

I would like to thank my sponsor Higher Committee for Education Development in Iraq (HCED) for their financial support to pursue my goal of getting $\mathrm{PhD}$ degree.

I would like to thank my lovely wife Nadia Al-Amery for her personal support and great patience at all time. My gratitude also extended to my kids Thamar, Shams Al-Zahraa, Ahmed and my youngest sweaty boy Hussein for giving me an amazing environment to achieve my goal. Also, my acknowledgement went to my father, brothers, sisters, my brothers in law, and friends for their supports and prayers.

And finally, I am most grateful to my friends Fawaz Al-Bakri, Ahmed Al-Zuheriy, Dr. Salwan Waheed, and Dr.Alaa Elsisi for their technical support to achieve my research program.

Aamer Jawdhari 


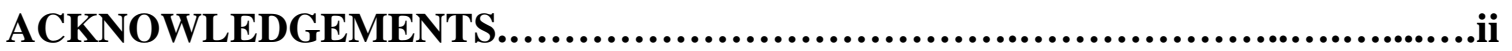

LIST OF FIGURES...................................................................

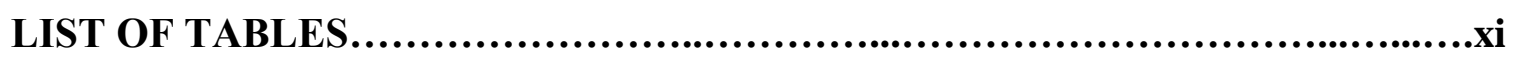

CHAPTER 1: STATEMENT OF PROBLEM........................................................ 1

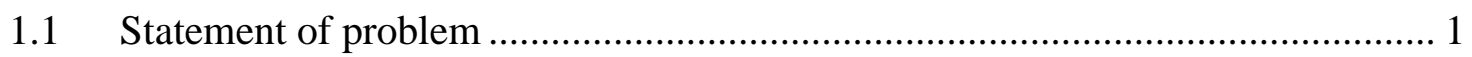

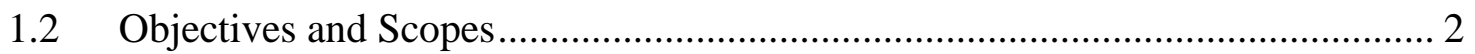

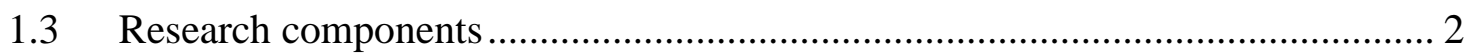

CHAPTER 2: LITERATURE REVIEW ............................................................................ 4

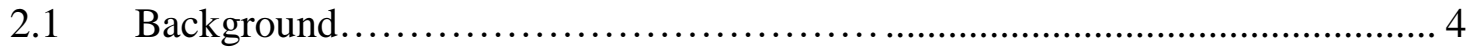

2.1.1 Progressive collapse .......................................................................... 4

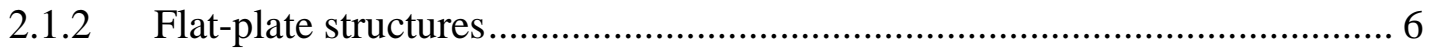

2.1.3 Punching capacity theories .................................................................... 7

2.2 Dynamic load effect on material properties ..................................................... 12

2.2.1 Plain concrete

2.2.2 Steel reinforcement .......................................................................... 15

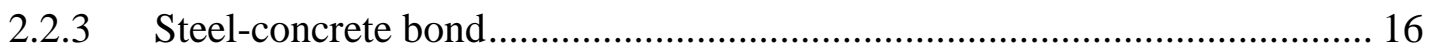

2.3 Dynamic load effect on RC structures ........................................................ 17

2.3.1 Experimental investigations.............................................................. 18

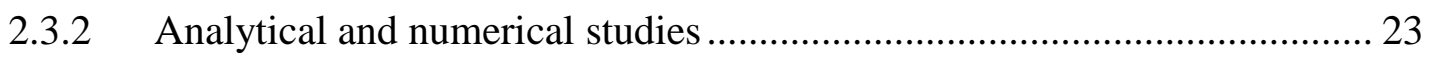

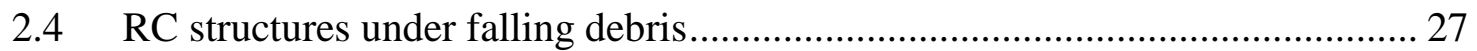

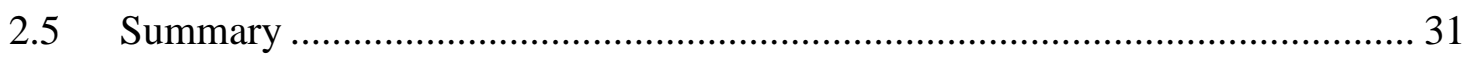

CHAPTER 3: EXPERIMENTAL INVESTIGATION OF LOADING RATE

EFFECTS ON RC SLAB-COLUMN CONNECTION .................................................33

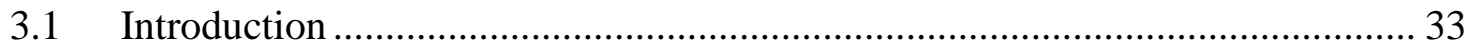




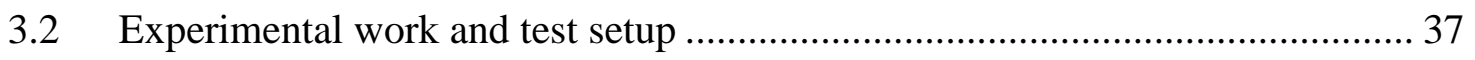

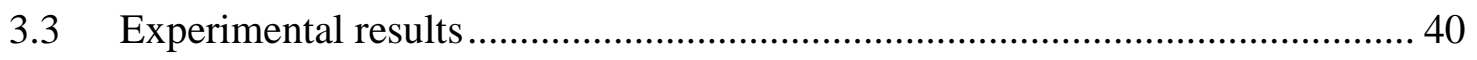

3.3.1 Load deflection behavior .................................................................... 40

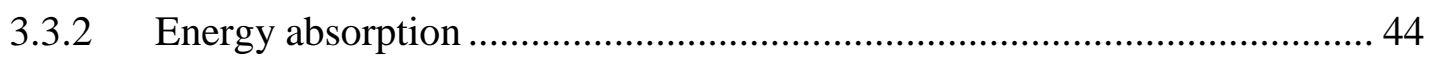

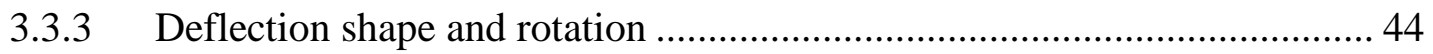

3.3.4 Rebar, concrete strain and strain rate effects ........................................... 46

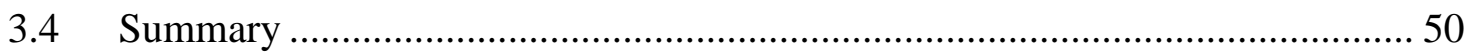

\section{CHAPTER 4: NUMERICAL SIMULATION OF LOADING RATE EFFECTS ON RC SLAB-COLUMN CONNECTION ...................................................................... 51}

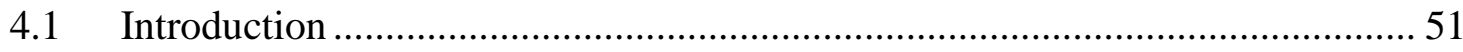

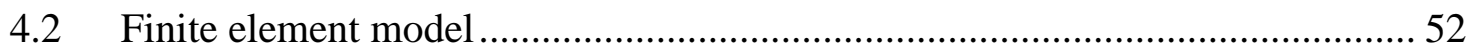

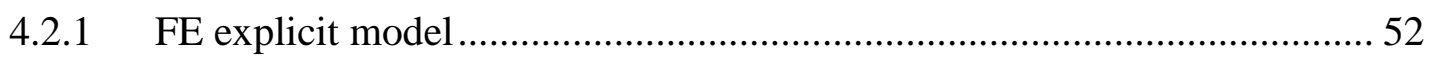

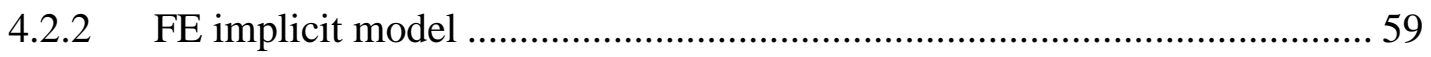

4.3 Validation of finite element model and analytical results................................... 62

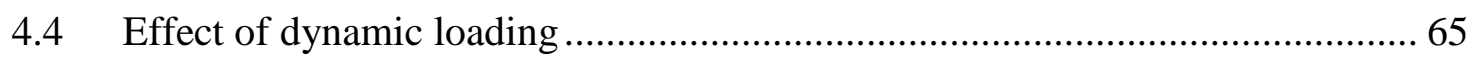

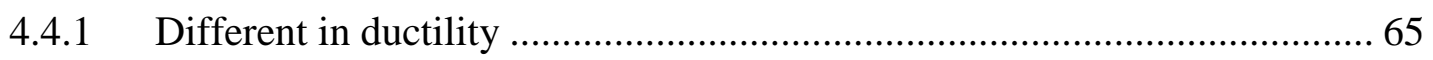

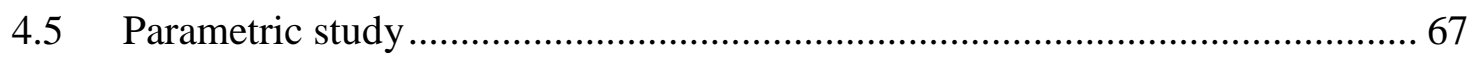

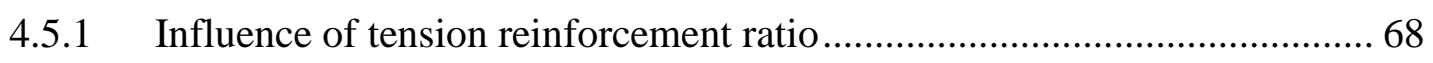

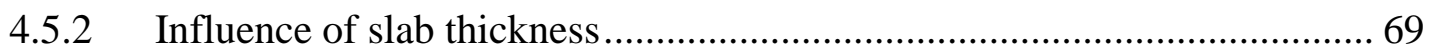

4.5.3 Influence of compressive strength of concrete ……………….................. 70

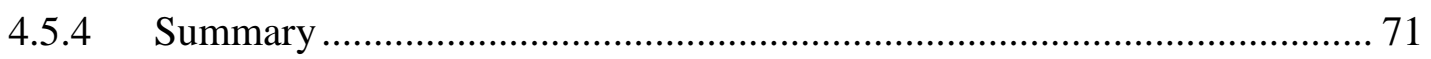

\section{CHAPTER 5: SIMPLYFIED SIMULATION OF LOADING RATE EFFECTS ON

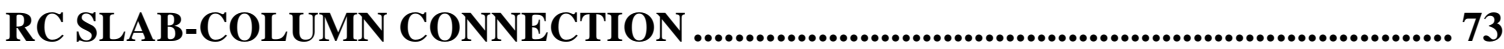

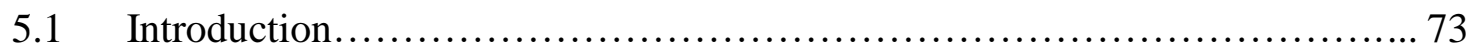

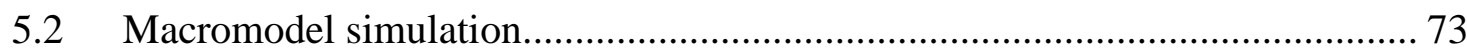

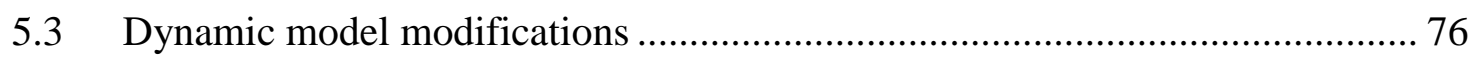

5.4 Simplified model validation of isolated slab-column connection....................... 78

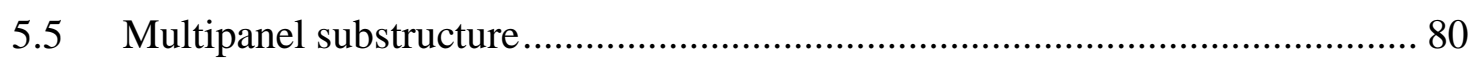

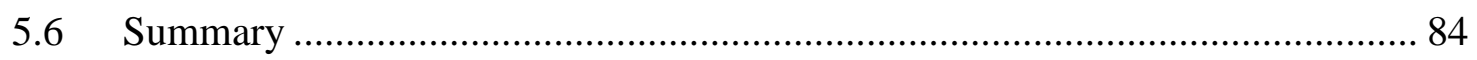




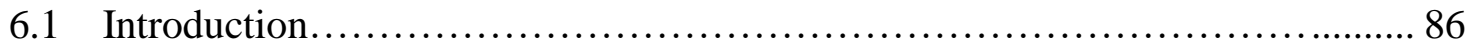

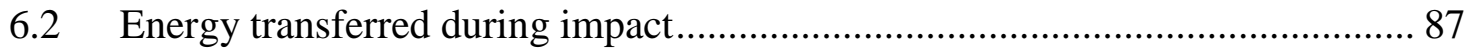

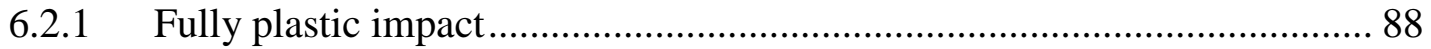

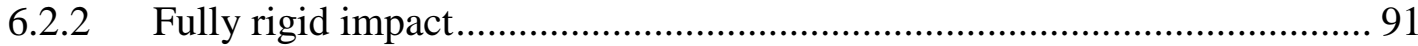

6.3 Assessment Methodology ........................................................................ 93

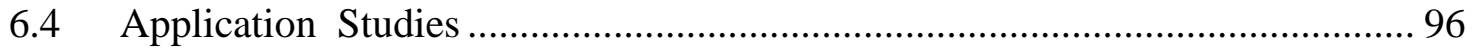

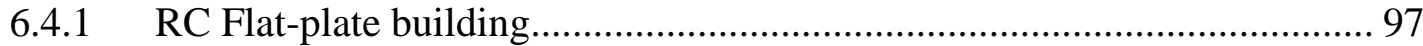

6.4.2 Composite steel -concrete floor building .................................................... 101

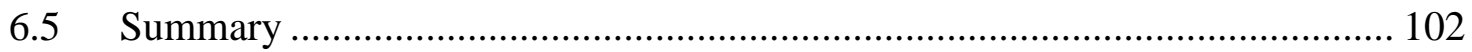

CHAPTER 7: CONCLUSIONS AND FUTURE WORK ......................................... 104

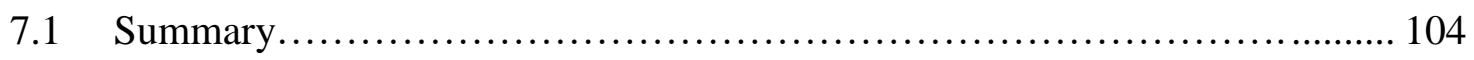

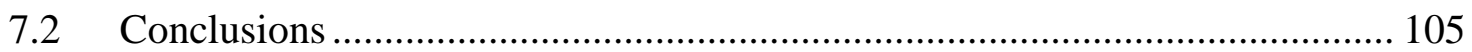

7.2.1 Experimental investigation of loading rate effects on RC slab-column

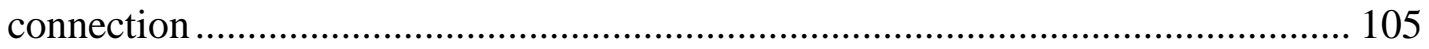

7.2.2 Numerical investigation of loading rate effects on RC slab-column

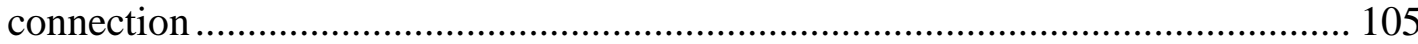

7.2.3 Simplified simulation of loading rate effect on RC slab-column

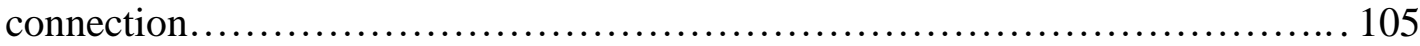

7.2.4 Dynamic debris loading in flat-plate buildings......................................... 106

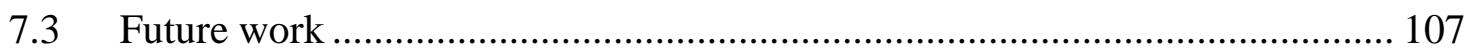

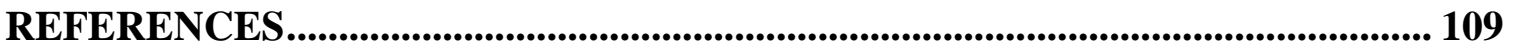

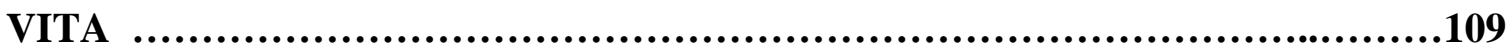




\section{LIST OF FIGURES}

Figure 2-1 Disproportionate collapse at Ronan point apartments in London England

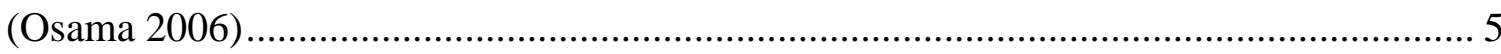

Figure 2-2 North wing collapse of Sampoong Department Store ................................. 6

Figure 2-3 Diagonal cracking resulting from shear forces (Harris 2004)...................... 8

Figure 2-4 Mechanical model of Kinnunen and Nylander (1960) ................................. 9

Figure 2-5 Punching shear strength specification of slab per Critical Shear Crack theory

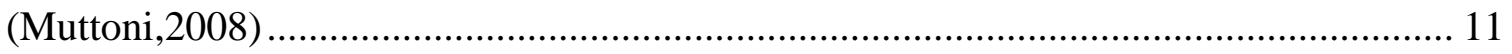

Figure 2-6 Load-displacement curves obtained from monotonic dynamic tests

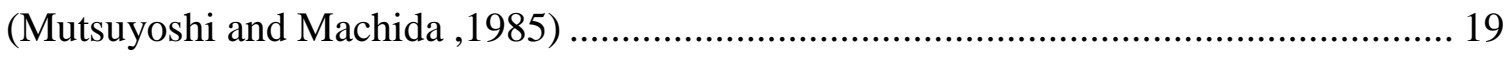

Figure 2-7 Load-deflection diagrams and crack patterns for specimens B4JL25-S and

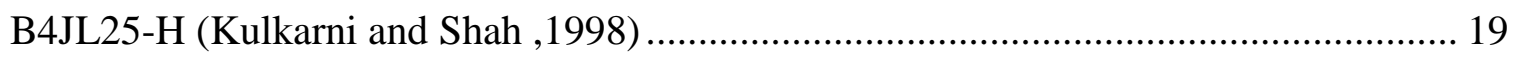

Figure 2-8 Relative enhancements of flexural and shear strengths (Kulkarni and

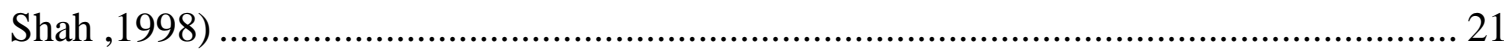

Figure 2-9 Analytical object (Fujikake,2009)....................................................... 25

Figure 2-10 Section analysis considering strain rate distribution (Fujikake, 2009) ........ 25

Figure 2-11 Influence of the longitudinal reinforcement ratio on the DIF of maximum

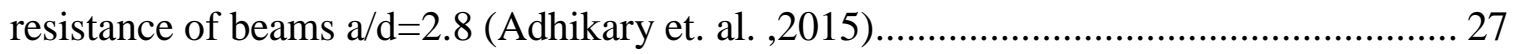

Figure 2-12 Floor impact assessment. (a) Original floor grillage;(b) Assumed initial gravity load distribution and approximate deformation mode upon impact. Vlassis et al. (2009) 28

Figure 2-13 Static load-deflection curve for the grillage system. (a)Peripheral floor plate;(b) Internal floor plate. (2009) 29 
Figure 2-14 Modified pseudo-static load -deflection curves for the grillage system. (a)Peripheral floor plate;(b) Internal floor plate. (Vlassis et al.,2009) ........................... 30

Figure 3-1 Geometry and reinforcement details of specimens ................................. 38

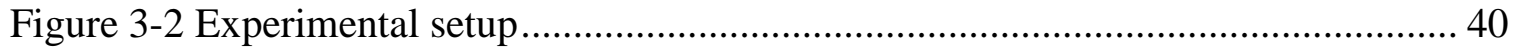

Figure 3-3 Normalized load-deflection response ............................................... 41

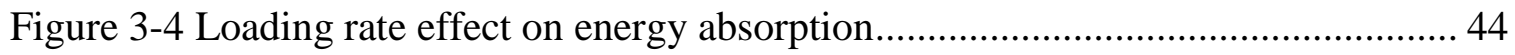

Figure 3-5 Deflected shape under static and dynamic loading rate ............................. 45

Figure 3-6 Comparison of distribution of strain in tension reinforcement passing through

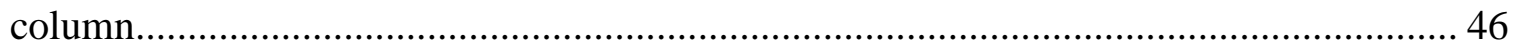

Figure 3-7 Concrete radial and tangential strains before punching shear failure ............ 47

Figure 3-8 a) Steel and concrete strain of dynamic test (1UN-D4) b) Steel strain rate vs time for isolated (1UN-D4) and multi-panel (Peng et al. 2018) tests ............................. 48

Figure 4-1 Finite element model and boundary conditions ..................................... 53

Figure 4-2 General shape of the concrete model yield surface in two dimentions in the

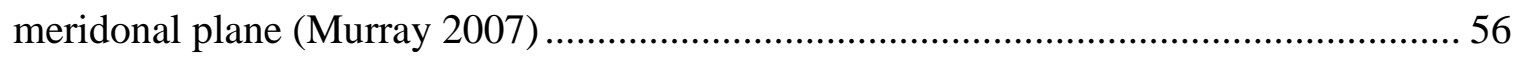

Figure 4-3 Strain softening and modulus reduction of cap model simulation (Murray 2007)

Figure 4-4 Tensile and compressive material dynamic increase factors for concrete model

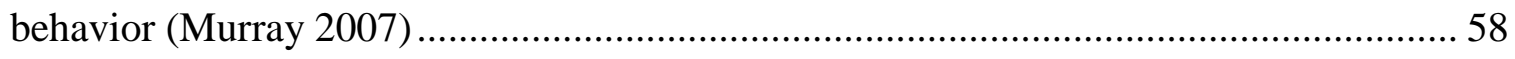

Figure 4-5 Stress -strain curve of tested reinforcement bars .................................... 59

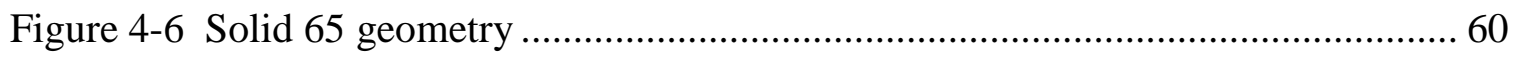

Figure 4-7 Compressive uniaxial stress -strain curve of concrete .............................. 61

Figure 4-8 Load- Deflection curve of dynamic test of specimen ................................. 63 
Figure 4-9 Strain history of tension reinforcement bars for specimen (1UN-D4). 64

Figure 4-10 Failure pattern on tension surface of slab-column connection model at punching. 64

Figure 4-11 Load-Deflection curve of static test for specimens (1.0UN-S3,0.64UN) .... 65

Figure 4-12 Relative enhancement of punching shear capacity 66

Figure 4-13 Loading rate effect on punching shear capacity by using FE model 67 Figure 4-14 Influence of reinforcement ration on: (a) load-deflection relationship of static and dynamic tests (b) punching shear strength of static and dynamic tests, (c) DIFs of maximum shear strength, (d) DIFu of deflection at punching shear failure 69 Figure 4-15 Influence of slab thickness on :(a) punching shear strength of static and dynamic tests, (b) DIFs of maximum shear strength, (c) DIFu of deflection at punching shear failure 70

Figure 4-16 Influence of concrete compressive strength on :(a) punching shear strength of static and dynamic tests, (b) DIFs of maximum shear strength, (c) DIFu of deflection at punching shear failure. 71

Figure 5-1Macromodel for flat plates Liu et al. (2015) 75

Figure 5-2 Load-deflection response predicted by macromodel versus test results (Peng et al.2017) 76 Figure 5-3 Load- Deflection curve of dynamic FE model of specimen 1.0UN-D4 based on original and modified connector properties 77

Figure 5-4 Muttoni failure criteria modification. 78

Figure 5-5 Load- Deflection curve of dynamic test and FE model of specimen ............. 80 Figure 5-6 Schematic model of test specimen (Peng et al. 2018) 82 
Figure 5-7 Experimental and simulation results for vertical displacement history at column

B2 83

Figure 6-1 Assumed failure mechanism of RC panel based on yield line theory. 90 Figure 6-2 Velocity profile for the two combined beams or slabs after fully plastic impact.

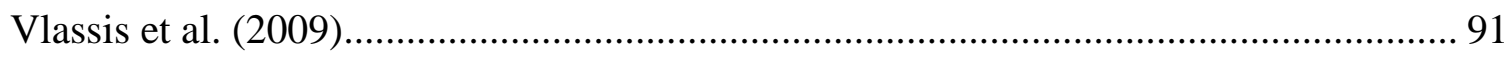

Figure 6-3 Simplified dynamic assessment and definition of modified pseudo-static response for impacted floor systems. (a) Dynamic response; (b) modified pseudo-static

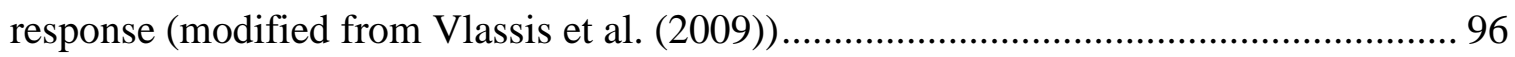
Figure 6-4 Assumed failure in four panels surrounding column in RC flat-plate structure

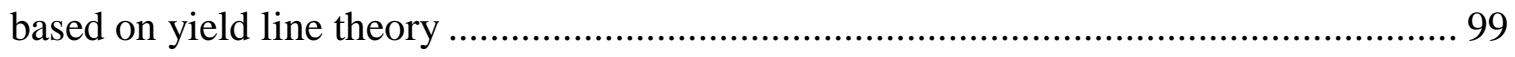

Figure 6-5 Static load-deflection curve for the RC flat-plate system .......................... 99 Figure 6-6 Modified pseudo-static load-deflection curve for the RC flat-plate system . 100 


\section{LIST OF TABLES}

Table 3-1 Specimen results at punching shear failure ............................................ 39

Table 3-2 Steel and concrete strain rate for dynamic tests at yielding of tension steel .... 50

Table 4-1 Total number and types of elements of LS-DYNA model............................ 53

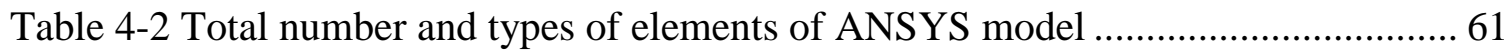

Table 5-1 A comparison in rotation for different slab-column connections specimens .. 84

Table 6-1 Energy transfer in a fully rigid impact for beam and slab construction

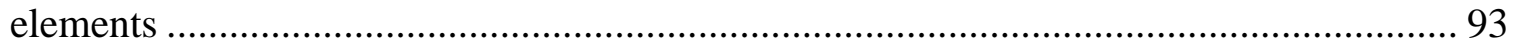




\title{
Investigation of the Effects of Dynamic Loads on Reinforced Concrete Flat- Plate Buildings under Collapse Scenarios
}

\author{
Aamer Jawdhari \\ Dr. Sarah Orton, Dissertation Supervisor
}

\begin{abstract}
During the initial stages of a collapse, failure of the initiating member (i.e. column loss) can cause a dynamic load redistribution in the surrounding members. The ability of the structure to withstand these dynamically redistributed loads will determine if the building is susceptible to collapse. If the surrounding members cannot support the redistributed load, the second stage of progressive collapse can happen. In this stage, there is falling debris from the failed members surrounding the removed column and dynamic impact on the floors below. Furthermore, while the behavior of RC members under static and high-rate (blast) loads are well researched, there is less information about the response under medium rate loads that occur during collapse. This research first looks specifically at flat-plate slab column connections to study the effect of collapse loading rate on the slab column connection behavior and how that behavior changes the collapse potential of the building. Second, the effect of falling debris load on the lower floors of flat-plate buildings during the collapse is investigated.

For the first stage of this research, an experimental program on four isolated connections with different tension reinforcement ratios $(1 \%, 0.64 \%)$ were tested by applying a dynamic load representative of the loading rate during collapse. The dynamically tested specimens have a significant increase in ductility compared to the statically tested specimens, however there was no significant change in punching capacity.
\end{abstract}


The increase in ductility comes from the differing effects on enhancement in material strength of steel and concrete due to the strain rate effect on the shear and flexural capacity of the member. The greater improvement in shear strength allows for more flexural response and more deflection before punching failure. Detailed numerical analysis was conducted using the finite element packages LS DYNA and ANSYS. Parametric studies present the effect of slab thickness and compressive strength of concrete. A simplified model in the FE analysis program Abaqus was analyzed to accurately predict the collapse potential in flat-plate structures. Results of the analysis showed that including the dynamic failure criteria of the connectors better represented the experimental test.

The impact loads from falling debris were also analyzed by using a simplified analysis approach. Estimation of the falling debris loading was carried out for a reinforced concrete flat-plate system and compared to an earlier analysis using a steel framed composite building. Theoretically, a plastic impact results in an amount of energy imparted to a lower floor of $33 \%$ and $37.5 \%$ of the initial kinetic energy of the falling floor for the reinforced concrete flat-plate building and steel- framed building, respectively. For a rigid impact this value is between $44 \%$ - $97 \%$ for reinforced concrete flat-plate and $41 \%-98 \%$ for steel framed building. The relative impact loads and ability of the impacted floors to arrest the progressive collapse was also analyzed. For both the concrete flat-plate buildings and steel frame, the impacted floor is highly unlikely to withstand an impact from the floor above. The analysis of the flat-plate system included a detailed look at how the dynamic loading can change the strength and ductility of the slab-column connection. 


\section{CHAPTER 1: STATEMENT OF PROBLEM}

\subsection{Statement of problem}

The collapse of a structure can have serious societal and economic consequences, yet the behavior of collapsing buildings is not well understood. More research is needed to fully understand the dynamic nonlinear behavior of these systems.

Currently, the robustness of a building, or the ability of that building to withstand collapse, is often analyzed in an alternate load path approach (GSA 2013, DoD 2016). In this approach a supporting element, such as a column, is suddenly removed and the ability of the building to withstand that removal is analyzed. Progressive collapse resulting from a removed column can be divided into two stages. The first stage analyzes the redistribution of load and if the members surrounding the failed column can support the redistributed load. However, most analysis of structures for collapse (GSA 2013, DoD 2016) use the static capacity of the surrounding members to determine if collapse will progress. As the loading is dynamic, this may introduce inaccuracy into the analysis. Therefore, experimental and numerical investigation is needed to examine the difference in behavior of structure under static and dynamic loading rates (collapse loading rate) and its effect on the collapse process.

If the surrounding members cannot support the redistributed load, the second stage of progressive collapse can happen. In this stage, there is falling debris from the failed members surrounding the removed column. This debris impacts the floor below and that floor must be able to withstand the dynamic impact to arrest progressive collapse. There 
has been some work in estimating the progressive collapse of floor systems in multi-story structures subjected to impact load due to falling slab or debris from the above floor. However, the complexity of studying the effect of impact load of impacting floor on the floor below necessitates the need to find a simple approach to analyze falling debris impact.

\subsection{Objectives and Scopes}

The objective of this research is to investigate the difference in behavior of flatplate slab column connections under static and dynamic loading rates (collapse loading rate) and its effect on the collapse process. The research implements improvements to a simplified model (similar to what would be available in design office) to account for the dynamic response of the connection. Furthermore, the research analyzes the impact loads from the falling debris and evaluates if the floor below would be able to withstand those loads.

Experimental tests were conducted to evaluate the punching capacity and failure mode of isolated RC flat-plate slab-column connections by applying concentrated load at a rate representative of the rate of load redistribution in a collapse scenario. Furthermore, the nonlinear finite element packages LS DYNA and ANSYS were used to create a 3D FE model to validate the experimental work. The influence of various parameters on the response of isolated RC flat-plate slab column connections was investigated numerically. Then, a simplified model was developed to accurately predict the collapse potential in flat-

plate structures. Finally, an estimation of debris load for a reinforced concrete (RC) flatplate was determined.

\subsection{Research components}

For this research, the following tasks were conducted: 
- Experimental program, consisting of four specimens, is carried out to inspect the punching capacity and failure mode in an isolated RC flat-plate slab-column connection for different levels of lateral restraint, and reinforcement ratio by applying concentrated load at a rate representative of the rate of load redistribution in a collapse scenario. The results of this series of dynamic tests are compared with an earlier static series by the research presented in Peng et al. (2017a).

- A 3D FE model is developed using LS DYNA and ANSYS to assess the punching shear strength and ductility of isolated slab-column connection under dynamic and static loading rate.

- A parametric study numerically evaluates the effect of tension reinforcement ratio, slab thickness, and grade of concrete compressive strength on the response of isolated RC flat-plate slab column connections under static and dynamic loading rate.

- A simplified model is developed to accurately predict collapse potential. The model is developed in the FE analysis program Abaqus. The model consists of shell elements representing the slab and beam elements to represent the columns. The area within the punching cone perimeter is modeled with connector elements as described in Liu et al. (2015). The properties of the connector elements are modified to include the effect of the dynamic redistribution of the load.

- An estimation of debris load using a simplified approach for a reinforced concrete (RC) flat-plate is modified to evaluate the floor below to withstand those loads. 


\section{CHAPTER 2}

\section{CHAPTER 2: LITERATURE REVIEW}

\subsection{Background}

This chapter focuses on giving a background of progressive collapse, flat-plate structural systems, and important theories of prediction punching shear capacity of flatplate structures. Furthermore, a comprehensive survey of the strain rate effect on material properties of reinforcement structures and steel-concrete bond properties give background needed to understand the nature of the redistributed dynamic load during progressive collapse. A literature review will be presented on the structural components exposed to a concentrated loading rate and debris impact load.

\subsubsection{Progressive collapse}

There are some events which are outside the ordinary design consideration. These events such as car accidents (impacts), gas explosion or blasts, occupant misuse, errors in design or construction etc. can trigger the progressive collapse by causing failure one or more supporting members leading to collapse part or entire structure. Progressive collapse has been defined in many ways. U.S General Services Administration (GSA) defines it as "a situation where local failure of a primary structural component leads to the collapse of adjoining members which, in turn, leads to additional collapse. Hence the total damage is disproportionate" (GSA, 2013). Also, ASCE Standard “7-05" Minimum Design Loads for Buildings and Other Structures states the progressive collapse as "the spread of an initial 
local failure from element to element, eventually resulting in the collapse of an entire structure or a disproportionately large part of it".

Progressive collapse of Ronan Point Apartment in London, England in 1968 represents one of the earliest cases of progressive collapse that caused a wave of interest in the structure engineering community. This building was partially collapsed due to the gas explosion on the $18^{\text {th }}$ floor causing loss of an exterior cladding panel. Due to the lack of tying of the panels together the loos of one panel lead the collapse almost the entire corner of this building (Osama, 2006) as seen in Figure 2-1.

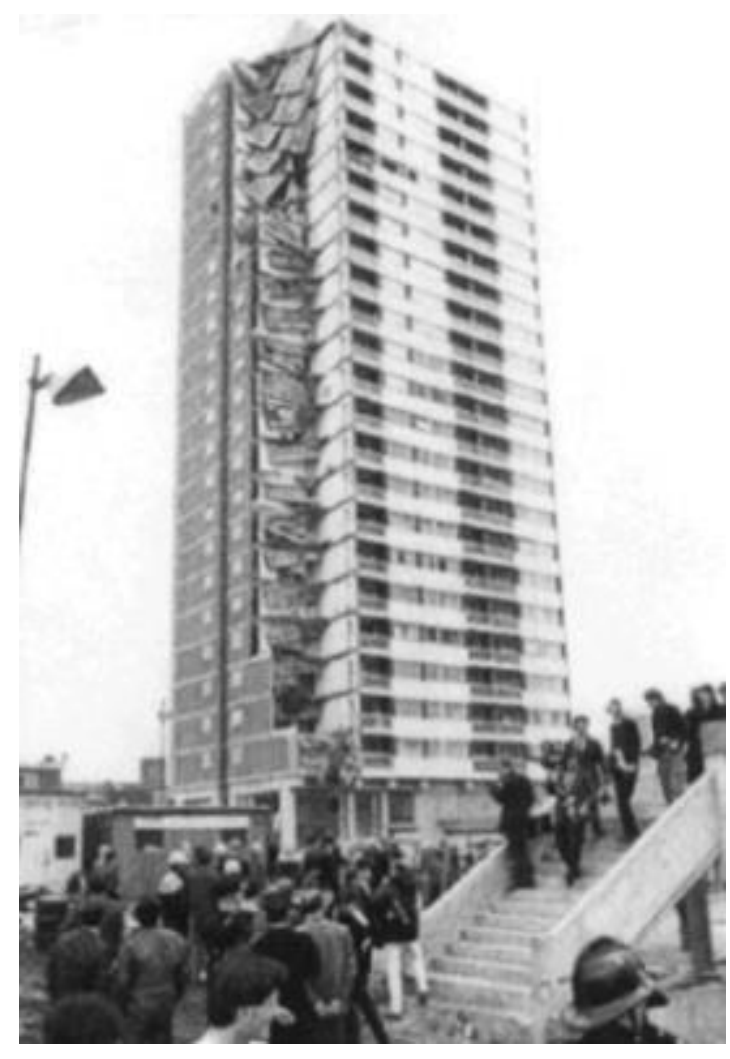

Figure 2-1 Disproportionate collapse at Ronan point apartments in London England (Osama 2006)

One of the worst progressive collapse causing death a huge number of people was happened for Sompoong Department Store in South Korea in 1995. The building was originally designed as an apartment of four story building of two wings. During the 
construction, some changing had been done to convert the building function to be a large store. Therefore, adding one more floor and cutting some supporting columns to install escalators was conducted leading to change the building's plan. Later, a cooling system was installed on the floor adding more loads on the building and leading to appear some initial cracks due to moving it across the roof to other side of the building. These cracks were seen around some column below the area of cooling units before the collapse, expanded, and leaded to collapse the entire south wing of the building as shown in Figure $2-2$.

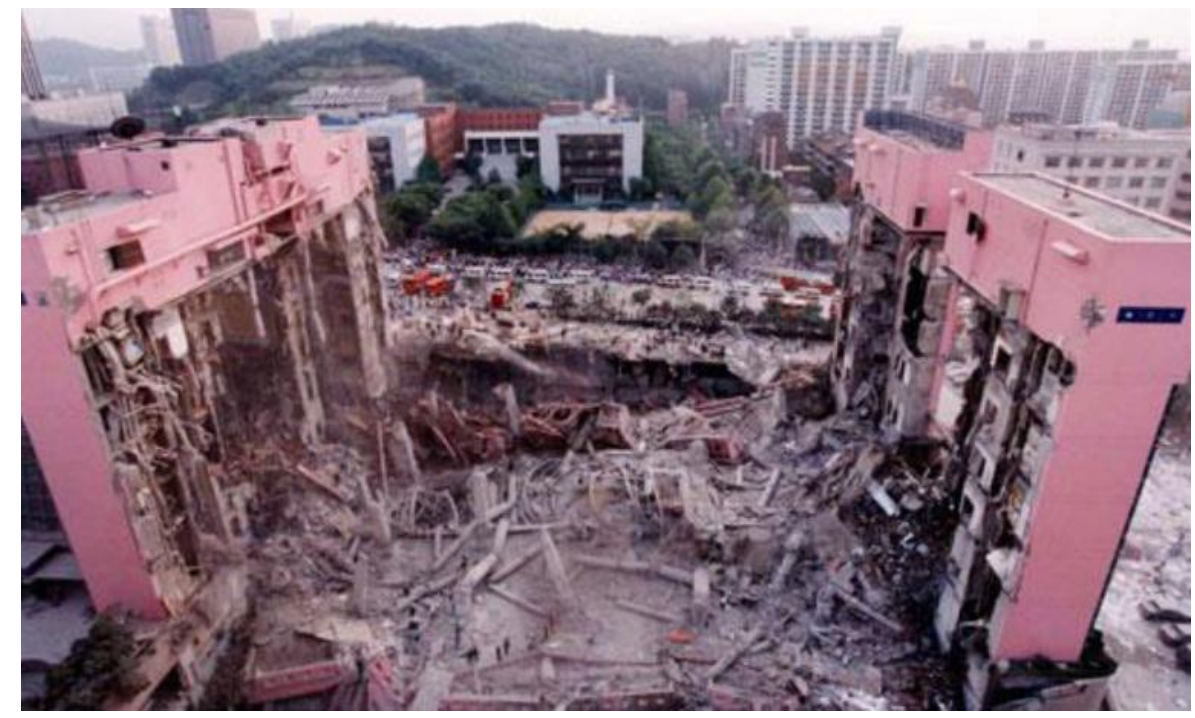

Figure 2-2 North wing collapse of Sampoong Department Store

\subsubsection{Flat-plate structures}

Flat-plate structures are a simple form of construction consisting of a uniform thickness of slab supported directly by columns without beams or girders. Due to its simplicity of construction, the economic cost of labor is reduced. It is one of the most common construction systems used to construct offices, apartments, hotels, and hospitals 
in the world. Its design is generally governed by punching shear capacity of the slab column connection and deflection of the slab (serviceability condition).

Because the slab-column connection is a critical link in the capacity of the system, when one of connections is overloaded and failed, the load carried by the connection must be dynamically redistributed to the surrounding columns which can lead to slab-column connection failure and leading to progressive collapse. These structures have a high potential of progressive collapse initiated by the loss of a supporting element. Furthermore, many of the RC flat-plate buildings constructed in the United States were designed prior to ACI 318-71 (1971) and have a lack of continuous bottom reinforcement at columns when further reduces the slab's capacity to redistribute load.

\subsubsection{Punching capacity theories}

Punching failure is the primary failure mode dominating in the $\mathrm{RC}$ flat-plate structure system. Punching failure occurs at the slab-column connection due to the concentration stresses around the column perimeter as the gravity loads in the slab are transferred to the column. Once the applied stress accedes the slab-column connection capacity, punching shear failure occurred. Generally, in flat-plate structure system, negative moment concentrates at the interface of slab-column region. This moment is transferred from the slab to the column and causing initial flexural cracks after a certain limit of stresses at the slab column interface. With increasing applied load, circular cracks pattern around the column will be formed leading to shear cracks as shown in Figure 2-3 


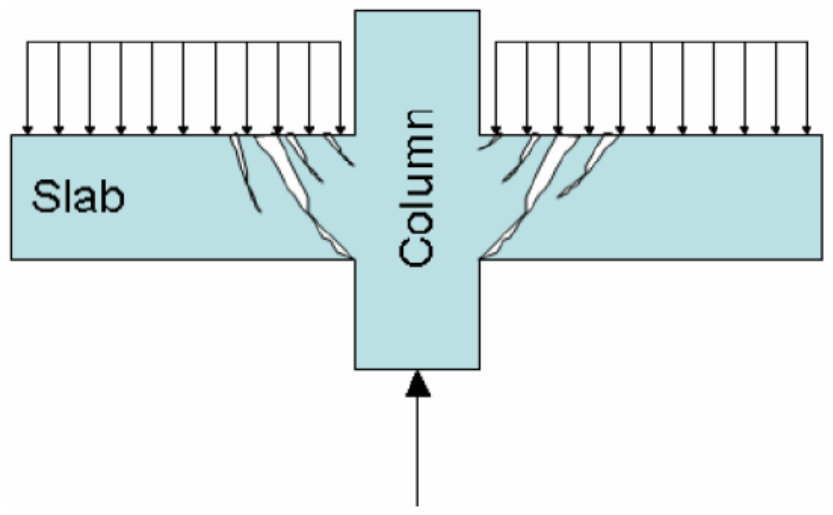

Figure 2-3 Diagonal cracking resulting from shear forces (Harris 2004)

One of the earlier theories to explain the punching capacity if from Kinnunen and Nylander (1960). They developed a mathematical model based on several experimental tests of a circular slab supported by column of circular cross section. The load is applied on the slabs edges as shown in Figure 2-4. The slab is divided into sectors of rigid segments outside the inclined shear cracks and supported at conical struts in compression zone right above the column. The failure criteria is defined when the stress at the conical shell and the tangential strain reach to the specific values. 


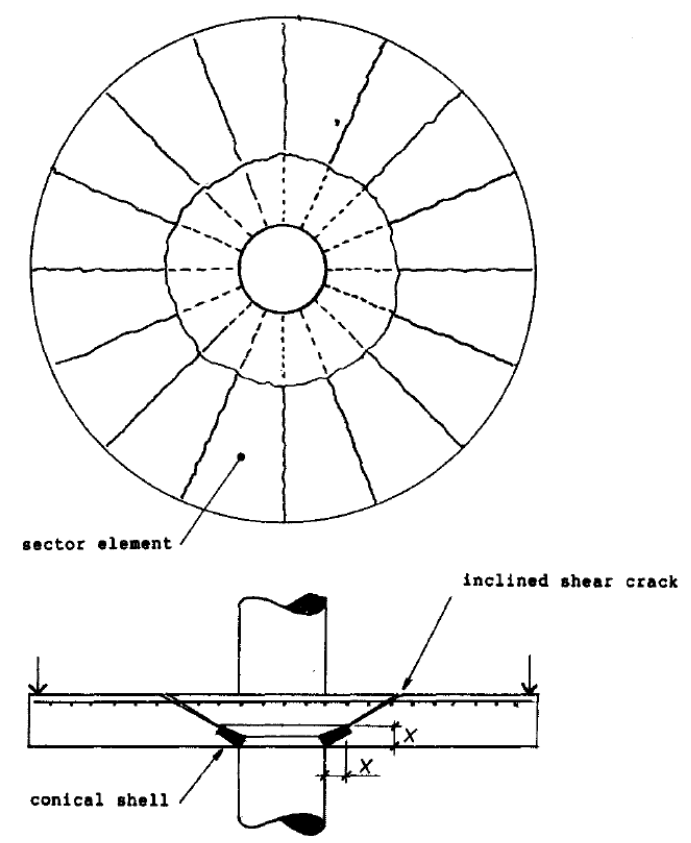

\section{Figure 2-4 Mechanical model of Kinnunen and Nylander (1960)}

Broms (1990) modified the Kinnunen and Nylander model by considering the slab depth (size effect) and concrete grade. Brom's model is calibrated by a wide array of experimental tests with various concrete properties. Furthermore, the compression zone is defined in radial and tangential directions without needing the iteration procedure used by Kinnunen and Nylander. High tangential compression strain or high radial compression stress is adopted as a base of failure mechanisms at the compression zone. The assumed value of the critical strain is 0.0008 . After this critical strain, parallel macro-cracks due to the growing of concrete micro-cracks propagate the incline shear cracks leading to punching failure. Based on the experimental test of uniaxial compressive cylinder specimens, the critical strain was calculated as follows:

$$
\varepsilon_{c p u}=0.0008 \cdot\left(\frac{150}{\alpha x_{p u}} \cdot \frac{25}{f_{c^{\prime}}}\right)^{0.333}
$$


Where 150 is the diameter of a standard test cylinder specimens; $x_{p u}$ is the height of the compression zone at flexure in tangential direction when punching occurs; $\alpha x_{p u}$ is the height of the equivalent rectangular stress block with the stress $f_{c^{\prime}}$; and $f_{c^{\prime}}$ is the concrete cylinder strength.

The critical radial stress is assumed to be $1.1 f_{c^{\prime}}$ because of the biaxial stress situation near the column which lead to increase the compressive strength of concrete. Equation (2.2) is derived based on the equilibrium condition in the vertical direction by considering the size effect and compression zone height in radial direction.

$$
\begin{aligned}
V_{\sigma} & =\left[\pi \cdot\left(B+2 y \frac{1}{\tan 30^{\circ}}\right) \cdot \frac{y \cdot \sin 15^{\circ}}{\sin 30^{\circ}} \cdot 1.1 f_{c^{\prime}}\left(\frac{150}{0.5 y}\right)^{0.333}\right] \cdot \sin 15^{\circ} \\
& \approx 0.46 \cdot(b+3.5 y) \cdot y \cdot f_{c^{\prime}}\left(\frac{300}{y}\right)^{0.333}
\end{aligned}
$$

Where 150 is diameter of a standard test cylinder specimen; $y$ is approximate thickness of conical shell; $f_{c^{\prime}}$ is the cylinder strength; and $\mathrm{b}$ is the diameter of column.

Muttoni (2008) developed a theory for prediction the punching shear capacity of RC slab-column connection based on a critical shear crack theory. The principles of this theory depend on the relationships between the rotation at slab-column connection and the maximum aggregate size in concrete. The theory is based on previous conclusions described in Muttoni and Schwarts (1991) about critical crack width developed under shear loading conditions. The crack width depends on the term $(\varphi d)$ where $\varphi$ is the connection rotation and $d$ is the effective slab width. In addition, crack roughness was addressed by considering the aggregate size effect which give an indication about the transferred shear across the critical shear crack. These variables are related by the following equation: 


$$
\frac{V_{R}}{b_{\circ} d \sqrt{f_{c^{\prime}}}}=\frac{3 / 4}{1+15 \frac{\psi d}{d_{g o}+d_{g}}}
$$

where $V_{R}$ is punching strength at slab-column connection, $\psi$ is rotation at connection at punching failure, $d_{g}$ is the maximum aggregate size, and $d_{g s}$ is a reference aggregate size equal to $16 \mathrm{~mm}$. To find punching shear strength of slab-column connection, load-rotation curve needs to be found by using any type of analysis or using the following equation:

$$
\psi=1.5 \frac{r_{s} f_{y}}{2 d E_{s}}\left(\frac{V}{V_{\text {flex }}}\right)^{1.5}
$$

Where $V_{\text {flex }}$ is the flexural strength, and $r_{s}$ is the distance between the column center and the point of contra-flexure. Based on the Equation (2-3), the failure criteria will be calculated for the slab and the intersection with load-rotation curve represents the punching shear strength of the slab as shown in Figure 2-5.

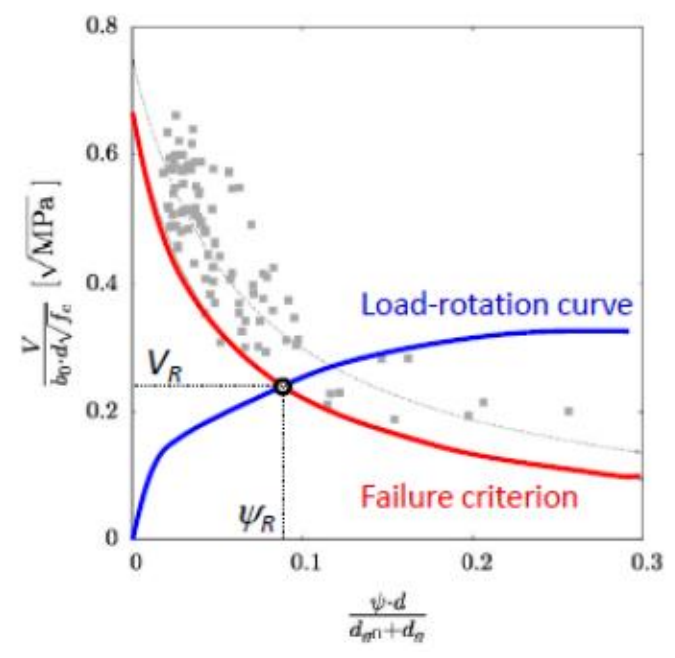

Figure 2-5 Punching shear strength specification of slab per Critical Shear Crack theory (Muttoni,2008) 


\subsection{Dynamic load effect on material properties}

The strain rate is one of the most important characteristics that must be considered in studying behavior of RC components structure subjected to a dynamic load. To understand the strain rate effect in RC structures, the effects in plain concrete, steel reinforcement, and bond properties will be covered.

\subsubsection{Plain concrete}

In order to capture the behavior of concrete under a dynamic load, it is necessary to cover three important aspects: 1) how crack development is affected by applying a dynamic load 2) variations in the behavior of material at the crack interface and 3) effect of external inertia loads.

Different methods are presented in literature for considering behavior of ratedependent structures. Mihashi and Wittman (1980) studied strain-rate theory to describe the first step of crack developing (crack initiation) on the atomic level. Crack initiation depends on how much energy stored in the system and is denoted by activation energy. They made a comparison between crack healing and crack developing and breaking after a critical value of an external loads. They concluded that the longer duration of dynamic loading, the more the damage and rupture in bond interface. In other words, dynamic load might be good or bad regarding structural load capacity, depending on the time duration of applying load. If the duration of the applied dynamic load is sustained for long time, the structure strength degrades and decreases continuously, however, if the duration is very short, the structure strength will increase dramatically. Mihashi (1980) suggested a mathematical expression to describe how material strength varies under tension, compression, and flexure loading conditions. 
Reinhardt and Weerheijm (1991) studied crack propagation processes from the material point of view. They pointed out that there is a critical velocity after which the crack propagates faster. At that level, the rate at which the energy supplied at the structure becomes very high because of the short time duration. The very short time of applied dynamic load is actually not enough for the applied energy to be absorbed, and therefore a large amount of that energy will be stored at the crack tip point. This behavior is considered as the main reason of increasing load capacity for a structure supplied to an external dynamic load.

Other researchers studied the effect of external loading rate on structural response by considering viscosity effect on crack growth using theory of activation. Bazant et al. (2000a, 2000b) explained this principle when he developed a simple model, but he did not consider inertia force effect.

Several models have developed to study concrete response under effect of external dynamic load for tension and compression conditions. One of these important model is the CEB model. Effect of strain rate was represented by Dynamic Increase Factor $\left(D I F_{c / t}\right)$ for compression and tension conditions. The DIF equation reported by CEB model was given as:

$$
D I F= \begin{cases}\left(\dot{\varepsilon} / \dot{\varepsilon}_{s}\right)^{1.026 \alpha_{s}} & \dot{\varepsilon} \leq 30 s^{-1} \\ \gamma_{s}\left(\dot{\varepsilon} / \dot{\varepsilon}_{s}\right)^{1 / 3} & \dot{\varepsilon}>30 s^{-1}\end{cases}
$$

Where $\dot{\varepsilon}$ is the strain rate in the range of $3 \times 10^{-6}$ to $300 \mathrm{~s}^{-1} ; \dot{\varepsilon}_{s}=30 \times 10^{-6} \mathrm{~s}^{-1}$ (static strain rate); $\log \gamma_{s}=6.156 \alpha_{s}-2 ; \alpha_{s}=1 /\left(5+9 f_{c s} / f_{c o}\right) ; f_{c o}=10 M P a ; f_{c s}$ is the concrete compressive strength. 
On the other hand, people have run several experiments to calculate the DIF in more precise way based on real data. For example, Fujikake et al (2001) ran rapid compressive tri-axial loading tests. He proposed a specific equation for DIF as:

$$
D I F=\left(\frac{\dot{\varepsilon}}{\dot{\varepsilon}_{s c}}\right)^{0.006\left[\log \left(\dot{\varepsilon} / \dot{\varepsilon}_{s c}\right)\right]^{1.05}}
$$

Where $\dot{\varepsilon}_{s c}=12 \times 10^{-5} s^{-1}$ and $\dot{\varepsilon}<10 s^{-1}$.

Malvar and Ross (1998) found some discrepancies and bias regarding validity of CEB model specially when the strain rate is smaller than $1 \mathrm{~s}^{-1}$. These differences motivated them to develop another equation to calculate DIF in tension conditions as:

$$
D I F=\left\{\begin{array}{cc}
\left(\dot{\varepsilon} / \dot{\varepsilon}_{s}\right)^{\delta} & \dot{\varepsilon} \leq 1 s^{-1} \\
\beta\left(\dot{\varepsilon} / \dot{\varepsilon}_{s}\right)^{1 / 3} & \dot{\varepsilon}>1 s^{-1}
\end{array}\right.
$$

Where $\dot{\varepsilon}$ is the strain rate in the range of $10^{-6}$ to $160 \mathrm{~s}^{-1} ; \dot{\varepsilon}_{s}=10^{-6} s^{-1}$ (static strain rate); $\log \beta=6 \delta-2 ; \delta=1 /\left(1+8 f_{c s} / f_{c o}\right) ; f_{c o}=10 M P a ; f_{c s}$ is the concrete compressive strength.

Another contribution to calculate DIF is reported by Xiao et al. (2010). He tested plain concrete at a $10^{-5}$ to $10^{-1}$ of strain rate in tension. The found that the dynamic strength increased by $6.3 \%, 13.08 \%, 20.48 \%$, and $25.47 \%$ at $10^{-4}, 10^{-3}, 10^{-2}$, and $10^{-1}$, respectively.

There are many equations to calculate the Dynamic Increase Factor of tension and compression concrete strength under different values of strain rate. The differences in the behavior between the models could be due to the concrete properties such as water-cement ratio, size aggregate, mix proportion, etc. Therefore, more experimental tests under different conditions are needed to get more accurate effect of strain rate on concrete strength. 


\subsubsection{Steel reinforcement}

Research has also been conducted to identify effect of strain rate on steel mechanical properties.

Wakabayashi et al. (1980), highlighted the distinction between effect of strain rate on yield stress point and the strain hardening region in stress-strain curve. They pointed out that yield stress is sensitive strain rate, while the strain hardening region is not as sensitive to strain rate. Similar conclusions are presented by Soroushian and Choi (1987) who also found that yield stress is more sensitive to the variations in strain rate than the ultimate stress. However, they showed that strain-rate had no effect on modulus of elasticity. Another conclusion can be drawn from their study is that the sensitivity of the steel wire of lower yield stress (lower mechanical properties) to the strain-rate effect is more dominant than that corresponding for the steel wire of high mechanical properties. In other words, the lower the yield strength, the higher the sensitivity to strain-rate effect.

On the other hand, Malvar (1998) proposed a mathematical representation to find $D I F_{s}$ for both yield stress and ultimate stress, respectively. The equation that described

the $\boldsymbol{D I F _ { s }}$ was basically created using the best curve fitting from experimental data. However, the formulation is not absolutely valid for all ranges of stresses and strain rates. It is valid for stress and strain range from $290 \mathrm{MPa}$ to $710 \mathrm{MPa}$ and $10^{-4} \mathrm{~s}^{-1}$ to $10 \mathrm{~s}^{-1}$, respectively. The equation is given by:

$$
D I F_{s}=\left(\dot{\varepsilon} / 10^{-4}\right)^{\alpha}
$$


Where $\dot{\varepsilon}$ is the strain rate in $s^{-1} ; \alpha=\alpha_{f y}$ which is equal to $\left(0.074-0.04 f_{y} / 414\right)$ in terms of yield stress calculations; $\alpha=\alpha_{f u}$ which is equal to $\left(0.019-0.009 f_{y} / 414\right)$ for ultimate stress calculations ; $f_{y}$ is static yield strength of steel rebar in MPa.

\subsubsection{Steel-concrete bond}

Bond characteristics are important to understand how bond properties (bond resistance and stress-displacement curve) behaves under the effect of dynamic loads. Bond behavior is a very critical topic due to its direct impact on reinforced concrete and reinforcement toughness. Many researches have studied effect of strain rate on bond properties for both static and dynamic loads conditions. However, there is a lack of references that state effect of strain rate on bond properties for structure supplied to dynamic working conditions. Weathersby (2003), Van and Reinhardt (1982), and Yan (1992) studied made the distinction about effect of loading rate between plain and deformed reinforced bars. The effect of strain rate on bonding properties is not significant for the plain bars while bond properties, stiffness, and strength increase with strain rate for deformed bars as stated by Van and Reinhardt (1982).

Yan (1992) developed a mathematical model to describe some characteristics of the bond between concrete and reinforcement. Based on that, he designed a program to predict behavior of the bond at different impact loads. He found that bond showed different behaviors for both plain and deformed bars, respectively. Furthermore, he pointed out that bond resistance for a smooth bar is developed by the frictional forces at the interface and by the chemical adhesive force. In addition, the relationship between stress and slip exactly at the interface (stress-slip) is a linear relationship and does not matter what kind of applied load is (static or dynamic). However, the situation is different for deformed bars so that the 
stress-slip relationship under dynamic loading is not predictable. It varies with time and different for every single point at the interface. In addition, capacity and bond resistance increase with increasing loading rates and compression strength. In other words, fracture energy increases with increasing loading rate. Yan concluded that stress distribution and stress concentration vary with the high rate loads and crack initiation and propagation is different from that corresponding of static loading due to stress concentration behavior.

Weathersby (2003) studied the effect of dynamic loading rate on the bond characteristic of concrete and steel rebar. The frictional static and chemical adhesion stresses for bars used in study were calculated by doing experimental tests. Regardless of loading rate, he found that the deformed bars gave $70 \%$ more pullout resistance compared to smooth bar. Also, the experimental and numerical model showed that the impact load gave more than $67 \%$ to $100 \%$ more pull out resistance compared to static load without changing the mode failure. Therefore, the bond under dynamic loads is assumed to be perfect during the numerical analysis in this study. In addition, the study demonstrated that the development length decreased with increasing in loading rate or the concrete confinement.

\subsection{Dynamic load effect on RC structures}

Reinforced concrete buildings can experience extreme events such as impact, blast, and earth quicks loads. In some cases, these loads can create collapse scenario by losing one or more supporting columns leading to progressive collapse of reinforced concrete buildings. While the behavior of reinforced concrete beam and flat-plate members under static loads has been widely investigated, less investigation has been done to the

corresponding behavior under dynamic loads especially on flat-plate structures. This 
section will focus on the literature review of concentrated dynamic loading rate effect on $\mathrm{RC}$ structures through experimental and numerical studies.

\subsubsection{Experimental investigations}

It is well known that the behavior of reinforced concrete members change with loading rate. Previous beam tests demonstrate that the change in behavior of RC beams under dynamic loads is not constant, but dependent on the strain-rate sensitivity and controlling failure mode. Steel and concrete are strain rate sensitive materials (Malvar 1998, Malvar and Ross 1998). Early tests on concrete beams showed that the failure mode can be changed from shear to flexural or vice versa with increasing loading rate depending on the strain rate sensitivity of steel and concrete materials used in the beam construction (Mutsuyoshi and Machida 1985, Kulkarni and Shah 1998).

Mutsuyoshi and Machida (1985) investigated 27 reinforced concrete (RC) beams with different shear span to effective depth ratios (a/d of 4 and 5.7) to study the effect of loading rates on the capacity and ductility of reinforced concrete members using a wide

range of strain rates, $1 \times 10^{-5}$ to 0.19 /s. The study showed that the load carrying capacity of reinforced concrete beam increased significantly with increasing loading rate as shown in Figure 2-6. This increasing in flexural capacity could come from the effect of strain rate on the steel reinforcement. Also, this study demonstrated that the mode of failure can be changed from flexural failure under static loading rate to shear failure mode under high loading rates. It was noticed that the mode of failure would not be changed when the beam lost its capacity before yielding occurred in bar reinforcement. In addition, beams which failed in shear mode before yielding in main reinforcement would have an increasing in shear strength with increasing in loading rate and it would reach to equal or greater than its flexural strength. 

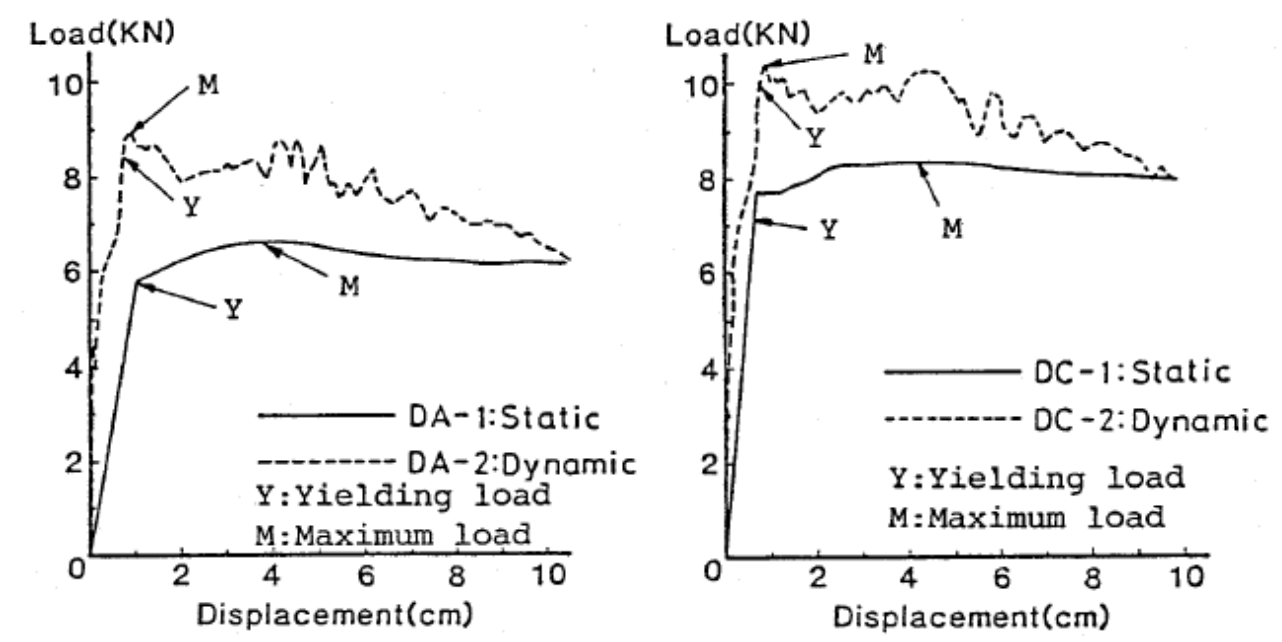

Figure 2-6 Load-displacement curves obtained from monotonic dynamic tests (Mutsuyoshi and Machida ,1985)

Kulkarni and Shah (1998) investigated seven pairs of four-point bending configuration RC beams to study the effect of loading rate (in strain rate range 0.000003 $0.3 / \mathrm{s})$ on the behavior of reinforced concrete members in terms of the load-carrying capacity and mode failure for different values of a/d ratio. The results showed that the loadcarrying capacity increased with increasing loading rate and flexurally controlled beams didn't show a sharp yield point under high loading rate as seen in Figure 2-7.

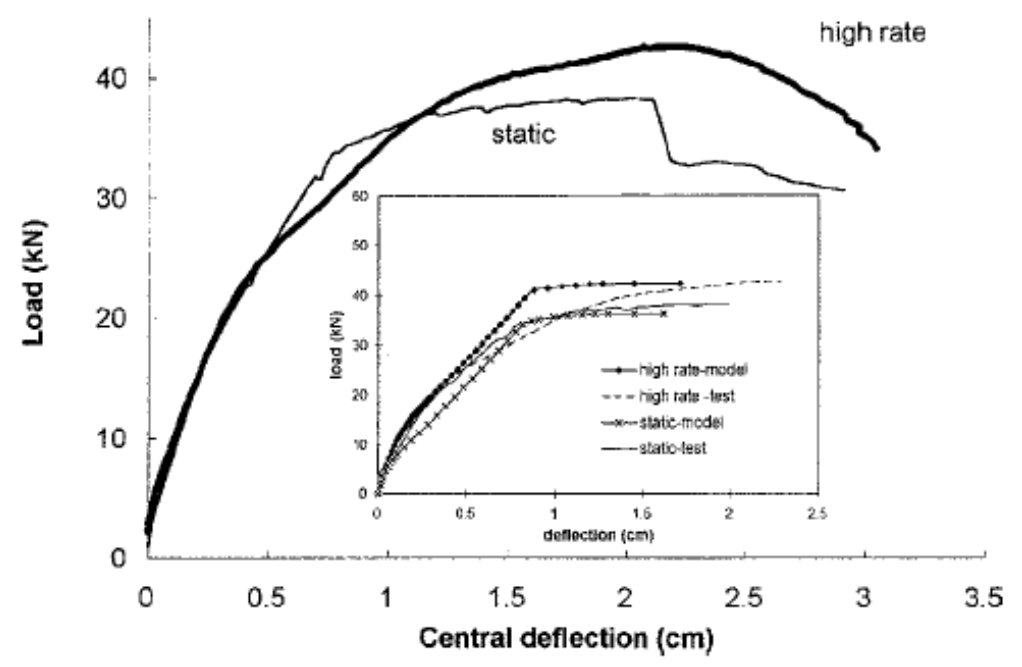

Figure 2-7 Load-deflection diagrams and crack patterns for specimens B4JL25-S and B4JL25-H (Kulkarni and Shah ,1998) 
Three pairs of beam had a failure mode shifted from shear mode at static load to flexural mode failure under high loading rate which is an opposite trend compared with previous research. This behavior could be due to the rate sensitivity of the different steel used in these work. Mutsuyoshi and Machida (1985) had two pairs with a/d equal 4 and 5.7 which their failure mode changed from flexural at static loading rate to shear at high loading rate. While, Kulkarni and Shah (1998) had three pairs of beams with a/d equal $4,4.5$ and 5 which their failure mode changed from shear failure at static loading rate to flexural failure at the high loading rate. Although the results of the two series of tests differed, the result can be explained based on the relative increase in flexural and shear strength under a high loading rate as shown in Figure 2-8. Kalkarni and Shah (1998) postulated that the change in failure mode may be due to the effect of strain rate on the yield strength of steel. For Mutsuyoshi and Machida (1985) beams, the yield strength was $310 \mathrm{MPa}$. Therefore, the increase in flexural strength with high loading rate was greater than the increase in shear strength leading to a shear failure at the high loading rate. For Kulkarni and Shah (1998), the yield strength was $517 \mathrm{MPa}$. The increase in flexural strength with high loading rate for the higher strength bars was less. Therefore, the improvement in shear capacity was more significant and led to a flexural failure at the higher loading rate. 


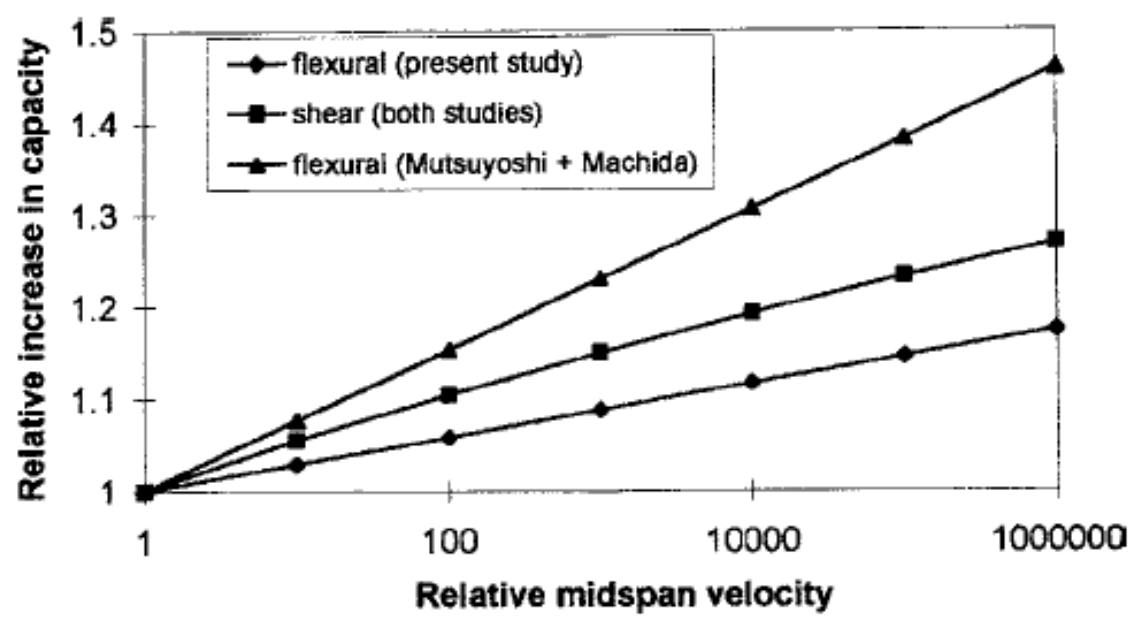

\section{Figure 2-8 Relative enhancements of flexural and shear strengths (Kulkarni and Shah ,1998)}

Adhikary et al. (2012) conducted three series of shear reinforcement ratios with a/d 3.33 on 4 pairs RC beams, applied to a wide range of loading rates $(0.0004 \mathrm{~m} / \mathrm{s}-2 \mathrm{~m} / \mathrm{s})$. Their study showed that the load carrying capacity increased with increasing in loading rate. The DIF was 1.16, 1.36, and 1.42 for low, medium, and high loading rate respectively. For specimens with no shear reinforcement as an example, the loading carrying capacity increased from $20 \%$ to $66 \%$ for low to high loading rate. The other specimens showed that The load carrying capacity and stiffness increased with increasing shear reinforcement ratio. In addition, by investigating the strain rate history during the test, the yield stresses for longitudinal reinforcement increased with increasing loading rate and it would be higher for specimens having more shear reinforcement. An equation to calculate strain rate based on loading rate was proposed as follow:

$$
\dot{\varepsilon}=1.25 \delta^{0.82}
$$

Where $\dot{\varepsilon}$ is the strain rate, and $\delta$ is applied the loading rate. With increasing loading rate and decreasing reinforcement ratio, the DIF increased. 
Adhikary et al. (2014) tested 24 RC beams of 0.3 of balance reinforcement ratio for two groups of 3.3 and 4.4 shear span to effective depth ratio series to investigate their behavior under a wide range of loading rate $(0.0157,1.575,15.748$, and $78.74 \mathrm{in} / \mathrm{sec})$ for static, low, medium and high loading rates respectively. These beams were divided into two groups based on shear span to effective depth ratio, and each group was divided into three sets based on shear reinforcement ratio. The results showed that the loading-carrying capacity for all the specimens increased with increasing loading rate leading to an increase the DIF. The DIF for smaller shear span to effective depth ratios was higher than those having higher shear span to effective depth ratios. This difference in behavior was because of the difference in their mode failure for those two groups. Also, this study explained that for specimens which fail in shear mode, the longitudinal reinforcement yielded early before reaching to the peak load for all loading rates except the static load case, leading to DIF less comparing with those yielding after shear failure. This is because the magnitude of DIF is affected by either strain rate sensitivity of yielding stress in steel reinforcement or by strain rate sensitivity of concrete tensile strength which is more rate sensitive comparing with yield stress in steel reinforcement. Also, this study showed that the strain rate for yielding longitudinal reinforcement could increase the flexural strength about 18 to $24.8 \%$, however there was no effect of strain rate in shear reinforcement on the shear resistance for high loading rate.

For reinforced concrete slab column connections, there are a few experimental tests that studied the dynamic effects on structures at both the sub-assemblage (isolated connection) and system levels. The tests conducted by Criswell (1974) indicated that connections in dynamically loaded slab-column specimens will display increased 
resistances and larger ductility. The deflections at failure increased 25 to 50 percent with the dynamic loading effects and strength increased on average 18 percent for lightly reinforced slabs and 26 percent for heavily reinforced specimens. However, the loads in his tests were applied with a rise time of only 0.009 to $0.0032 \mathrm{sec}$.

Ghali et al. (1976) investigated the strength and deformation of six full scale specimens of isolated slab-column connections by subjecting the column to static or dynamic horizontal forces. Specimens had different amount of reinforcement ratios with no shear reinforcement. Results indicated that the strength of isolated slab-column connection was $15 \%$ to $28 \%$ higher in the dynamic test compared to the static tests and it increased with increasing reinforcement ratio 0.5 to 1.5 for both static and dynamic tests. Also, the results showed that the dynamic test had higher energy absorption capacities of the slab in comparison with the static tests.

Xiao et al. (2016) tested RC slab specimens by applying concentrated load at the middle of a flat slab specimen with fixed boundary conditions at all sides for a wide range of loading rates from static $(0.0004 \mathrm{~m} / \mathrm{s})$ to high $(2 \mathrm{~m} / \mathrm{s})$. The results showed that the punching strength increased $15 \%$ to $54 \%$ at medium loading rates and $42 \%$ to $73 \%$ at high loading rates. Specimens with $0.59 \%$ reinforcement ratio showed increasing in ductility with increasing loading rate. Also, punching failure was the dominate mode irrespective of loading rate, and the effect of inertial force became more significant at high loading rate than medium loading rate. All of these tests seem to indicate an increase in ductility in slabcolumn connections under dynamic loading.

\subsubsection{Analytical and numerical studies}

There were very few analytical and numerical attempts to predict the loaddeflection behavior of RC structures under dynamic collapse loading rates. Kulkarni and 
Shah (1998) predicted flexural load-deflection response of RC beams under high loading rates by using the standard sectional analysis with taking the material strain rate effect into consideration. A good agreement was concluded in terms of predicting the maximum load capacity for static and dynamic tests. However, load-deflection curves showed poor agreement with the experimental tests applied to high loading rate. The main reason behind this disagreement is the nature of steel-concrete interaction which showed different response under high loading rate comparing to static loading rate. It was noticed that the spacing between the cracks increased with increasing loading rate due to the strain localization of reinforcing bar after yielding close to cracks leading sometimes to fracture the reinforcing bar under high loading of extreme events as reported by Chang and Shah (1989). A modification had made by considering the localization effect on the stress-strain curve of steel bar by averaging stress-strain relationship at high rate leading to an improvement to predict the load-deflection curve under high loading rate.

Fujikake et al. (2009) adopted the sectional analysis approach as a base of his nonlinear analytical solution considering the effect of strain rate on material properties. The load-deflection curve at mid-span was predicted by using the moment-curvature relationship of a section. In addition to the main assumptions of sectional analysis approach, the stress-strain curve of concrete and reinforcement bar was modified based on the effect of strain rate, and curvature rate $(\dot{\phi})$ and displacement rate $(\dot{\delta})$ relationship. Based on the linear elastic theory, the relationship of mid-span deflection and the curvature, as shown in Figure 2-9, can be written:

$$
\phi=\frac{M}{E I}=\frac{12}{L^{2}} \delta
$$




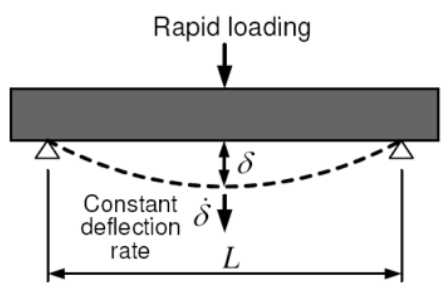

Figure 2-9 Analytical object (Fujikake,2009)

By using equation (2-10), the assumed curvature rate and mid-span deflection rate is:

$$
\dot{\phi}=\frac{12}{L^{2}} \dot{\delta}
$$

As shown in Figure 2-10, the beam section divided into number of concrete and steel elements to calculate the axial load and bending moment at any curvature on the section considering strain rate distribution.

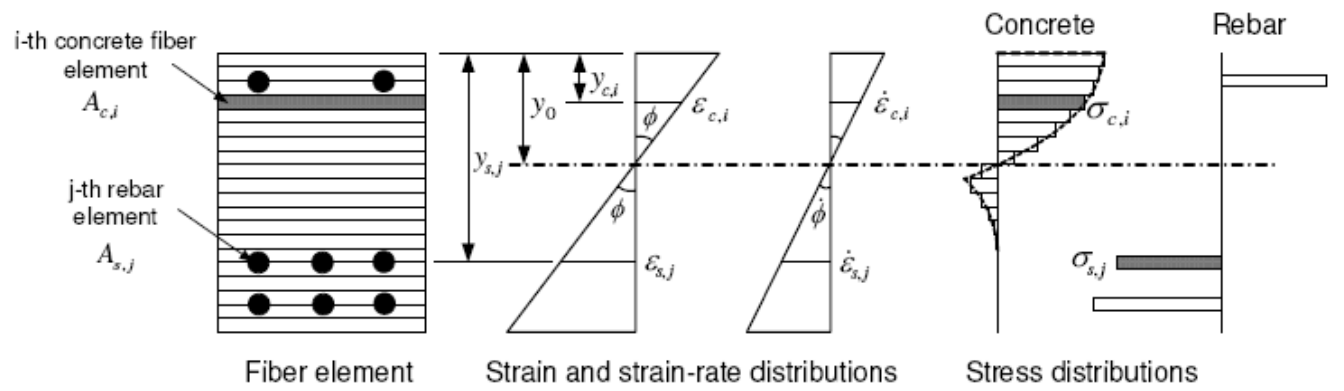

Figure 2-10 Section analysis considering strain rate distribution (Fujikake, 2009)

The load-deflection curve was determined and compared to the experimental test showing a good agreement of predicting the maximum deflection at the mid-span of beams failed in flexural mode under dynamic load.

Adhikary et. al. (2015) numerically investigated a wider range of loading rates by using 3D explicit finite element (FE) analysis. Nonlinear explicit FE program LS-DYNA in 2007 version was used in the numerical simulation for the dynamic and static tests. Concrete, loading plates, and supporting steel parts were represented by solid elements, while the reinforcing bars were represented by beam elements. $15 \mathrm{~mm}$ mesh size was used 
in this study. To avoid zero-energy or hourglass modes for concrete, Flanagan-Belytschko viscous form with one integration point was used. Reinforcement bars were modeled by a two-node Hughes-Liu beam element formulation with $2 \times 2$ Gauss quadrature integration. A perfect bond between the steel and the concrete was assumed in this study. Reinforcement bars were modeled as a strain rate sensitive material and the strain rate effect was modeled with the equations from Malvar. Continuous Surface Cap Model (CSCM), indexed in LS-DYNA as MAT 159, is used to model the concrete. This material model can predict material behavior during the dynamic loading considering elastic deformation and failure. The approach used by Adhikary et al. (2015) was implemented in the FE analysis in Chapter 4.A good agreement between the experimental and numerical model was resulted and a parametric study was conducted to investigate the effects of longitudinal and transverse reinforcement ratios, concrete grade, and yield strength of longitudinal steel bars under applying different loading rates of RC beams. DIF was used as a base of study these effects. It was found that DIF was high for beams having low amount of longitudinal reinforcement ratio compared to other beams having high ratio as shown in Figure 2-11. Also, the study showed that beams having large amount of transverse reinforcement ratio gave low DIF in comparison with beams having small amount of transverse reinforcement. Finally, one of the significant conclusion was that the yield strength of longitudinal steel played a big role on changing failure mode from shear to flexural or vice versa with increasing loading rate. 

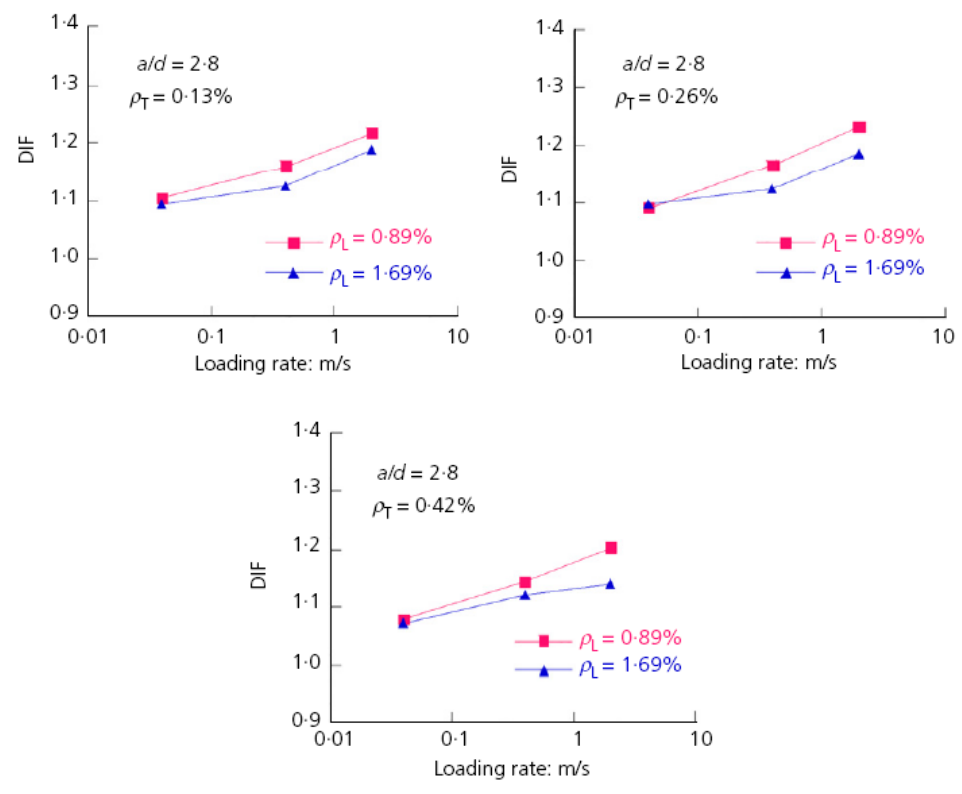

\section{Figure 2-11 Influence of the longitudinal reinforcement ratio on the DIF of maximum resistance of beams a/d=2.8 (Adhikary et. al. ,2015)}

Xiao et al. (2017) employed LS-DYNA finite element package to conduct 3D model to study the slab energy capacity under impact load. The results showed that the concrete compresive streength, slab thicknness, and diameter of impacted area can enhance the energy capacity of low reinforcement ratio slab specimens. Furthermore, FE model results were used in the regression analysis to propose two imperical equations to calculate the impact energy of low reinforcement RC slabe through punching shear failure.

\subsection{RC structures under falling debris}

In the past years, there has been some work in estimating the progressive collapse of floor systems in multi-story structures subjected to impact load due to falling slab or debris from the above floor.

Vlassis et al. (2009) investigated the steel frame structures subjected to falling slab from the above floor. A simplified approach based on determining the kinetic energy of 
impacting floor that is transmitted to the impacted floor was used to examine two extreme impact events namely fully rigid and fully plastic impact. This approach was originally based on the framework developed by Izzuddin et al (2007) for assessing the consequences of sudden column removal scenario. This approach contained three main steps ;(i) calculation of nonlinear static response of impacted floor, (ii) simplified dynamic assessment, and (iii) ductility assessment. The maximum dynamic deformation demands can be obtained by using the nonlinear static response of impacted floor by applying an energy balance concept without the need for detailed nonlinear dynamic analysis. An application of this methodology was conducted. In summary, a seven-story steel-framed building with identical floors and story to story height of $3.5 \mathrm{~m}$ was used as a prototype. Each floor was designed to carry an unfractured uniformly distributed dead and imposed loads of $4.2 \mathrm{KN} / \mathrm{m} 2$ and $5 \mathrm{KN} / \mathrm{m} 2$ respectively. A grillage-type approximation was conducted to create the nonlinear static response of impacted floor. Figure 2-12 shows the original floor grillage and assumed initial gravity load distribution and failure mechanism of impacted floor.

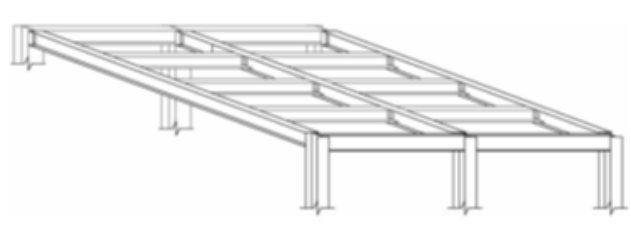

a

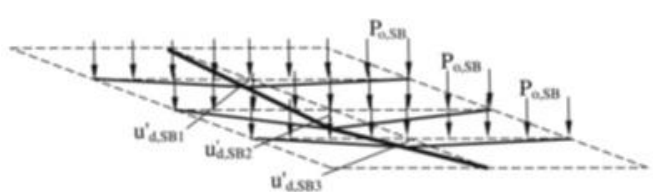

b

Figure 2-12 Floor impact assessment. (a) Original floor grillage;(b) Assumed initial gravity load distribution and approximate deformation mode upon impact. Vlassis et al. (2009)

Failure of a single support joint in one of the grillage components was adopted as the limit state of the grillage floor system. By using static analysis performed by ADAPTIC (Izzuddin 1991), initial static response of gravity load on the impacted floor prior the 
impact was determined and resulted $P_{o}=585 K N$ and mid span deflection $14 \mathrm{~mm}$ based on a load combination of 1.0DL+0. 25LL.Moreover, the nonlinear static response of grillage system representing a peripheral and an internal floor plate was determined as Figure 2-13 (a) and (b), respectively.
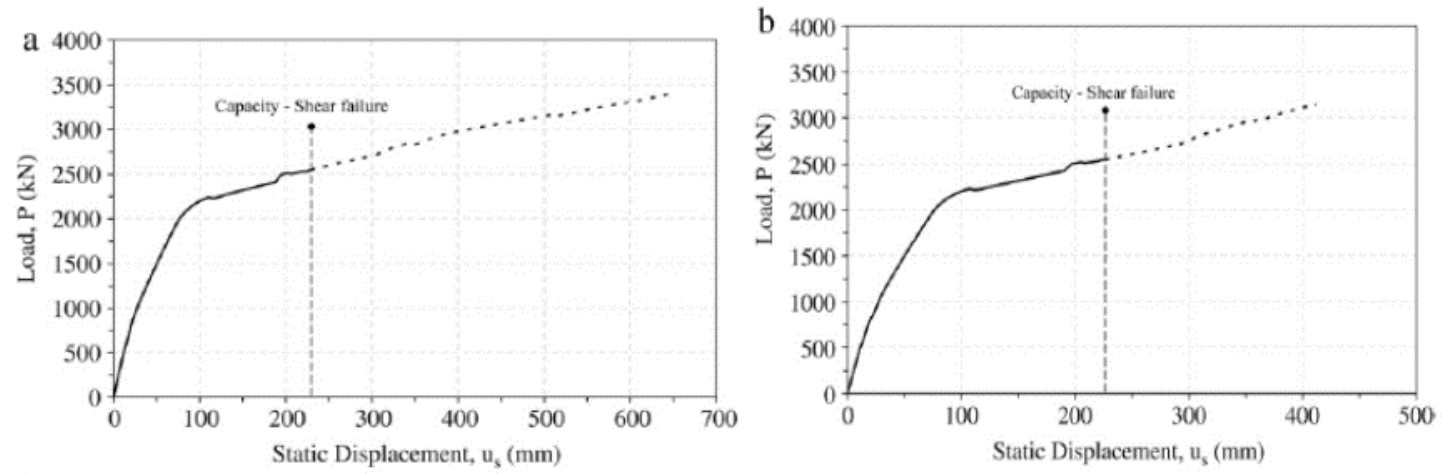

\section{Figure 2-13 Static load-deflection curve for the grillage system. (a)Peripheral floor plate;(b) Internal floor plate. (2009)}

To apply the methodology assessment, the axes of nonlinear static response was shifted to account for the initial static response of gravity load on the impacted floor prior the impact by subtracting $P_{o}=585 \mathrm{KN}$ and deflection of $14 \mathrm{~mm}$ from the nonlinear static response curve to create $P^{\prime}-u_{s}^{\prime}$ curve. Since all the longitudinal secondary beams were assumed to carry a uniform distributed load and deform in a triangular mode, the weighting factor $\alpha$ was determined to be 0.376 and 0.379 for the grillage floor system to calculate the work required for peripheral and internal floor plates respectively. To establish the modified pseudo-static response curve, it was necessary to estimate the amount of energy transmitted to the impacted floor. Based on the theoretical analyses for assumed impact events for steel-framed building type, the transferred energy varied between $40 \%$ for fully plastic impact to $98 \%$ for fully rigid impact events. Therefore, a range of non-dimensional energy reduction factor $\gamma_{i}$ was considered to reflect a wide range of impact scenarios. Figure 
2-14(a) and (b) show the modified pseudo-static load deflection curve for the two different scenarios with respect to the location of the impacted floor plate the peripheral and the internal floor, respectively, for a $20 \%-70 \%$ range of $\gamma_{i}$. The percentage of the initial lower floor load $P_{o}$ that the lower floor can carry it as a dynamic impact load can be seen in the right axes of Figure 2-14. It was noticed that even with a very small amount of transferred energy (20\%), the structure survived only if it carried impact load of $26 \%$ of gravity load of impacted floor. Less carrying impact capacity could happen with increasing amount of transfer energy as shown in Figure 2-14.
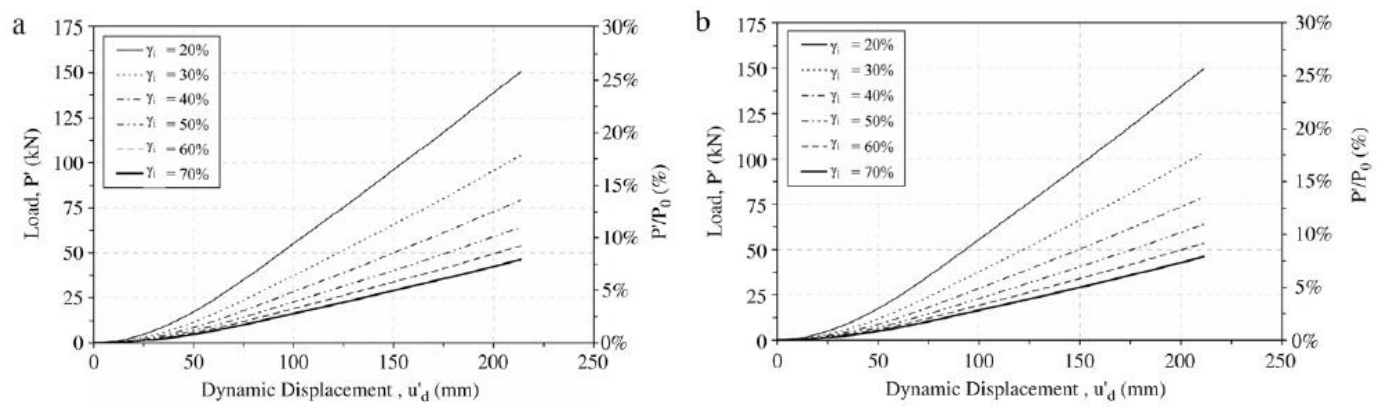

\section{Figure 2-14 Modified pseudo-static load -deflection curves for the grillage system. (a)Peripheral floor plate;(b) Internal floor plate. (Vlassis et al.,2009)}

Olmati et al. (2017) presented a framework for simplified reliability analysis for computing the probability of punching failure due to a slab falling from above. The analysis assumed an arbitrary portion of the impacting slab is in freefall and assumed to fail in three steps to induce some asymmetry to the impact. An FE model determined the demand at the slab column connection, and the capacity of the connection was assessed with Eurocode 2 and critical shear crack theory. The analysis showed that the demand quickly exceeded the punching shear capacity at the early stages of impact event and that a flat-plate building would be highly unlikely to survive the impact from a falling floor. 


\subsection{Summary}

The following is a summary of the major points from previous research:

- For RC beam components, it was shown that the change in behavior of RC beams under dynamic loads is not constant, but dependent on the strain-rate sensitivity and controlling failure mode. Early tests on concrete beams showed that the failure mode can be changed from shear to flexural or vice versa with increasing loading rate depending on the strain rate sensitivity of steel and concrete materials used in the beam construction. However, for reinforced concrete slab column connections, there are a few experimental tests that studied the dynamic effects on structures at both the sub-assemblage (isolated connection) and system levels. Therefore, an experimental program is needed to inspect the punching capacity and failure mode in an isolated RC flat-plate slab-column connection for different levels of lateral restraint, and reinforcement ratio by applying concentrated load at a rate representative of the rate of load redistribution in a collapse scenario.

- There are few numerical studies to investigate the behavior of RC structures components subjected to dynamic loading rate. Even though there was some research on RC beams, RC slab-column connections need more numerical study to investigate parameters such as reinforcement ratio, size effect, and grade of compressive strength of concrete when applying concentrated dynamic load at a rate representative of the rate of load redistribution in a collapse scenario. Therefore, a detailed model by implementing a 3D FE is necessary to assess the punching shear strength and ductility of isolated slab-column connection under dynamic loading rate. 
- There has been some work in estimating the progressive collapse of floor systems in multi-story structures subjected to impact load due to falling slab or debris from the above floor. However, the simplified approach has only been applied to steel composite buildings. The approach should also be applied to flat-plate buildings and compared with the other approaches to study the ability of RC flat-plate structures against the debris load. 


\section{CHAPTER 3}

\section{CHAPTER 3: EXPERIMENTAL INVESTIGATION OF LOADING RATE EFFECTS ON RC SLAB-COLUMN CONNECTION}

\subsection{Introduction}

During the initial stages of a collapse, failure of the initiating member (i.e. column loss) can cause a dynamic load redistribution in the surrounding members. For example, in a flat-plate structure if one connection fails the loads once carried in that connection must be redistributed to the surrounding members. Most analysis of structures for collapse (GSA 2013, DoD 2016) use the static capacity of the surrounding members to determine if collapse will progress. However, as the loading is dynamic, this may introduce inaccuracy into the analysis. Previous research has widely investigated the response of members under static and high (blast) loading rates, this research focuses on difference in behavior of flatplate slab column connections under static and dynamic loading rates representative of the load redistribution during collapse for which there is little previous work.

The collapse loading rate is dependent on the rate of removal of the supporting element and the natural period of the system. However, in most cases the collapse loading rate is not sensitive to the rate of removal of the supporting element. If the rise time for load application is less than $1 / 4$ of the natural period of a system, the structure will see the load application like a suddenly applied force (Chopra 2012). Analysis for progressive collapse in GSA considers the column removal time to be less than $10 \%$ of the natural period of the system (GSA 2013). Therefore, the rate of removal of the supporting element 
is not governing, but rather the response of the system is governed by the natural period of the system, in most cases the floor. Therefore, the natural period of the floor system governs the load redistribution rate. For the prototype, flat-plate building in this study the natural period of the floor is approximately $0.3 \mathrm{sec}$. leading to an approximate load rate of $0.4 \mathrm{~m} / \mathrm{s}$.

The experimental tests of real or scaled structure can also give some estimation of load redistribution rate or the strain rate that the structure experiences during the collapse. Based on the 0.4 scale multi-panel specimens tested in Peng et al. (2017b, 2018), the strain rate in the tension reinforcement was $0.035 / \mathrm{s}$ and $0.016 / \mathrm{s}$ for the exterior and interior column removal specimens and $0.01 / \mathrm{s}$ and $0.003 / \mathrm{s}$ for the concrete. Therefore, after adjusting for the scale, the strain rates are $0.039 / \mathrm{s}$ to $0.0838 / \mathrm{s}$ and $0.0082 / \mathrm{s}$ to $0.019 / \mathrm{s}$ in the steel and concrete respectively. For the specimen geometry discussed later, this would lead to a loading rate of $0.23 \mathrm{~m} / \mathrm{s}$ which is close to the loading rate predicted based on the natural period.

It is well known that the behavior of reinforced concrete members change with loading rate. Previous beam tests demonstrate that the change in behavior of RC beams under dynamic loads is not constant, but dependent on the strain-rate sensitivity and controlling failure mode. Steel and concrete are strain rate sensitive materials (Malvar 1998, Malvar and Ross1998). Early tests on concrete beams showed that the failure mode can be changed from shear to flexural or vice versa with increasing loading rate depending on the strain rate sensitivity of steel and concrete materials used in the beam construction (Mutsuyoshi and Machida 1985, Kulkarni and Shah 1998). Mutsuyoshi and Machida (1985) and Kulkarni and Shah (1998) investigated the effect of loading rates on the capacity and 
ductility of reinforced concrete members using a wide range of strain rates, $1 \times 10^{-5}$ to 0.19 /s and $3 \times 10^{-6}$ to 0.3 /s respectively. Mutsuyoshi and Machida. (1985) studied beams with different shear span to effective depth ratios (a/d of 4 and 5.7). The failure mode changed from flexural under static loading rate to shear under high loading rate. Kulkarni and Shah (1998) studied beams with a/d of 4, 4.5, and 5. The failure mode changed from shear failure under static loading rate to flexural failure under the high loading rate. Although the results of the two series of tests differed, the result can be explained based on the relative increase in flexural and shear strength under a high loading rate. Kalkarni and Shah (1998) postulated that the change in failure mode may be due to the effect of strain rate on the yield strength of steel. For Mutsuyoshi and Machida (1985) beams, the yield strength was $310 \mathrm{MPa}$. Therefore, the increase in flexural strength with high loading rate was greater than the increase in shear strength leading to a shear failure at the high loading rate. For Kulkarni and Shah (1998), the yield strength was $517 \mathrm{MPa}$. The increase in flexural strength with high loading rate for the higher strength bars was less. Therefore, the improvement in shear capacity was more significant and led to a flexural failure at the higher loading rate.

Adhikary et. al. $(2014,2015)$ experimentally and numerically investigated a wider range of loading rates (from $4 \times 10^{-4} \mathrm{~m} / \mathrm{s}$ to $2 \mathrm{~m} / \mathrm{s}$ ) resulting in strain rates from $4 \times 10^{-4} / \mathrm{s}$ to 10/s through experimental tests. The loading-carrying capacity for all the specimens increased with increasing loading rate. Numerical simulation showed that the yield strength of longitudinal steel played a big role on changing failure mode from shear to flexural or vice versa with increasing loading rate. Also, beams with more flexural capacity than their shear capacity (shear-dominate) showed higher strength with increasing loading rate in 
comparison with flexural-dominate beams. This is because the magnitude of increase in strength with loading rate is affected by strain rate sensitivity of steel yield stress for flexural dominate beams. For shear-dominate beams, the influence of the strain rate sensitivity of the concrete tensile strength is greater and leads to more significant increases in the strength of the beam.

For reinforced concrete slab column connections, there are a few experimental tests that studied the dynamic effects on structures at both the sub-assemblage (isolated connection) and system levels. The tests conducted by Criswell (1974) indicated that connections in dynamically loaded slab-column specimens will display increased resistances and larger ductility. The deflections at failure increased 25 to 50 percent with the dynamic loading effects and strength increased on average 18 percent for lightly reinforced slabs and 26 percent for heavily reinforced specimens. However, the loads in his tests were applied with a rise time of only 0.009 to $0.0032 \mathrm{sec}$. and therefore the loading rate is 6.6 times faster than the tests in this paper. Ghali et al. (1976) investigated the strength and deformation of isolated slab-column connections by subjecting the column to static or dynamic horizontal forces. Results indicate higher strength and higher energy absorption capacities of the slab in the dynamic tests. Xiao et al. (2016) tested RC slab specimens by applying concentrated load at the middle of a flat slab specimen with fixed boundary conditions at all sides for a wide range of loading rates from static $(0.0004 \mathrm{~m} / \mathrm{s})$ to high $(2 \mathrm{~m} / \mathrm{s})$. The results showed that the punching strength increased $15 \%$ to $54 \%$ at medium loading rates and $42 \%$ to $73 \%$ at high loading rates. Specimens with $0.59 \%$ reinforcement ratio showed increasing in ductility with increasing loading rate. Also, punching failure was the dominate mode irrespective of loading rate, and the effect of 
inertial force became more significant at high loading rate than medium loading rate. All of these tests seem to indicate an increase in ductility in slab-column connections under dynamic loading.

This research specifically considers older flat-plate structures in the U.S. designed prior to ACI 318-71 (1971) that have a lack of continuous bottom reinforcement at columns. These structures have a high potential of progressive collapse initiated by the loss of a supporting element (Liu et al. 2013). When one of connections is overloaded and failed, the load carried by the connection must be dynamically redistributed to the surrounding columns. Although, the testing and analysis is specific to slab-column connections without continuous reinforcement, the results can be related to connections with continuous reinforcement.

In this study, an experimental test of four specimens having two different values of reinforcement ratio $(0.64 \%, 1 \%)$ was conducted to evaluate the punching capacity and failure mode in an isolated RC flat-plate slab-column connection by applying concentrated load at a rate representative of the rate of load redistribution in a collapse scenario.

\subsection{Experimental work and test setup}

Four isolated square RC slabs with longitudinal reinforcement ratios of $1 \%$ and $0.64 \%$ were constructed at a 0.73 scale. The slabs were tested dynamically by using a hydraulic ram at a loading speed of approximately $0.23 \mathrm{~m} / \mathrm{s}(9 \mathrm{in} / \mathrm{s})$ to apply dynamic load. However, 1.0RE-D3, was loaded at $0.46 \mathrm{~m} / \mathrm{s}$ (18 in/s). The slab thickness was $140 \mathrm{~mm}(5.5$ in) and the effective depth was $114 \mathrm{~mm}$ (4.5 in). A $229 \mathrm{~mm}$ (9 in) square column extended $280 \mathrm{~mm}$ (11 in) above and below the slab to accurately represent the stress distribution at slab-column connections. The design of slab-column specimens followed the provisions ACI 318-71, no integrity reinforcement was used through columns. These specimens were 
similar in dimensions and reinforcement details to the specimens tested statically by the same research group (Peng et. al. 2017a). The dimensions and reinforcement layout of the specimens are shown in Figure 3-1.

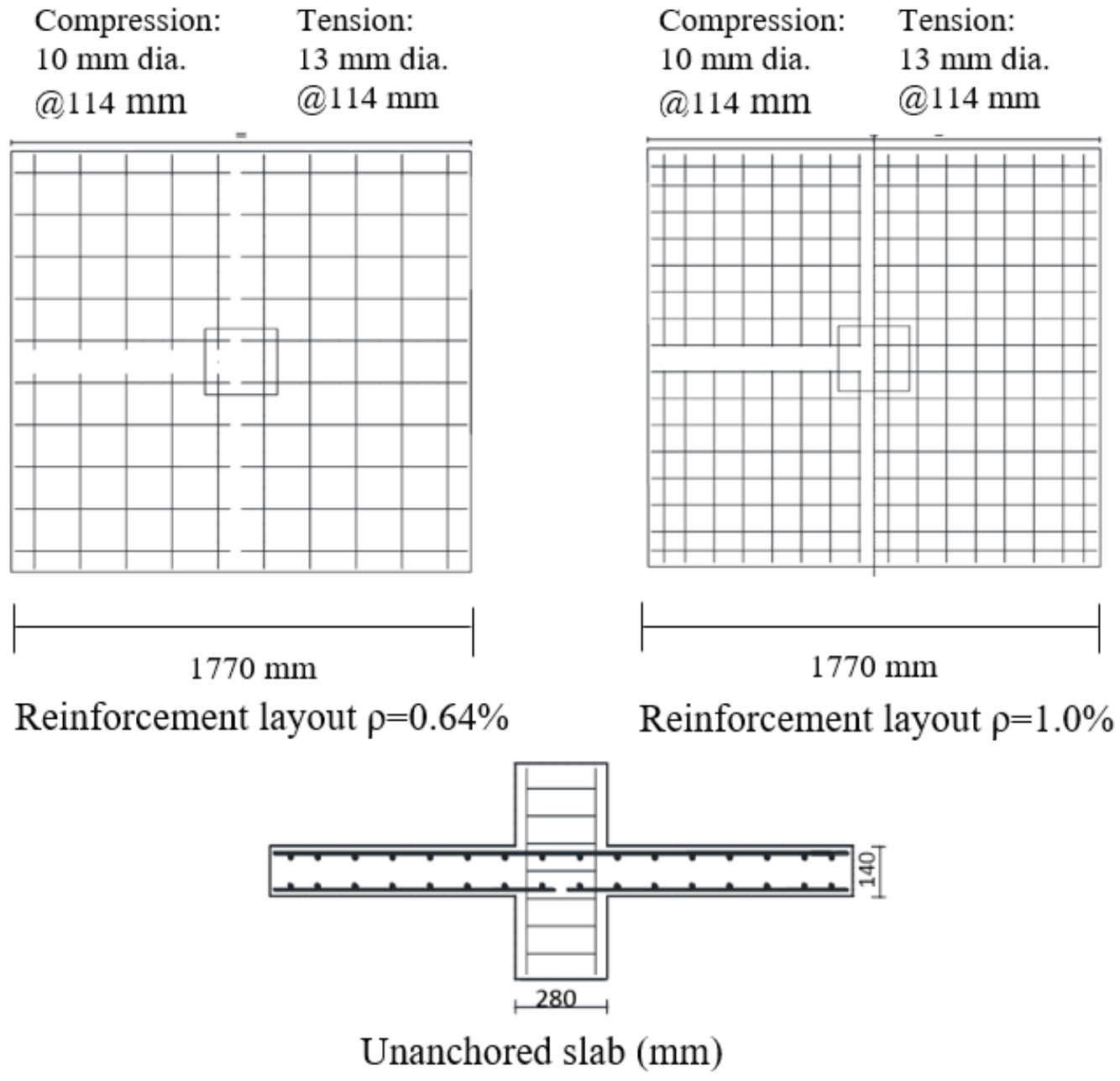

Figure 3-1 Geometry and reinforcement details of specimens

The reinforcement consisted of No.3 bars (9.53 mm diameter) and No.4 bars (12.7 $\mathrm{mm}$ diameter) for compressive and tensile reinforcement, respectively, with a yield strength of $420 \mathrm{MPa}$ and ultimate strength of $690 \mathrm{MPa}$. Strain at yield was 0.0023 . The compressive bars were anchored into the column stub $89 \mathrm{~mm}$ without continuity. Concrete had a specified maximum coarse aggregate size of $9.5 \mathrm{~mm}$. The cylinder compressive strength of concrete measured at the test of each specimen is given in Table 3-1. The 
designation of the specimens consists of a number showing the percentage tensile reinforcement ratio and letters indicating the restraining conditions at slab edges and applied loading type.

Table 3-1 Specimen results at punching shear failure

\begin{tabular}{|c|c|c|c|c|c|c|c|c|}
\hline Specimens & $\begin{array}{c}\text { Loading } \\
\text { type }\end{array}$ & $\begin{array}{c}\text { Concrete } \\
\text { strength } \\
(\mathbf{M P a})\end{array}$ & $\begin{array}{c}\text { Lateral } \\
\text { force } \\
\mathbf{( k N )}\end{array}$ & $\begin{array}{c}\text { Lateral } \\
\text { movement } \\
(\mathbf{m m})\end{array}$ & $\begin{array}{c}\text { Lateral } \\
\text { stiffness } \\
(\mathbf{k N / m m})\end{array}$ & $\begin{array}{c}\text { Punching } \\
\text { shear } \\
\text { capacity } \\
(\mathbf{k N})\end{array}$ & $\begin{array}{c}\text { Rotation } \\
\text { at } \\
\text { punching } \\
\text { (rad.) }\end{array}$ & $\begin{array}{c}\text { Deflection } \\
\text { at } \\
\text { punching } \\
\text { (mm) }\end{array}$ \\
\hline $0.64 R E-D 1$ & Dynamic & 38.34 & 47.3 & 0.5 & 47.7 & 279.6 & 0.0372 & 33.1 \\
\hline $0.64 R E-D 2$ & Dynamic & 29.61 & 132 & 1.24 & 53.1 & 254.5 & 0.0519 & 46.2 \\
\hline 0.64RE-S1 & Static & 29.34 & 104.1 & 0.69 & 75.4 & 253.3 & 0.0492 & 43.8 \\
\hline 0.64RE-S2 & Static & 36.94 & 60.7 & 1.40 & 21.7 & 250.9 & 0.0299 & 26.6 \\
\hline 1.0RE-D3 & Dynamic & 29.00 & 5.2 & 0.69 & 3.7 & 298.2 & 0.0313 & 27.9 \\
\hline 1.0UN-D4 & Dynamic & 32.04 & - & 0.83 & - & 302.8 & 0.0287 & 25.6 \\
\hline 1.0UN-S3 & Static & 33.40 & - & 0.48 & - & 307.5 & 0.0242 & 21.6 \\
\hline
\end{tabular}

The test setup was designed to support the specimens vertically at eight locations around the perimeter of the slab (two points per side) using clevises as seen in Figure 3-2. The clevises are located at the contra-flexural points in the prototype structure, 0.2 of clear span length away from the column. A steel circular tube column was used to support each clevis vertically. To prevent the specimens from rigid body motion and provide in-plane restraint, the clevis was connected to the wide-flange column of steel reaction frame by a $38 \mathrm{~mm}$ diameter steel rod. The in-plane restraint was passive and relied on the expansion of the specimen to build the in-plane forces. As a result, the lateral stiffness of the restrained specimens varied. The specimen was inversely placed and load was applied downward on the center column using a hydraulic actuator.

Electrical resistance strain gages were used to measure the strain in the reinforcement prior to punching failure at selected locations. In addition, radial and tangential strains in the concrete at $76 \mathrm{~mm}$ from the column face were also measured. Linear variable displacement transducers (LVDTs) and string pots were used to record the 
slab lateral expansions and vertical deflections. A load cell measured the load applied by the hydraulic actuator on the column of the specimen.

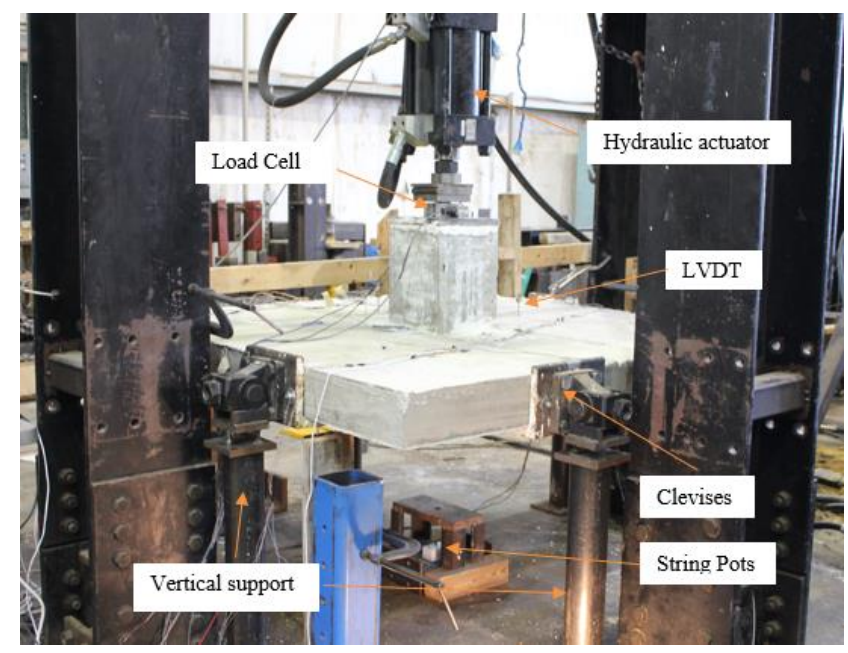

Figure 3-2 Experimental setup

\subsection{Experimental results}

\subsubsection{Load deflection behavior}

The results of the dynamic tests are compared with an earlier static series by the same researchers presented in Peng et al. (2017a). Figure 3-3 illustrates the relationship between the normalized load (punching strength divided by the square root of concrete compressive strength, $b_{0}=1576 \mathrm{~mm}$ and $d=114 \mathrm{~mm}$ ) and the column deflection until punching failure. It can clearly be seen that slab tensile reinforcement ratio dominates the difference in response of the tests. Punching shear capacity increased on average $20 \%$ with increasing reinforcement ratio from $0.64 \%$ to $1 \%$. 


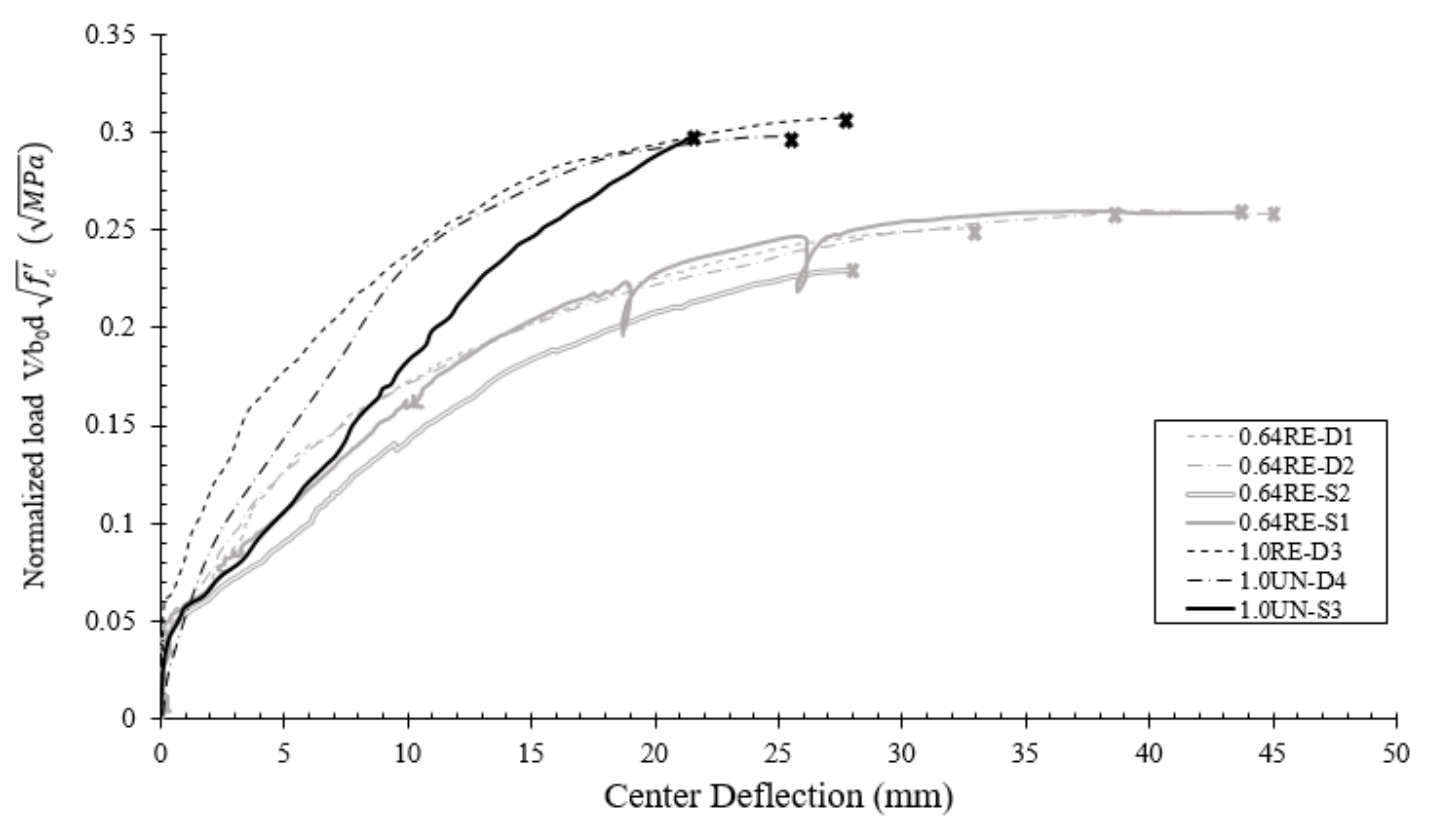

Figure 3-3 Normalized load-deflection response

The tests conducted at a $1 \%$ reinforcement ratio all had little to no lateral stiffness and similar concrete compressive strengths, thus the difference in their behavior was due primarily to the loading rate. Specimen 1.0 RE-D3 was restrained; however, the lateral restraint was measured as only $3.7 \mathrm{kN} / \mathrm{mm}$ and therefore not significant. As can be seen in Figure 3 and Table 1, the punching shear capacity of the static (1.0UN-S3 tested at $0.00004 \mathrm{~m} / \mathrm{s}$ loading rate) and dynamic (1.0RE-D3 tested at $0.46 \mathrm{~m} / \mathrm{s}$ loading rate and $1.0 \mathrm{UN}-\mathrm{D} 4$ tested at $0.23 \mathrm{~m} / \mathrm{s}$ loading rate) tests was within $3 \%$ of each other. This indicates that the rate of loading did not significantly affect the punching capacity. However, the shape of the load deflection curve is significantly different. The static test had an average load-deflection slope of $0.0142 \mathrm{~mm} / \mathrm{N}$ between cracking (normalized load of $0.05 \sqrt{M P a}$ ) and a normalized load of $0.25(\sqrt{M P a})$ Whereas specimen 1.0RE-D3 tested at the highest loading rate had a 2.1 times greater slope at $0.03 \mathrm{~mm} / \mathrm{N}$ and specimen $1.0 \mathrm{UN}-\mathrm{D} 4 \mathrm{had}$ a 1.3 times greater slope at $0.019(\mathrm{~mm} / \mathrm{N})$. The difference in the slope indicates the difference 
in the stiffness of the specimens at the different loading rates. It is expected that tests with higher load rates will exhibit stiffer behavior as the loading rate effectively increases the concrete material strength (Iwai et al. 1972, Isaac et al. 2013, Mutsuyoshi et al. 1985).

The other major difference in the tests is the deflection at punching failure. For the static specimen, this deflection was $21.6 \mathrm{~mm}$, approximately $23 \%$ less than the deflection for the dynamic tests at $27.9 \mathrm{~mm}$ (1.0RE-D3) and $25.6 \mathrm{~mm}$ (1.0UN-D4). This result indicates that dynamically tested specimens have more ductility than static specimens. This observation agrees with the dynamic specimens tested by Criswell (1974) who observed a nearly $25 \%$ to $50 \%$ increase in deflection in comparison with corresponding static tests. A possible explanation for the increase in ductility for dynamically loaded connections relies on the differing increases in shear strength vs. flexural strength of the connection due to material strength enhancement under loading rate. Most slab-column connections at a low reinforcement ratio will yield the reinforcement before final punching failure. However, it is possible that under dynamic load the enhancement in the material strength of the concrete enhances the shear capacity of the connection more than the flexural capacity. Thus, greater flexural response and deflection is observed before final punching failure.

For the tests conducted at the $0.64 \%$ reinforcement ratio, the results are more complicated as the lateral restraint and concrete compressive strength is not consistent between tests. Statically tested specimens 0.64RE-S1 and 0.64RE-S2 had the same reinforcement design; however, the compressive strength of $0.64 \mathrm{RE}-\mathrm{S} 2$ was $26 \%$ greater and the lateral restraint $28 \%$ less than $0.64 \mathrm{RE}-\mathrm{S} 1$. This yielded the very different load deflection curves for the two tests seen in Figure 3. For 0.64RE-S1 the slope of the loaddeflection curve became nearly flat prior to punching failure, an obvious flexure- 
dominating response. Peng et al. (2017a) theorized that the compressive membrane forces enhanced aggregate interlocking at inclined shear cracks and hence delayed punching failure and thus shifted the transition point where significant flexural yielding occurs prior to punching leading to increased deflections before punching failure.

Overall, it can be seen in Figure 3 that the slope of the load-deflection curve for the dynamically tested specimens is on average $60 \%$ higher than the statically tested specimens (between $0.05 \sqrt{M P a}$ ) normalized load and $0.2 \sqrt{M P a}$ normalized load). Then the behavior of the dynamic and static specimens becomes similar.

Specimens $0.64 \mathrm{RE}-\mathrm{S} 1$ and $0.65 \mathrm{RE}-\mathrm{D} 2$ can be more closely compared. These specimens had nearly identical concrete strength and a 30\% difference in lateral restraint. Both of these tests had nearly identical punching capacities (within $1 \mathrm{kN}$ of each other), however the deflection at failure of the dynamic specimen 0.64RE-D2 was 5\% higher than the static specimen 0.64RE-S1. This is similar to the behavior of the $1.0 \%$ reinforcement ratio tests that found the dynamically loaded specimen had higher deflection at failure. However, the lateral restraint in 0.64RE-S1 was the highest of any test, and it is likely that this lateral restraint could have more influence on the deflection at punching than the loading rate.

For specimens $0.64 \mathrm{RE}-\mathrm{S} 2$ and 0.64RE-D1 the difference in concrete strength is only $4 \%$ but the difference in lateral restraint $54 \%$. The punching capacity of the dynamically loaded connection is $10 \%$ higher than the statically loaded connection, and the deflection is $24 \%$ greater. As in the $1.0 \%$ reinforcement ratio tests the deflection at failure is greater, but the lateral restraint of the dynamically loaded specimen was also greater thus may contribute to this result. 


\subsubsection{Energy absorption}

Figure 3-4 shows the effect of loading rate on the energy absorption of the isolated slab-column connections. Greater energy absorption under dynamic loads may improve the ability of a building to resist progressive punching failures. The specimens under high loading rates exhibited more energy absorption in comparison with the lower values of loading rate. The absorbed energy, represented by the area under the load-deflection curve, is $43 \%$ higher for 1.0UN-D4 and compared to 1.0UN-S3. It can also be seen that specimens with low reinforcement ratios have more absorbed energy than specimens with higher reinforcement ratios. Moreover, the specimens with greater lateral restraint absorbed more energy in comparison with low or unrestrained specimens. The increase in absorbed energy with loading rate is in agreement with the results by Ghali et al (1976); Kulkarni and Shah (1998); Xiao et al. (2016).

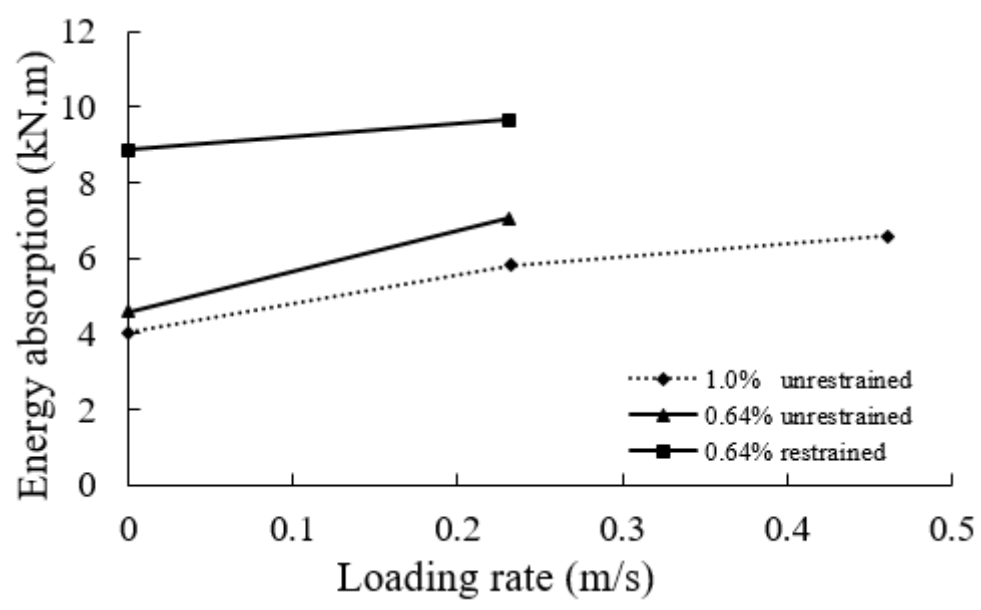

Figure 3-4 Loading rate effect on energy absorption

\subsubsection{Deflection shape and rotation}

In order to investigate the difference in behavior of the specimens, the deflected shape of static and dynamic specimens at a $1 \%$ reinforcement ratio is plotted based on measured deflections at the column, $254 \mathrm{~mm}$ from the column face, and at the support 
location. Two deflection measurements (along perpendicular axes) were made at $254 \mathrm{~mm}$ away from the column and averaged together. All deflections were normalized to the support deflection. As shown in Figure 3-5, the deflected shape of the static and dynamic tests are similar however the static test shows more rotation near the column at failure. The theory by Muttoni (2008) says the rotation between the slab of the column can indicate punching failure of the connection, therefore, if the rotation is higher for the same level of deflection for the static tests, that might indicate why the static test failed at a lower level of deflection. For example, the static test $1.0 \mathrm{UN}-\mathrm{S} 3$ gave $8.6 \%$ higher in rotation than 1.0UN-D4 for the same level of deflection. At failure, the rotation in 1.0 UN-S1 was 0.0242 rad. Specimen 1.0RE-D3 and 1.0RE-D4 had 29\% and 19\% higher rotations between the slab and column at punching failure. For the 0.64 reinforcement ratio tests, the rotation of specimen 0.64RE-D1, and 0.64RE-D2 was $0.0372 \mathrm{rad}$, and $0.0519 \mathrm{rad}$ respectively. These rotation values are $24 \%$ and $5 \%$ higher compared to corresponding static test of specimen 0.64RE-S2 and 0.64RE-S1, respectively. Although the much greater rotation in 0.64RE-D2 and 0.64RE-S1 could be the result of the in-plane lateral restraint.

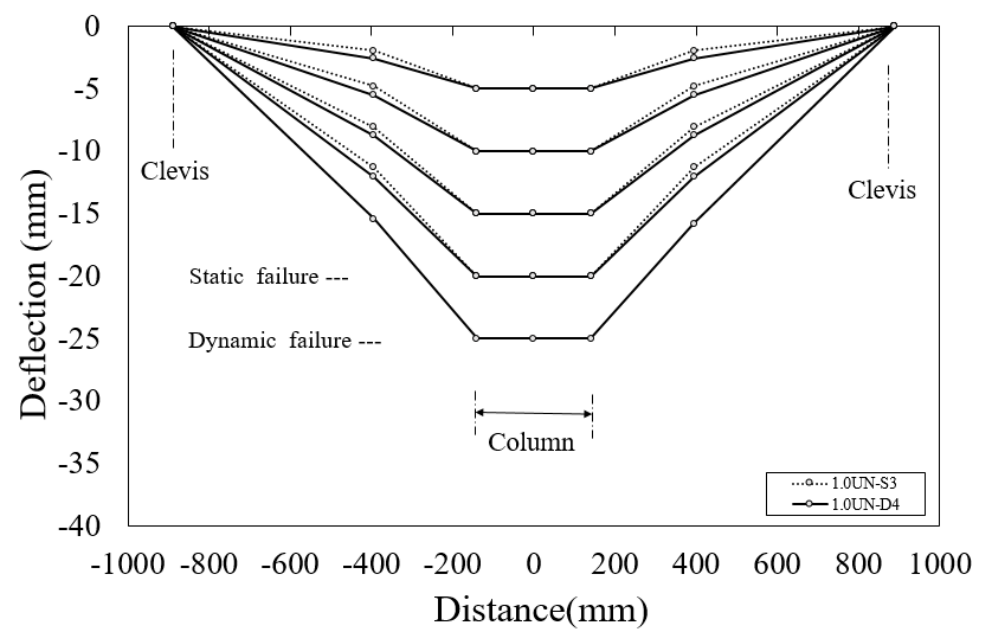

Figure 3-5 Deflected shape under static and dynamic loading rate 


\subsubsection{Rebar, concrete strain and strain rate effects}

Figure 3-6 shows a comparison of strain in tension reinforcement bars between the static and dynamic test at different column loads. The strains are based on averaged strain data measured on bars passing through the column at the indicated distance from the center of the column. The distribution of strain along a reinforcement bar is similar in the static and dynamic tests at early stages of loading. However, as the specimen nears punching the strain distribution in the dynamic test becomes increasingly sharp for both the $0.64 \%$ and $1.0 \%$ reinforcement ratio tests indicating a concentration of strain near the slab column connection. Furthermore, the dynamic tests showed higher strains at punching failure than the static tests.
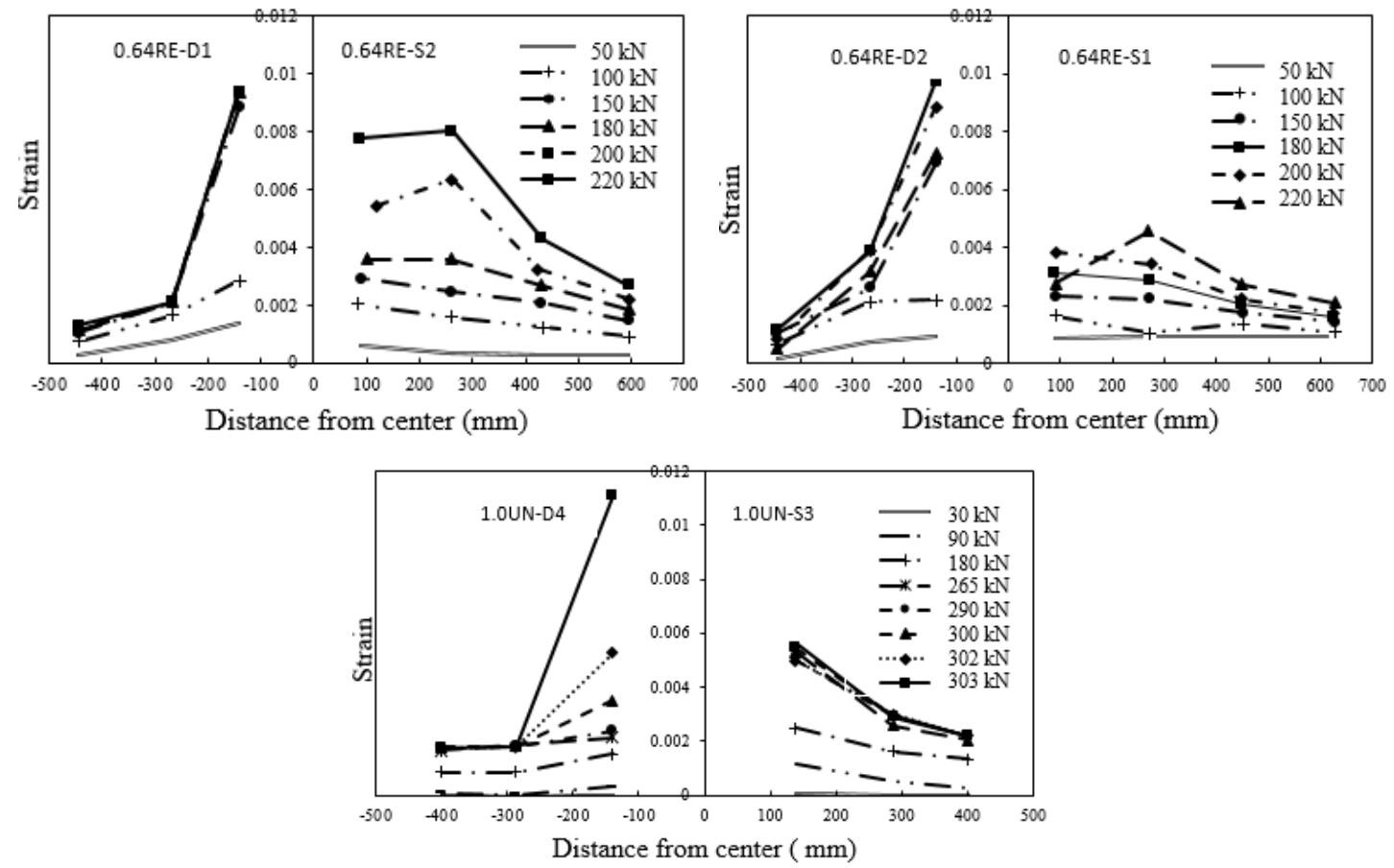

Figure 3-6 Comparison of distribution of strain in tension reinforcement passing through column

The radial and tangential strain of concrete, measured at $76 \mathrm{~mm}$ from the North and

West column face, is shown in Figure 3-7 for 1.0UN-S3 and 1.0UN-D4. When the 
specimen nears punching shear capacity, a sharp drop in radial strain of concrete is noticed in both tests. This agrees with Broms (1990) in that the radial strain approached zero near punching. However, the development rate of the radial strain of concrete for dynamic test is faster than the static test and it experiences $46 \%$ more radial strain compared to the static test. Furthermore, the tangential strain developed faster in dynamic test compared to static. The higher strains in dynamic testing agrees with the observations of Criswell (1974).

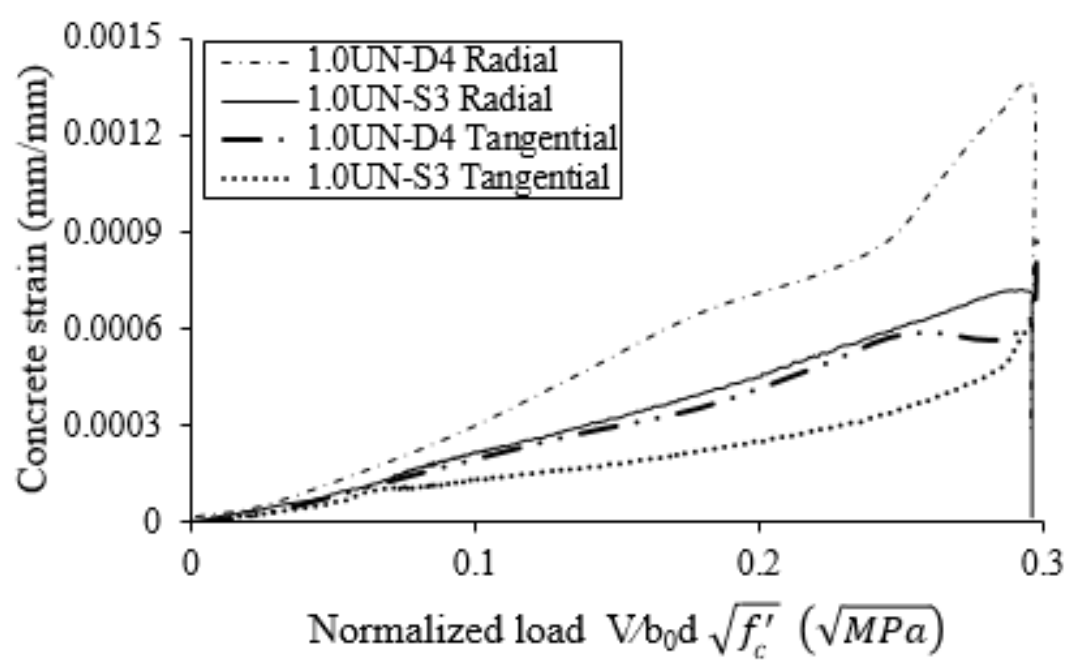

\section{Figure 3-7 Concrete radial and tangential strains before punching shear failure}

Strain rates were determined for each of the dynamic tests. Malvar (1998) and others relate the strain rate to the material strength increase. However, the strain rates in the concrete and steel were not constant during the testing. Figure 3-8a shows steel and concrete strain for specimen 1UN-D4. The data show a sharp increase in the steel strain after yield and before punching. The average strain rate measured in the T7, T16, and T20 reinforcing bars at $146 \mathrm{~mm}$ from the column face at the yielding of tension steel was 0.039/sec. Based on Malvar (1998) this would lead to a material strength increase of 1.21. 
The strain rates of tensile reinforcement for other dynamic specimens at the yielding of tension bars can be varied between $0.0375 / \mathrm{sec}$ to $0.0838 / \mathrm{sec}$ as seen in Table $3-2$.

The concrete strain rate of specimen 1UN-D4 at the point of yielding tension bars is $0.0112 / \mathrm{sec}$. According to CEB-FIP MC1990 (1990) the material strength DIF for compressive and tensile strengths of concrete are 1.20 and 1.21 , respectively. The concrete strain rate for other specimens varies between $0.0082 / \mathrm{sec}$ to $0.019 / \mathrm{sec}$ as shown in Table 3-2 .

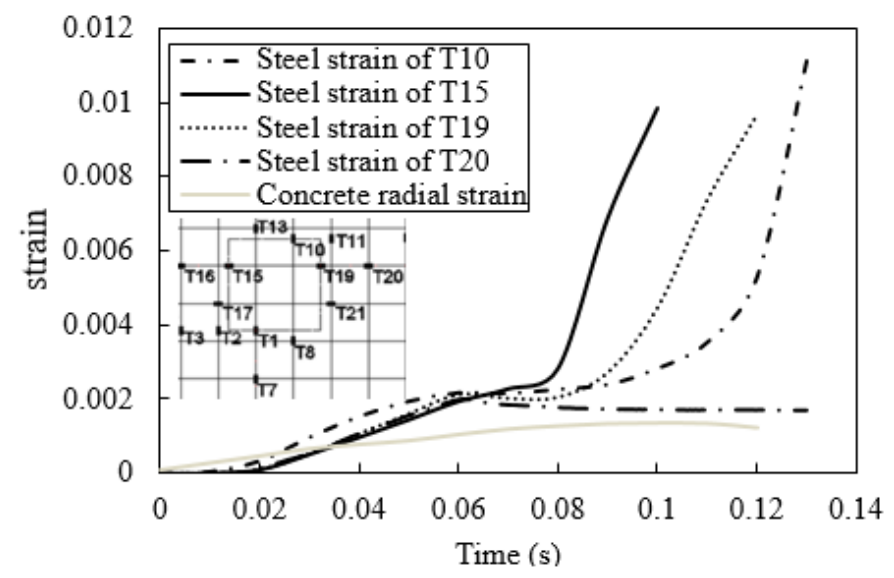

(a) Steel and concrete strain of 1.0UN-D4

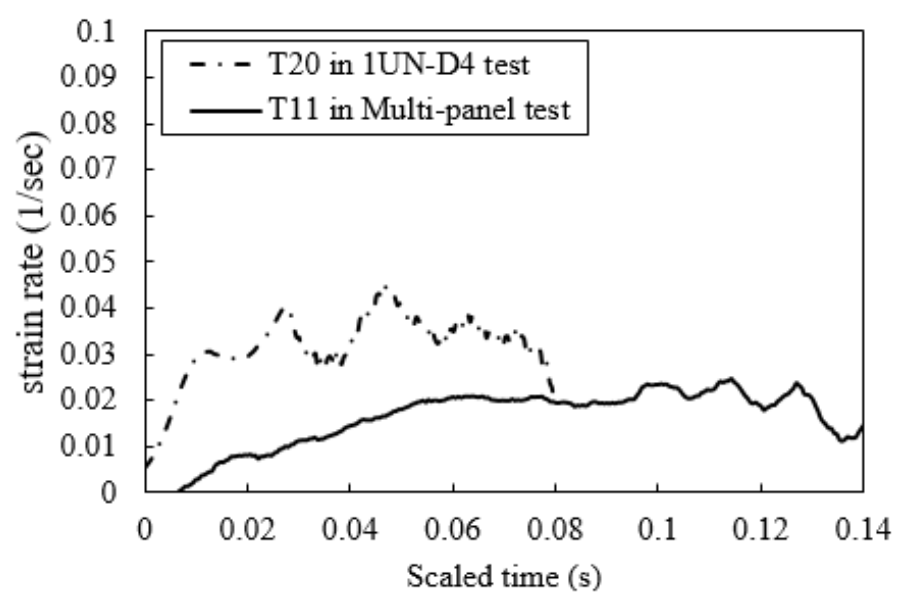

(b) Steel strain rate

Figure 3-8 a) Steel and concrete strain of dynamic test (1UN-D4) b) Steel strain rate vs time for isolated (1UN-D4) and multi-panel (Peng et al. 2018) tests 
Even with these theoretical increases in material strength due to strain rate, the punching capacity only had marginal $0.5 \%$ increase as discussed before. However, as seen in Figure 3-6, the strains in the dynamically loaded specimens are higher than the statically loaded specimens indicating a dynamic amplification of the strain. For the reinforcement ratio and load rates tested, it is possible that the dynamic amplification of the strain counterbalanced the material strength increase and led to little change in the punching capacity.

In order to verify that the strain rates used in the isolated connection tests are comparable to strain rates in structures under collapse, a comparison is made with a 0.4 scaled dynamic multi-panel test by Peng et. al (2017). The multi-panel test dynamically removed one interior column and most closely represents the actual collapse case. For Peng et. al (2017) the strain rate at yielding in tension bars were $0.0103 / \mathrm{s}$ and $0.002 / \mathrm{s}$ respectively (after applying scale factors to adjust the rate to a full-scale). This would lead to an enhancement the steel and concrete material strength $17 \%$ and $14 \%$ respectively according to Malvar (1998) and CEB-FIP MC (1990). For the isolated test, after applying scale factors to adjust the rate to full scale, the strain rate of steel and concrete is between $(0.0274 / \mathrm{s}-0.0612 / \mathrm{s})$ and $(0.006 / \mathrm{s}-0.0138 / \mathrm{s})$ respectively. This would lead to an average enhancement the steel and concrete material strength $21 \%$ and $18 \%$ respectively according to Malvar (1998) and CEB-FIP MC (1990). The strain rates in the isolated dynamic tests on the same order (approximately 2 to 5 times greater than) as the multi-panel test, and the predicted enhancement in material strength is almost identical (within 4\%). Therefore, the loading rate used in this study can be viewed as representative of collapse loading rates. 
Table 3-2 Steel and concrete strain rate for dynamic tests at yielding of tension steel

\begin{tabular}{|c|c|c|}
\hline Specimens & $\begin{array}{c}\text { steel strain rate } \\
(\mathbf{1} / \mathbf{s e c})\end{array}$ & $\begin{array}{c}\text { concrete strain rate } \\
\mathbf{( 1 / s e c )}\end{array}$ \\
\hline $0.64 \mathrm{RE}-\mathrm{D} 1$ & 0.0553 & 0.0111 \\
\hline $0.64 \mathrm{RE}-\mathrm{D} 2$ & 0.0459 & 0.0082 \\
\hline 1RE-D3 & 0.0838 & 0.019 \\
\hline 1UN-D4 & 0.039 & 0.0112 \\
\hline
\end{tabular}

\subsection{Summary}

This chapter presents the experimental investigations on punching shear strength of isolated slab-column connections under dynamic loading rates. Experimental program, consisting of four specimens, was carried out to inspect the punching capacity and failure mode in an isolated RC flat-plate slab-column connection for different levels of lateral restraint, and reinforcement ratio by applying concentrated load at a rate representative of the rate of load redistribution in a collapse scenario. The results of this series of dynamic tests were compared with an earlier static series by the work presented in Peng et al. (2017a). The experimental results show a significant increasing in ductility in dynamic test compared with the static test with no significant change in punching shear capacity. The increase in ductility could be from the difference in rate enhancement of shear and flexural capacity of the member due to stain rate effect on materials strength. Also, all the experimental tests showed increased energy absorption of column-slab connections with increasing loading rate especially for $0.64 \%$ reinforcement ratio specimens which absorbed more energy compared to $1.0 \%$ reinforcement ratio. This may improve the ability of a building to resist progressive punching failures. 


\section{CHAPTER 4}

\section{CHAPTER 4: NUMERICAL SIMULATION OF LOADING RATE EFFECTS ON RC SLAB-COLUMN CONNECTION}

\subsection{Introduction}

Due to the limitation of the experimental programs for this and the previous researches of investigation the slab-column connection behavior subjected to concentrated dynamic loading rate, it is worthwhile of expanding this study to create a numerical model to get much more understanding of slab-column connection behavior subjected to dynamic load by reducing the time and the cost effectively. Many parameters need to be studied to find its effect on the slab-column connection behavior such as reinforcement ratio, concrete compressive strength, and size effect. Previous chapter showed some interesting experimental results, so the main goal of this chapter is to create a reliable FE model to understand these results by validating the numerical model with experimental results in terms of load-deflection behavior and strain history of reinforcement. Furthermore, the FE model will be used to investigate the reasons behind the increasing in ductility of the specimens tested dynamically compared to the static tests. Therefore, 3D detailed finite element models of the specimens are validated with the experimental data and use for a parametric study. ANSYS (2015) is used to simulate the static tests while Ls-Dyna (LSTC, 2016) is used to simulate the dynamic tests. The latest modelling procedure was used early by Xiao et al (2016). Two different programs are used because of their effectiveness at the two different loading rates. 


\subsection{Finite element model}

Two finite element solvers were used in this study. Due to the effectiveness and less time consuming of implicit analyses to simulate quasi -static problems, implicit program ANSYS (2015) was used to simulate the static tests, while the nonlinear explicit FE program LS-DYNA (LSTC, 2016) was used in the numerical simulation process for dynamic tests. The main difference between explicit and implicit analyses is the time step size (running time). In general, time step in implicit analyses is much more than that corresponding in the explicit time, and stable solution is needed for explicit analyses, so the time step should be less than the travel time of sound wave through an element. To capture the load-deflection characteristics of slab behavior and to study the effect of some parameter on punching shear capacity, 3D finite model was selected in this study. This model describes the structural geometry of slab, boundary conditions and load application, in addition to constitutive model of material used in both explicit and implicit analyses.

\subsubsection{FE explicit model}

\subsubsection{Geometry, boundary condition, and load application}

Nonlinear explicit FE program LS-DYNA (LSTC, 2007) was used in the numerical simulation for dynamic test. To capture the detailed response of any experimental test, it is essential to develop a finite element model that closer in geometry and boundary condition to the experimental. Due to the symmetry of tested specimens, one quarter of the specimens was modeled, and 3D finite element mesh was adopted to represent all parts in this model as illustrated in Figure 4-1. Concrete, loading plate, and supporting steel angles parts were represented by solid element, while beam element was used to simulate the reinforcement bars. A mesh study (convergence criteria) was done at the early stages of analyses to get model verification by trying different mesh sizes. A mesh size of $10 \mathrm{~mm}$ was adopted which 
give almost no change in punching shear capacity when go less further in mesh size.

Table 4-1shows the total number and types of element of all parts used in this model.

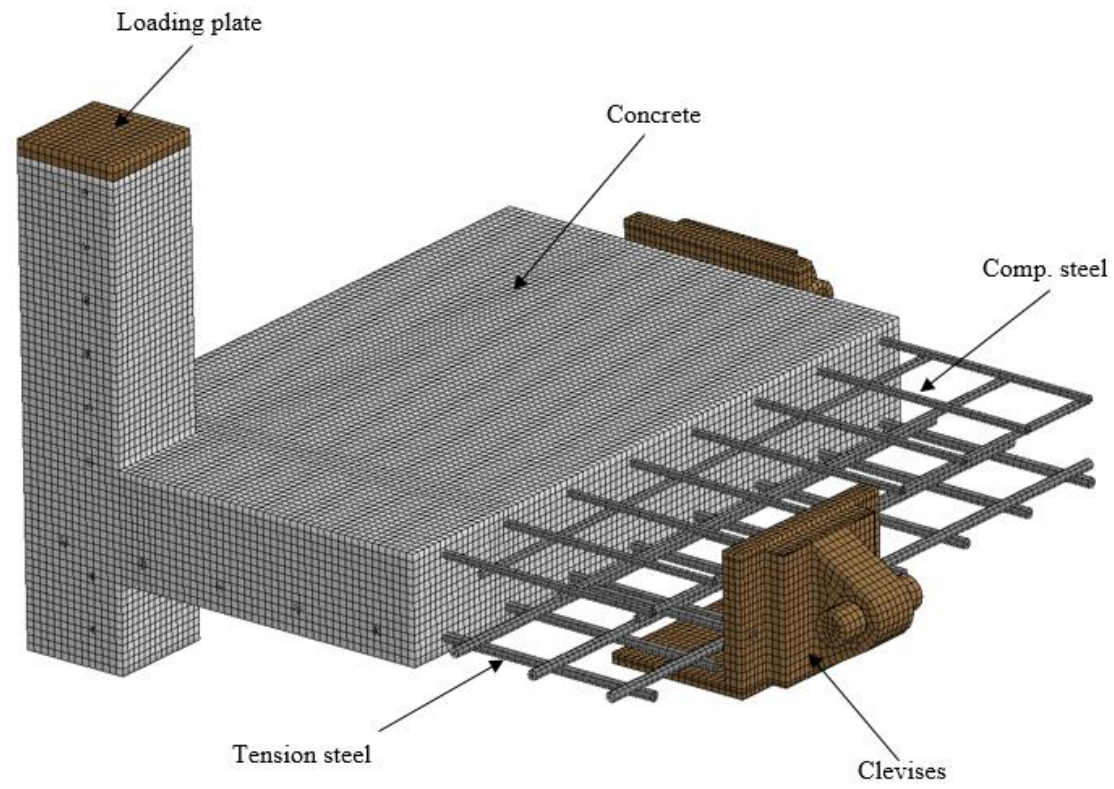

Figure 4-1 Finite element model and boundary conditions

Table 4-1 Total number and types of elements of LS-DYNA model

\begin{tabular}{|l|l|c|}
\hline \multicolumn{1}{|c|}{ FE parts } & \multicolumn{1}{c|}{ Element type } & Element number \\
\hline concrete & Eight nodes solid element & 122808 \\
\hline Reinforcement steel & two nodes beam elemnt & 2736 \\
\hline Loading plate and support & solid element & 11088 \\
\hline
\end{tabular}

To reduce the computational time of analyses ,8 nodes solid element with one integration points was used to represent the concrete part. However, zero- energy modes or Hourglass modes are expected to appearance in the model which is one of the disadvantages of using single integration points. LS-DYNA has many types of hourglass control to avoid these modes in the analyses. The Belytschko-Bindeman (1993) assumed strain co-rotational stiffness was selected in this study. All reinforcement bars were modeled by two -nodes Hughes-Liu beam element formulation with $2 \mathrm{X} 2$ Gauss quadrature integration. This element has many desirable features such as its compatibility 
with the brick element because of its formulation based on degeneration of the isoperimetric 8 nodes solid element and its simplicity by allowing for effectiveness and robustness computations. Also, it is incrementally objective that allowing for treatment of finite strain which could occur in some applications. In addition, this element includes finite transverse shear strain and having three translational and three rotational degree of freedom in each node. A perfect bond was assumed in this study. Many researchers (Vos et al 1982, Wei Yao et al 2013, Zhang et al 2014, Yan et al 2012) show that the bond strength increases with increasing loading rate and dynamic load gives more than $67 \%$ to $100 \%$ pull out resistance compared to static load without changing in mode failure (Weathersby,2003). The explicit approach was used to model the reinforcement bars by using a constrained method allowing to construct independent meshes of the reinforcement and concrete. In suitable geometric configuration, the two meshes of steel and concrete are superimposed and, LS-DYNA creates an internal constrained system to permit a consistent motion of these two meshes by using the algorithm *CONSTRAIND_LAGRANGE_IN _SOLID. Moreover, loading plate and supporting steel angle was modeled by a solid element and the last was connected to the concrete through anchor bars which modeled explicitly by using beam element connected to the shared nodes of concrete and steel angles. The boundary conditions of experimental test were modeled exactly in the numerical model. The specimen was restrained vertically at the end of supporting steel angle and horizontally to reflect the lateral stiffness by using a discrete element. The boundary condition was applied at the symmetrical axes by restrained the specimen to rotate and translate axially at the symmetrical axes. All the contact areas between the concrete part and the loading plate, supporting steel angle were defined by using algorithm *CONTACT 
_AUTOMATIC SURFACE TO SURFACE. This type is a penalty -based contact which creates a proportional force to eliminate the penetration of a slave nodes through a master segments which could happen between the contacted parts. Loading pale was defined as a rigid body and moved vertically in displacement exactly as the displacement history from the experimental test to generate the desirable loading rate. The reaction force at loading plate and supporting steel angles were found through the trucking the contact forces at the contacted bodies.

\subsubsection{LS-DYNA Material model}

One of the most important steps for the finite element analysis is to use a suitable material properties describe all the material used in the analysis. In this study, a reinforced concrete and loading plate as a rigid body representation are simulated in LS-DYNA. The big question that arise during finite element simulation, in general, is that "what is the most accurate material model should be considered to predict the most accurate response". To answer the question, one need to review most material models. Response of the RC structures are very complex and goes to be nonlinear in most of events of loading. The main reason beyond the complicated and unpredictive response is heterogenous concrete behavior which is due to the random distribution of concrete constituents (fine and coarse aggregate) inside the mortar. Different material models of concrete are presented in the literature. They are either, elastic, plastic, elastoplastic damages, or fracture based.

In this work, MAT_CSCM for Continuous Surface Cap Model is used to model the concrete (Murray 2007). MAT 159 as indexed in LS-DYNA can predict material behavior during the dynamic loading considering elastic deformation and failure. This model is developed for some application which exposed to tension and low confining 
pressure regimes as roadside safety applications. There are many features recognizing this model such as elasticity, plasticity, hardening cap that expands and contracts, damagebased softening with erosion and rate effects for high rate applications. This model is isotropic constitutive equations with elastic and plastic updating formulation. It has a smooth cap to define the yield surface shape by using a multiplicative formulation to combine the shear failure surface with the hardening cap as shown in Figure 4-2. Multiplying the cap ellipse function by the shear surface function allows the cap and shear surfaces to take on the same slope at their intersection. Three stress invariants are used to formulate the yield surface, because the isotropic material has three independent stress invariants.

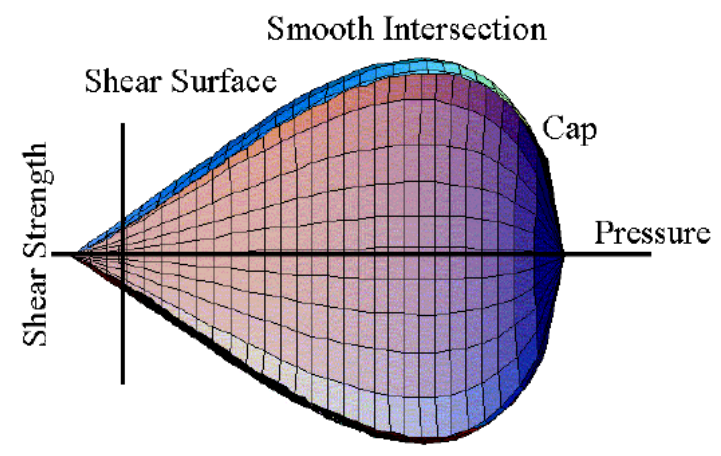

\section{Figure 4-2 General shape of the concrete model yield surface in two dimentions in the meridonal plane (Murray 2007)}

Moreover, in the tensile and low to moderate compressive regime, concrete shows softening which can be modeled by a damage formulation in the model. Otherwise, the cap model predicts perfectly plastic behavior which is not realistic for some experimental test simulation of concrete. Modulus reduction and strain softening are modeled in the damage formulation as Figure 4-3 which is based on work done by (Simo and Ju,). where $\mathrm{d}$ is a scalar damage parameter that transforms the stress tensor without damage, denoted $\sigma_{v p}$, 
into the stress tensor with damage, denoted $\sigma_{d}$. The damage parameter $\mathrm{d}$ ranges from zero for no damage to 1 for complete damage. Thus $(1-\mathrm{d})$ is a reduction factor whose value depends on the accumulation of damage which is based on two distinguished formulation called brittle and ductile damage.

$$
\sigma_{i j}^{d}=(1-d) \cdot \sigma_{i j}^{v p}
$$

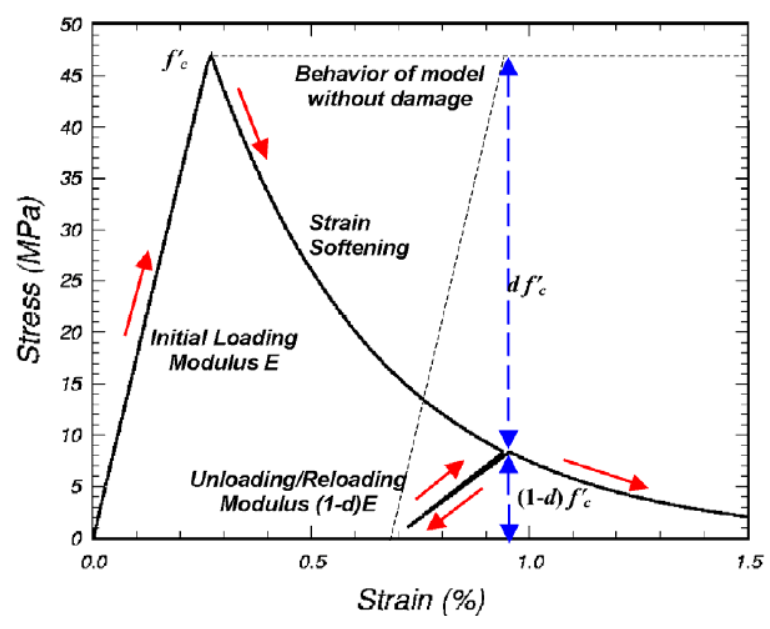

Figure 4-3 Strain softening and modulus reduction of cap model simulation (Murray 2007)

The effect of this reduction factor is to reduce the bulk and shear moduli isotopically (simultaneously and proportionally). In addition, rate effect is taken in consideration causing increasing in strength with increasing strain rate. Figure 4-4 shows the formulation of dynamic increase factor (DIF) which is the ratio of dynamic to static strength used in this model to reflect the increasing in tension and compression concrete strength. The rate effect formulations are applied to the plasticity surface, the damage surface, and the fracture energy in this model. 


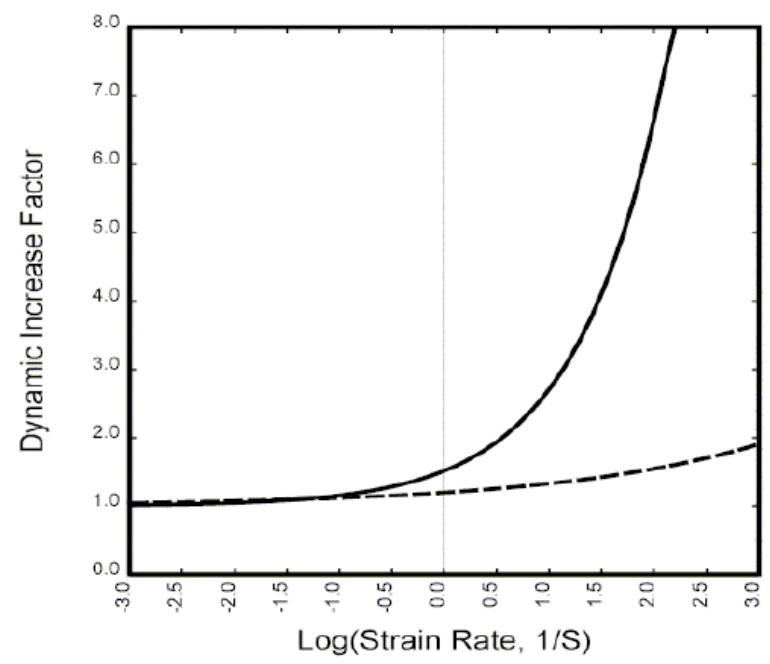

Figure 4-4 Tensile and compressive material dynamic increase factors for concrete model behavior (Murray 2007)

Three input specifications of concrete are needed to define the default material model parameters: the unconfined compression strength (grade), the aggregate size, and the units. The validation values of unconfined compression strength to use them in this model are between 20 to $58 \mathrm{MPa}$ (2901 to 8412 psi) with a range of aggregate size between 8 and $32 \mathrm{~mm}$ (0.3 and 1.3 inches). The CEB-FIP Model Code (1990) was used as a base to determine the model parameters. The unconfined compression strength affects all aspects of the fit, including stiffness, three-dimensional yield strength, hardening, and damage. The fracture energy affects only the softening behavior of the damage formulation. Softening is fit to data for aggregate sizes. In addition, Strain rate effect can be activated by choosing the strain rate option through the user input parameters. More details about this model can be found in a user's manual published by Federal Highway Administration (FHWA 2007).

The other material that need to be defined in RC model is reinforcement bars. All reinforcement bars in the isolated slab-column specimens were modeled as a strain rate sensitive of complete stress -strain curve of uniaxial test as shown in Figure 4-5. The material (Mat 024, Mat Piecewise Linear Plasticity) in Ls-Dyna Material Library (2016) 
was used with ability of defining the strain rate curve. Malvar expression(Malvar 1998) based on equation (2-7) was considered to calculate the effect of strain rate on yield and ultimate stress. A liner function of increasing in stress due to strain rate effect beyond the yield point was assumed to define the whole modified stress- strain curve of steel due to strain rate effect.

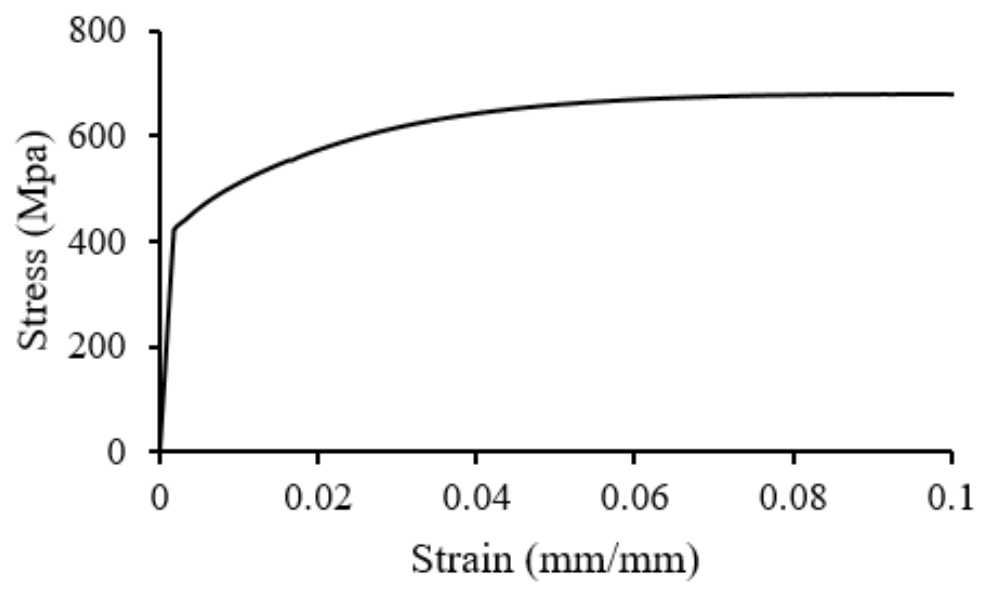

Figure 4-5 Stress -strain curve of tested reinforcement bars

Loading plate and supporting steel angle was assumed as a rigid body in the model. (Mat 20) from the Ls-Dyna (2016) was selected to represent these parts. To prevent a numerical problem due to contact, a realistic values of steel properties were used to define the rigid properties such as Young's modulus, Mass density, and Poisson's ratio.

\subsubsection{FE implicit model}

Regardless of type of FE solver, implicit and explicit solvers have the same features in terms of a variety of element types to be suitable for different applications. In the numerical simulation for static test, nonlinear implicit FE program ANSYS (2015) was used. To represent the model parts (concrete, reinforcement bars, loading plate, and supporting steel angle), 3D FE mesh was adopted and each part was represented by a suitable element. Concrete part was modeled by a Solid element (Solid65) which is an 8- 
nodes with three degree of freedom that each node can translate in three direction $(\mathrm{X}, \mathrm{Y}$, and $\mathrm{Z}$ ). The treatment of nonlinear material properties is one of the most important aspect in this element. This element has a powerful capability in plastic deformation, cracking (in three orthogonal direction), and crushing, which are modeled by smeared crack approach that make it more convenience to represent concrete which has these capabilities in its behavior. A geometry of the element is shown in Figure 4-6.

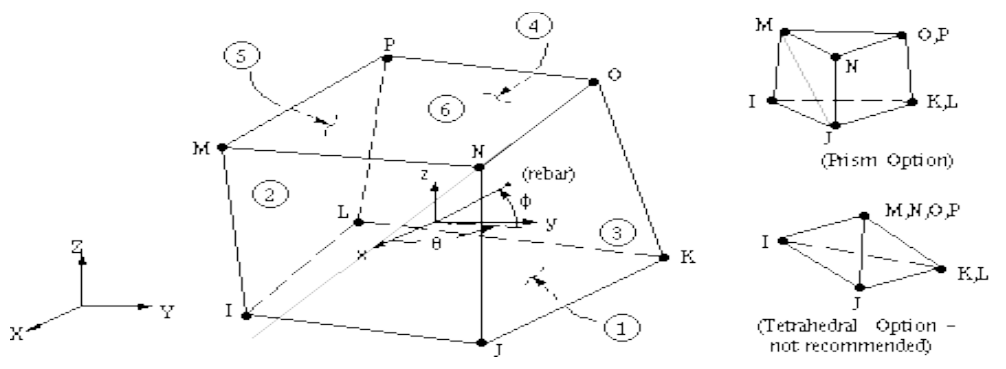

Figure 4-6 Solid 65 geometry

Top and bottom Reinforcement bars of the slab in addition to column reinforcements were modeled by using beam element (Beam188). This element is a linear (2-nodes) in 3D with six degree of freedom. It is very suitable for linear and large strain nonlinear applications. Material properties such as elasticity and isotropic hardening plasticity can be modeled in this element. Reinforcement bars were meshed and its nodes were shared with the concrete nodes to prevent the slippage between them. Other parts such as loading plate and supporting steel angle were modeled by using solid element (Solid185) which has 8-nodes with three degree of freedom in each node with capability of simulating plastic and hyperplastic materials. In terms of the boundary condition and load application, same technique in the explicit model was implemented in implicit analyses. Moreover, as explicit model, a mesh sensitivity was studied and $20 \mathrm{~mm}$ mesh size was selected which give a steady punching shear capacity irrespective of increasing 
total number of elements in the model. Table 4-2 shows the total number of element used in the implicit model.

Table 4-2 Total number and types of elements of ANSYS model

\begin{tabular}{|l|l|c|}
\hline \multicolumn{1}{|c|}{ FE parts } & \multicolumn{1}{|c|}{ Element type } & Element number \\
\hline concrete & solid element ( SOLID 65) & 26359 \\
\hline Reinforcement steel & beam element (189 BEAM ELEMENT) & 1520 \\
\hline Loading plate and support & solid element & 2304 \\
\hline
\end{tabular}

Material properties of implicit model were defined based on the experimental characteristics of material used in the experimental test. A multilinear isotropic stress-strain curve based on Shah model (Shah et al.1983) was adopted to define the compressive uniaxial stress-strain relationship for concrete as shown in Figure 4-7. Tension behavior of concrete was assumed linear until tensile strength of concrete. Material properties of reinforcement bars, loading plate, and supporting steel angle in explicit model were used in implicit model.

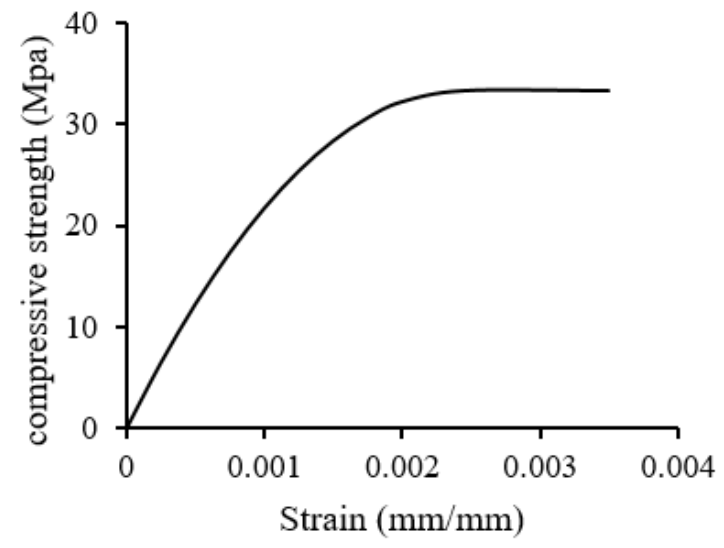

Figure 4-7 Compressive uniaxial stress -strain curve of concrete 


\subsection{Validation of finite element model and analytical results}

The results of the FEM study are compared to the experimental tests until punching shear failure in order to validate the analysis method. The results for load vs. center deflection for all specimens and tension reinforcement strain vs. time for specimen 1UND4 are compared in Figure 4-8 and Figure 4-9, respectively. Even though there is a little difference in stiffness after the first crack, the overall response of load-deflection curve of slab column connection is captured in FE model up to punching shear failure. The damage of the slab-column connection at punching failure is shown in Figure 4-10 by plotting the contour of effective plastic strain. The numerical punching shear capacity of specimens 0.64RE-D1, 0.64RE-D2, and 1UN-D4 are $286 \mathrm{KN}, 254 \mathrm{KN}$, and $318 \mathrm{KN}$, respectively, and generally they are within 5\% difference in comparison with the experimental tests. However, there are some differences ranging from $4.8 \%$ to $9.7 \%$ in deflection at punching shear failure for all dynamic test except specimens 1RE-D3 and 0.64RE-D2 which had 25\% more experimental deflection even within just $4 \%$ difference in simulation punching strength.

In addition, specimen 1UN-D4 was selected to show the comparison of strain history of tension reinforcement bars. Strain gages T10 and T14 show good agreement between the tested strain and the simulation at early stage of loading as shown in Figure 16. Although there are some differences in the history of T10, the maximum strain at punching is similar in the experiment and simulation.

The static tests were validated with the ANSYS FEM model. The previous results of specimens 1.0UN-S3 and 0.64UN tested by Peng et al. (2017a) were used as a base of validation. These specimens have the same geometry and boundary conditions with two different ratios of tension reinforcements $1 \%$ and $0.64 \%$. Figure $4-11$ illustrates the load 
vs center column deflection. FE model matches the overall response of load vs. deflection curves in $1 \%$ and $0.64 \%$ reinforcement ratio specimens, and the predicted punching shear capacity is within $1.5 \%$ difference compared with experimental data. Also FE model captures the initial stiffness and the load deflection response after the first crack occurrence.
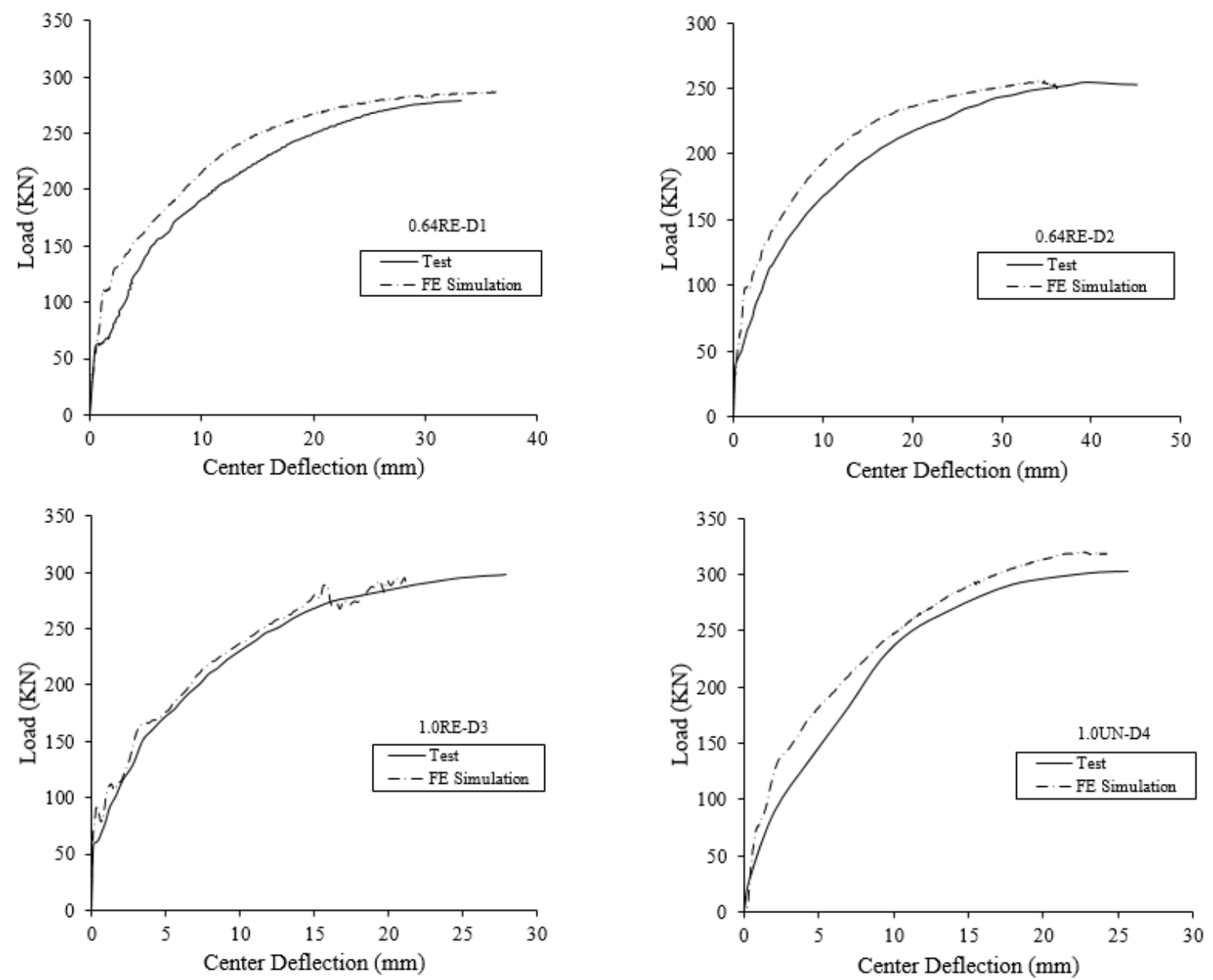

Figure 4-8 Load- Deflection curve of dynamic test of specimen 

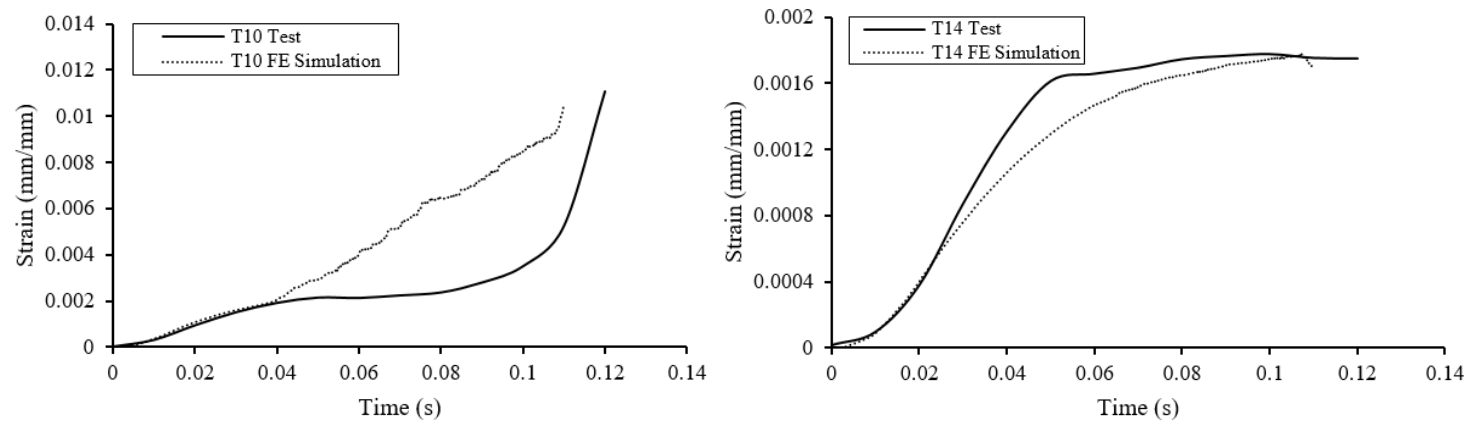

Figure 4-9 Strain history of tension reinforcement bars for specimen (1UN-D4)

Effective Plastic Strain
$9.990 \mathrm{e}-01$
$8.991 \mathrm{e}-01$
$7.992 \mathrm{e}-01$
$6.993 \mathrm{e}-01$
$5.994 \mathrm{e}-01$
$4.995 \mathrm{e}-01$
$3.996 \mathrm{e}-01$
$2.997 \mathrm{e}-01$
$1.998 \mathrm{e}-01$
$9.990 \mathrm{e}-02$
$0.000 \mathrm{e}+00$

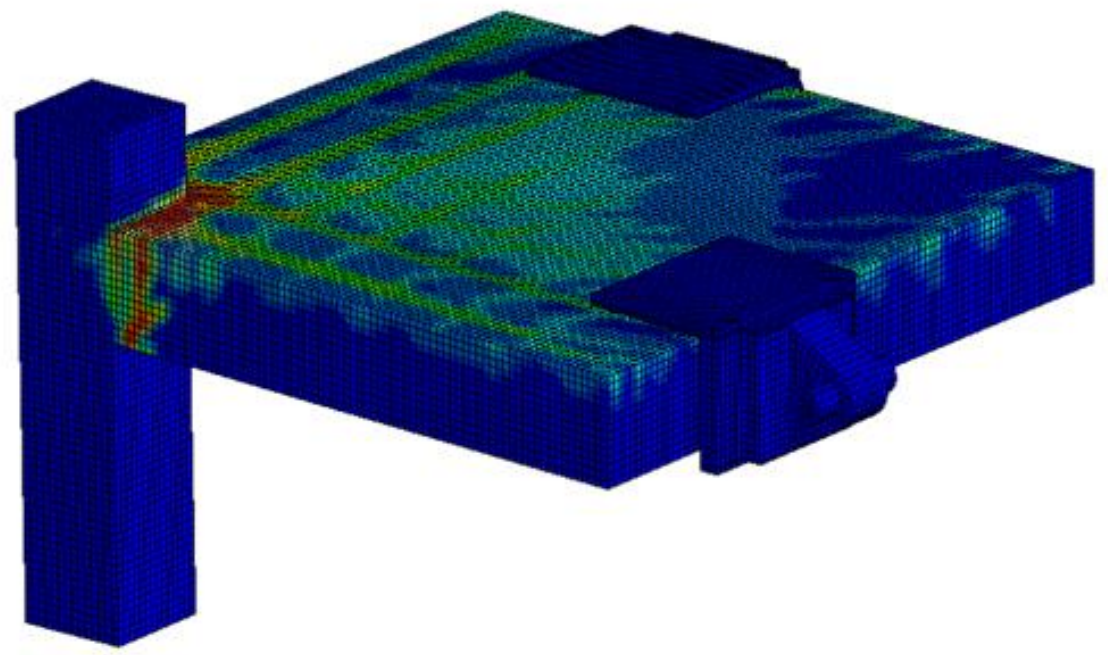

Figure 4-10 Failure pattern on tension surface of slab-column connection model at punching 

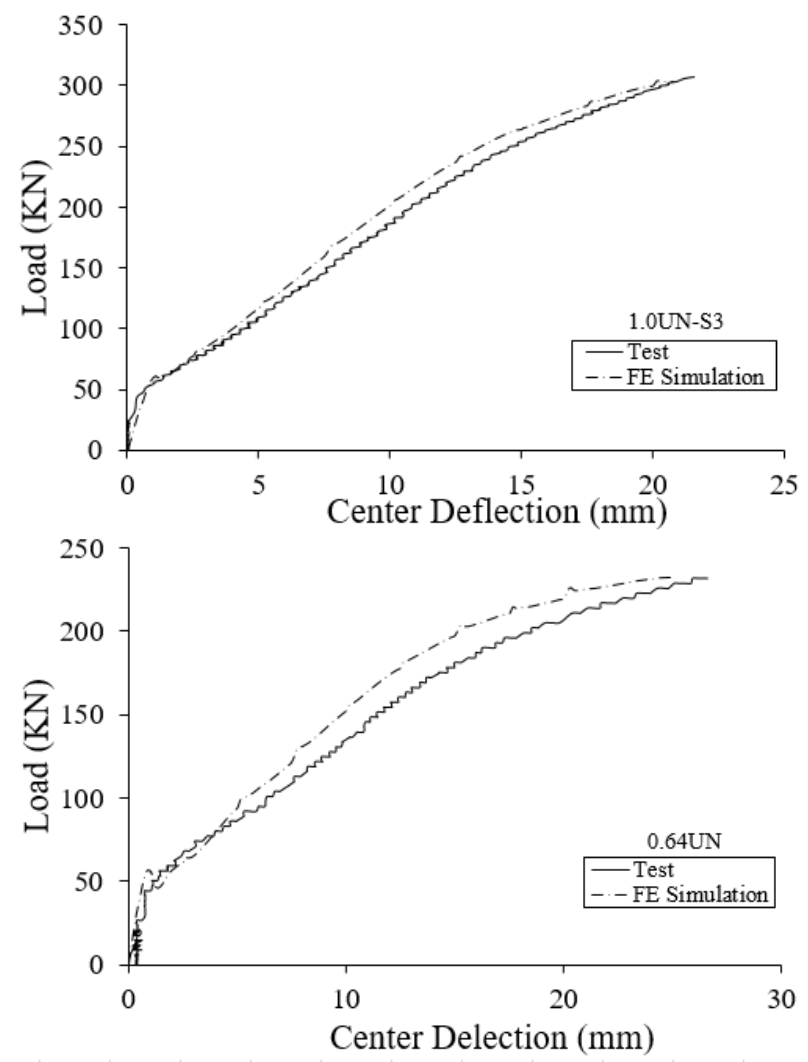

Figure 4-11 Load-Deflection curve of static test for specimens (1.0UN-S3,0.64UN)

\subsection{Effect of dynamic loading}

\subsubsection{Different in ductility}

The experimental tests found that the dynamically loaded specimens exhibited little increase in punching capacity, but greater ductility than the statically loaded specimens. The numerical model can be used to evaluate this behavior. For most RC members, flexural and shear strength play an important role to form the final failure mode. However, material properties of concrete and steel are sensitive in different degrees to the strain rate. In a RC beam, material strain rate sensitivity causes different increases in flexural and shear rate strength leading to change in failure mode (Kulkarni and Shah 1998, Adhikary and Fujikake 2015). For lower strength bars, steel is more strain rate sensitive and controls the flexural strength of the beam. Therefore, under a high strain rate, the flexural strength will 
increase more than the shear strength leading to the possibility of shear failure as seen in Mutsuyoshi and Machida (1985).

However, RC slab-column connections are complicated and it is impossible to separate the flexural and shear behavior. Criswell (1974) indicated that if yielding of the flexural reinforcement occurs before punching there would be greater deformation in the slab. Therefore, strain rate effect of material properties such as yield and ultimate strength of steel and compressive strength of concrete are used individually in the FE implicit model to calculate the corresponding punching shear capacity of specimens with a $1 \%$ reinforcement ratio. Material strength dynamic increase factors based on a prescribed loading rate are applied to the static model for the steel and concrete individually. Figure 4-12 shows that the rate of increasing punching capacity due to enhancing only the concrete compressive strength is higher than due to enhancing steel strength only. As the steel strength is more closely related to the flexural behavior of the connection and the concrete strength has a stronger influence on the punching capacity of the connection, this result would seem to indicate that at increased loading rates, the punching capacity is enhanced to a greater extent than the flexural capacity. This could allow for more flexural deformation in the slab before final punching failure.

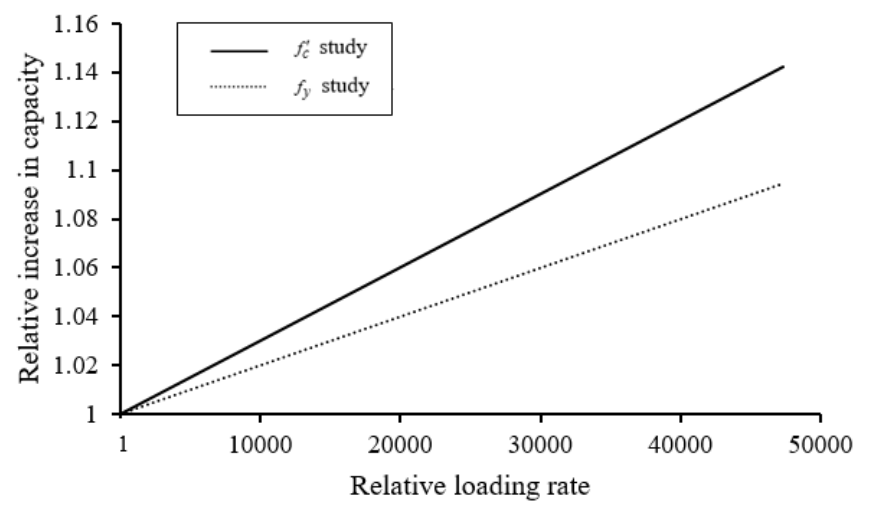

Figure 4-12 Relative enhancement of punching shear capacity 
The previous discussion may explain the reason for the $19.2 \%$ greater deflection at punching for the $1 \%$ reinforcement ratio tests and the $24.4 \%$ greater deflection for the $0.64 \%$ reinforcement ratio tests for low lateral restraint specimens. The higher loading rate enhanced the punching response and allowed for greater flexural deformation before failure.

To further investigate this behavior, the loading rate effect was studied through the FE model by changing the loading rate from $0.00004 \mathrm{~m} / \mathrm{s}$ to $0.46 \mathrm{~m} / \mathrm{s}$ as shown in Figure 4-13. All other properties were constant. The simulation showed little increase (5\%) in punching capacity with increasing loading rate from static to collapse loading rate which is in agreement with the experimental testing. The strain data presented in Figure 6 showed that the strains in the dynamic specimen were higher at punching than the corresponding static specimens. This would seem to indicate a dynamic amplification of the strain in the dynamic specimens. Such an amplification would offset the material strength increase and could lead to nearly the same load at punching failure.

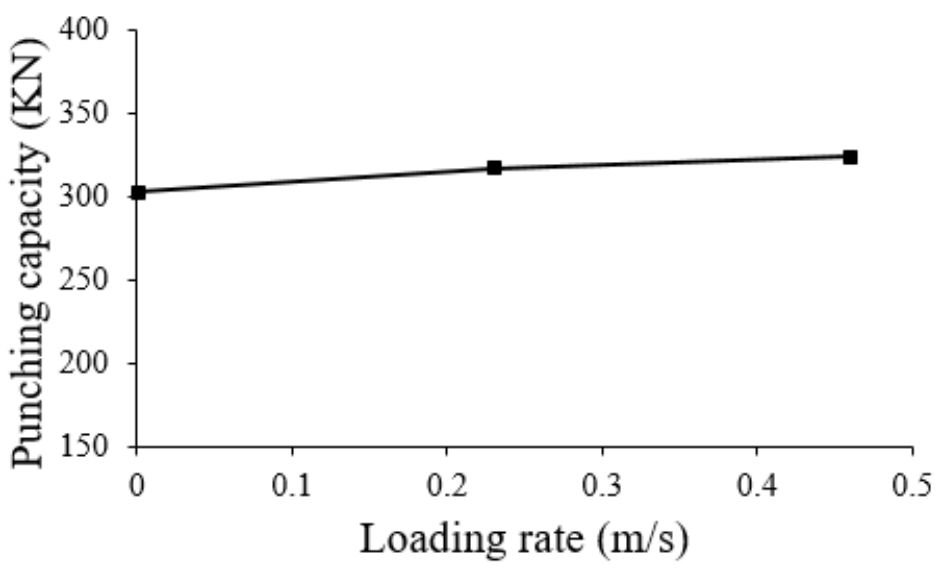

Figure 4-13 Loading rate effect on punching shear capacity by using FE model

\subsection{Parametric study}

A parametric study was conducted to investigate the effect of tension reinforcement ratio, slab thickness, and grade of compressive strength of concrete on punching shear 
capacity and the ductility of the unrestrained isolated slab-column connection subjected to static and dynamic (loading rate $0.23 \mathrm{~m} / \mathrm{sec}$ ) loads. The response of the connections was studied by calculating the dynamic strength increase factor $\left(\mathrm{DIF}_{\mathrm{s}}\right)$ and dynamic ductility increase factor $\left(\mathrm{DIF}_{\mathrm{u}}\right)$. These factors can be found by dividing the maximum punching shear load and deflection at punching of isolated slab-column connection under dynamic load by the corresponding results of static load tests.

\subsubsection{Influence of tension reinforcement ratio}

Tension reinforcement ratio ratios of $0.64 \%, 1.5 \%$, and $2 \%$ were studied. Other properties corresponded to specimen 1.0UN-D4. Figure 4-14 (a) and (b) shows that the punching shear capacity increases with increasing reinforcement ratio as expected. However, there is little change in DIFs with increasing reinforcement ratio indicating that the punching capacity is not greatly affected by the collapse loading rate at any tensile reinforcement ratio as shown in Figure 4-14(c). On the other hand, the lower values of reinforcement ratio $(0.64 \%$ and $1 \%)$ show higher DIFu compared to $1.5 \%$ and $2 \%$ reinforcement ratio specimens as seen in Figure 4-14(d). The reason behind this observation could be due to the effect of strain rate on material strength of steel and concrete. For low values of reinforcement ratio, the greater improvement in shear capacity which comes from the enhancement in concrete strength leads to more flexural response already expected for these values of reinforcement ratios. However, the specimens having high values of reinforcement ratio are more likely to fail brittlely (without significant flexural response) regardless of the increase in shear capacity. Therefore, connections with lower values of tensile reinforcement would see a greater enhancement in their ductility (and toughness) than connections with higher tensile reinforcement. The toughness of the 
connection may be important in determining if the connection would fail in a dynamic analysis.

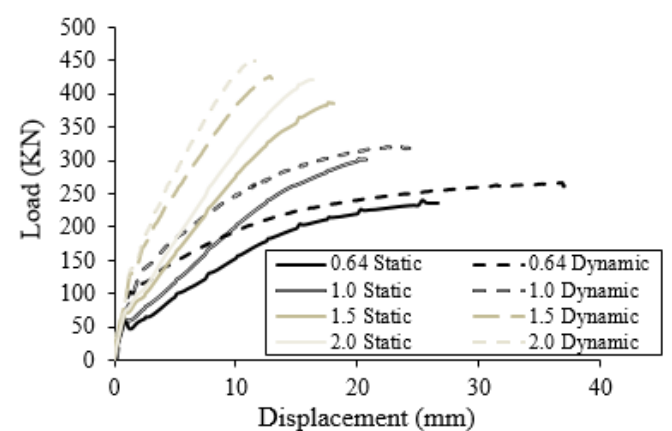

(a)

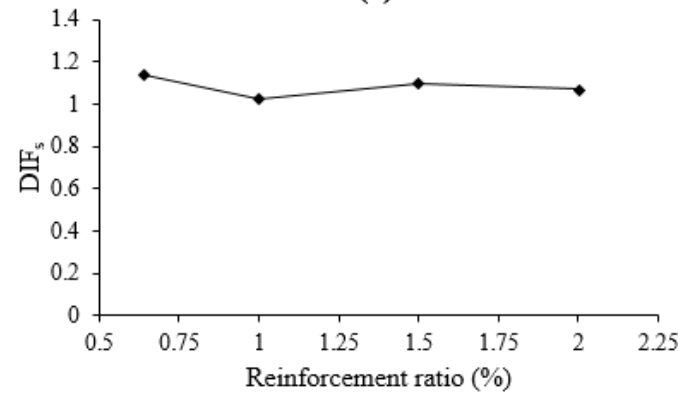

(c)

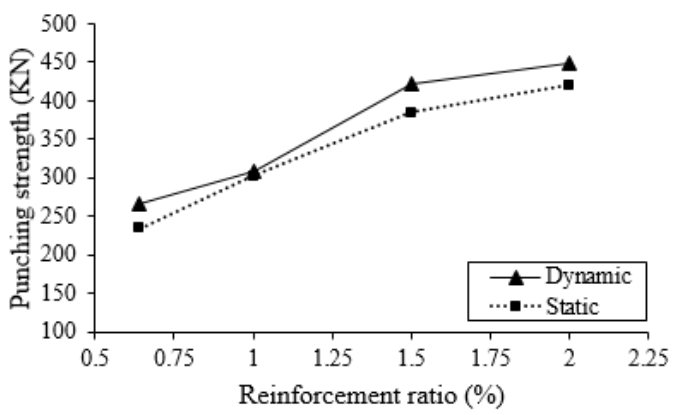

(b)

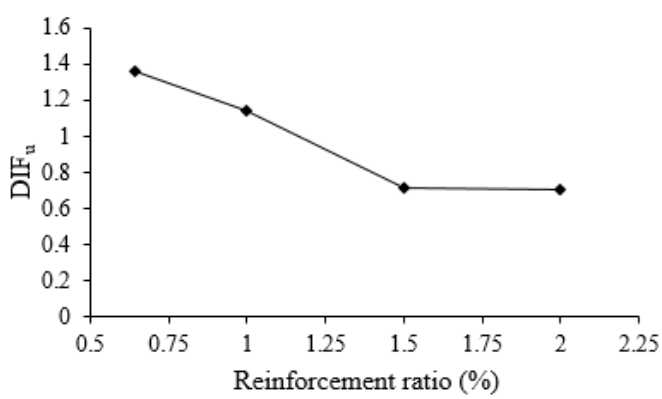

(d)

Figure 4-14 Influence of reinforcement ration on: (a) load-deflection relationship of static and dynamic tests (b) punching shear strength of static and dynamic tests, (c) DIFs of maximum shear strength, (d) DIF of deflection at punching shear failure

\subsubsection{Influence of slab thickness}

Three slab thickness of $100 \mathrm{~mm}, 185 \mathrm{~m}$, and $220 \mathrm{~mm}$ were evaluated. Slab thickness has significant effect on punching shear capacity as expected and shown in Figure 4-15a. However, there is not a significant effect of slab thickness on punching strength $\mathrm{DIF}_{\mathrm{s}}$ under static and dynamic loading rate as shown in Figure 4-15b. The deflection $\mathrm{DIF}_{\mathrm{u}}$ does show decreasing values as the slab thickness increased as illustrated in Figure 4-15c. This trend is similar to that of the tensile reinforcement, and indicates that thinner slabs may exhibit more ductility at higher loading rates than thicker slabs. 


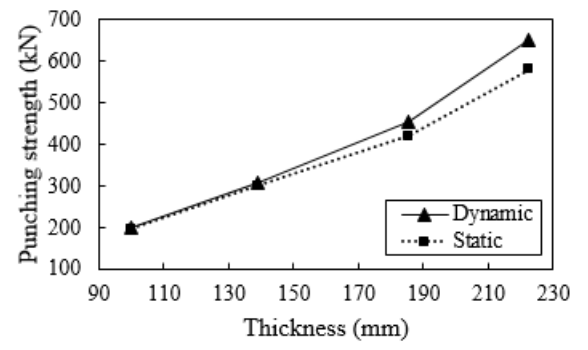

(a)

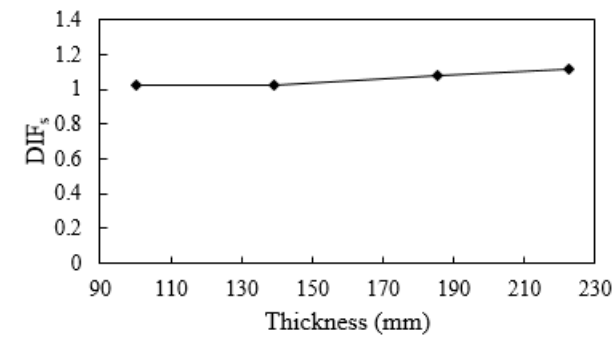

(b)

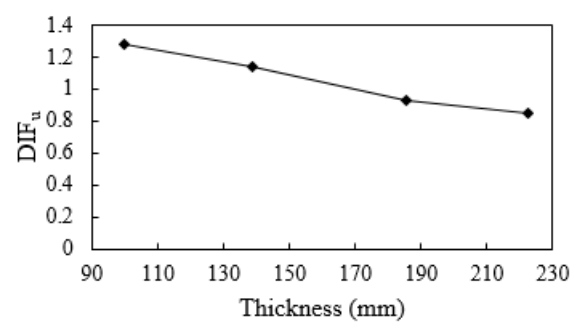

(c)

Figure 4-15 Influence of slab thickness on :(a) punching shear strength of static and dynamic tests, (b) DIF of maximum shear strength, (c) DIF $\mathrm{u}$ of deflection at punching shear failure

\subsubsection{Influence of compressive strength of concrete}

Three values, $33 \mathrm{MPa}, 40 \mathrm{MPa}$, and 50MPa, of concrete compressive strength were selected for comparison. As shown in Figure 4-16a, punching capacity increases with increasing compressive strength of concrete. However, there is not a significant change in $\mathrm{DIF}_{\mathrm{s}}$ with increasing compressive strength of concrete as shown in Figure 4-16b. Figure 4-16c shows that $\mathrm{DIF}_{\mathrm{u}}$ decreases with increasing concrete compressive strength. In fact, the DIF $\mathrm{F}_{\mathrm{u}}$ drops below 1 for high values of concrete compressive strength. This would indicate that a dynamically loaded connection would experience less ductility than a statically loaded connection. 


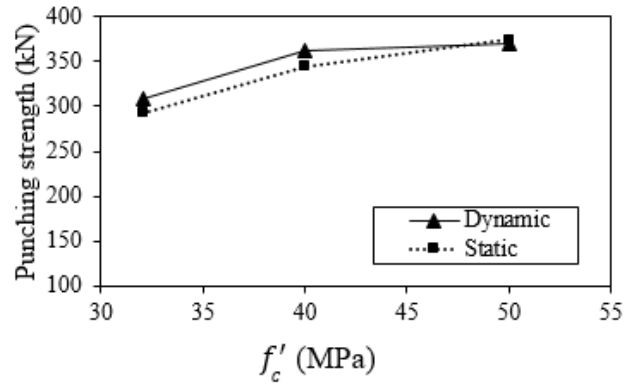

(a)

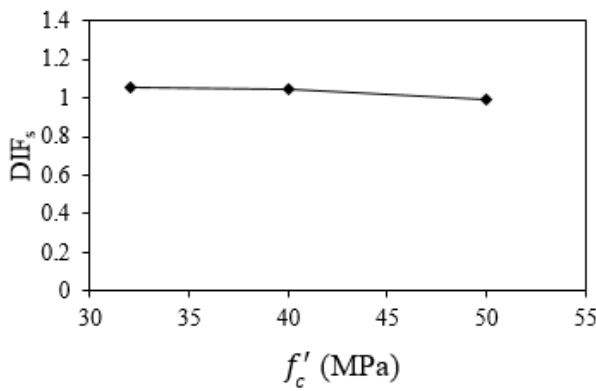

(b)

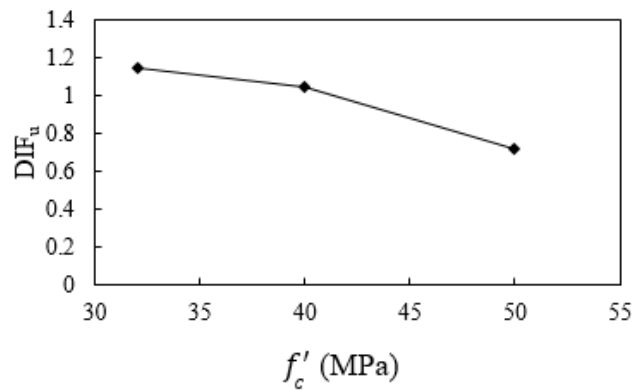

(c)

Figure 4-16 Influence of concrete compressive strength on :(a) punching shear strength of static and dynamic tests, (b) DIF s of maximum shear strength, (c) DIFu of deflection at punching shear failure

\subsubsection{Summary}

In this Chapter, a 3D FE model was developed using LS DYNA and ANSYS wa used to assess the punching shear strength and ductility of isolated slab-column connection under dynamic and static loading rate. Even though there is a little difference in stiffness after the first crack for the dynamic model, the overall response of load-deflection curve of slab column connection is captured in FE model up to punching shear failure. Also, the FE study showed that at increased loading rates, the punching capacity is enhanced to a greater extent than the flexural capacity. This could allow for more flexural deformation in the slab before final punching failure as explanation of having more ductility for specimens tested dynamically than the static tests.

A parametric study was investigated numerically. These parameters include the effect of tension reinforcement ratio, slab thickness, and grade of concrete compressive 
strength on the response of isolated RC flat-plate slab column connections under static and dynamic loading rate. The parametric study showed more ductility for lower tensile reinforcement, smaller slab thickness, and reduced concrete strength in compression under dynamic loading rates while the strength of the connection remained relatively unchanged. 


\section{CHAPTER 5}

\section{CHAPTER 5: SIMPLYFIED SIMULATION OF LOADING RATE EFFECTS ON RC SLAB-COLUMN CONNECTION}

\subsection{Introduction}

The ability of detailed numerical simulation to determine the response of structural components under applied load conditions is effective, however, time consuming and inefficient for complex systems (such as entire buildings). Therefore, a simplified approach to understand the global behavior of the structural system is needed to save time while maintaining accuracy. This chapter focuses on developing a simplified analysis model that can capture the overall response of isolated slab-column connections under a concentrated dynamic load. The model is validated with experimental tests and detailed FE analysis. Then, the model is utilized on the RC multi-panel test to study its ability of recognizing the global behavior of RC flat-plate structure under collapse. Abaqus (2011) is used to simulate the dynamic tests for RC isolated slab-column connection and multi-panel tests.

\subsection{Macromodel simulation}

Finite element (FE) simulation by using ABAQUS (2011) was used in this study to simulate a portion of the prototype building by adapting the macro-model proposed by Liu et al. (2015) with modification on connecter properties to account for the effect of dynamic loads which will be clarified later in this chapter.

The macro-model contains shell and connector elements joined at column perimeter to simulate the nonlinear slab behavior as shown in Figure 5-1. Punching shear perimeter position or connecter length was assumed based on the ACI 318-14 (ACI 2014) as the 
distance of half slab effective depth. Thin shell elements containing rebar layers were selected to simulate the slab outside the punching shear perimeter. Concrete Damage Plasticity (Lubliner et al.1989, Lee and Fenves 1998) with tension stiffening behavior was adopted to model the concrete. Slab-column connection area and the column were modeled as a rigid shell and beam elements, respectively. Two connector beam elements in each side of punching shear perimeter were assumed with six degree of freedom at each node to represent the transfer forces from the slab to the column. Nonlinear behavior for primary bending moment and torsion was assumed, while shear force was assumed as a linear behavior. Punching shear failure is reached when the rotation of the slab to the column exceed the rotation limit given by the Muttoni criteria.

The original model adopted the Muttoni equation (Equation (2-3)) (2008) for punching strength as a failure criteria of connector beam element. The new failure criteria, which will be presented later, is made by modifying the Muttoni equation to take the effect of dynamic loading rate in consideration. The $V_{u}$ used in Muttoni equation represents the total punching shear capacity of the slab-column connection and each side of the slabcolumn connection has two connector elements. Therefore, the shear force capacity of each connector element is $1 / 8$ of $V_{u}$ used in Muttoni equation. More details of the macro-model can be found elsewhere (Liu et al. (2015)). 


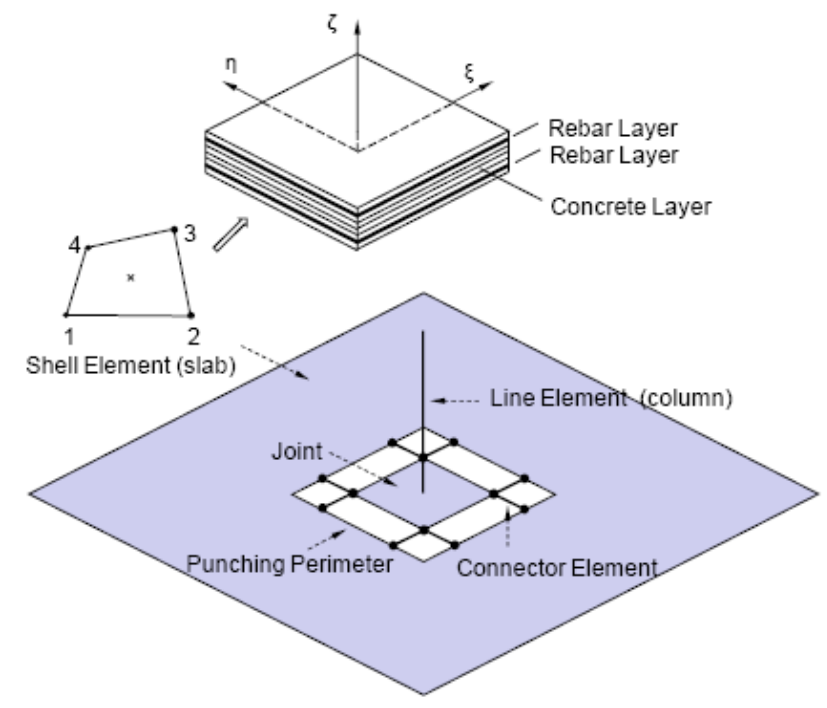

Figure 5-1Macromodel for flat plates Liu et al. (2015)

This model was validated by Peng et al. (2017) with the corresponding experimental static tests as shown in Error! Reference source not found.. The overall $r$ esponse showed a good agreement in comparison between the simulation model and the experimental test. However, the deflection of specimens 0.64RE-NH showed less deformation compared to the experimental test. This additional deformation due to the flexural yielding was neglected in this model (Peng et al. 2017). 

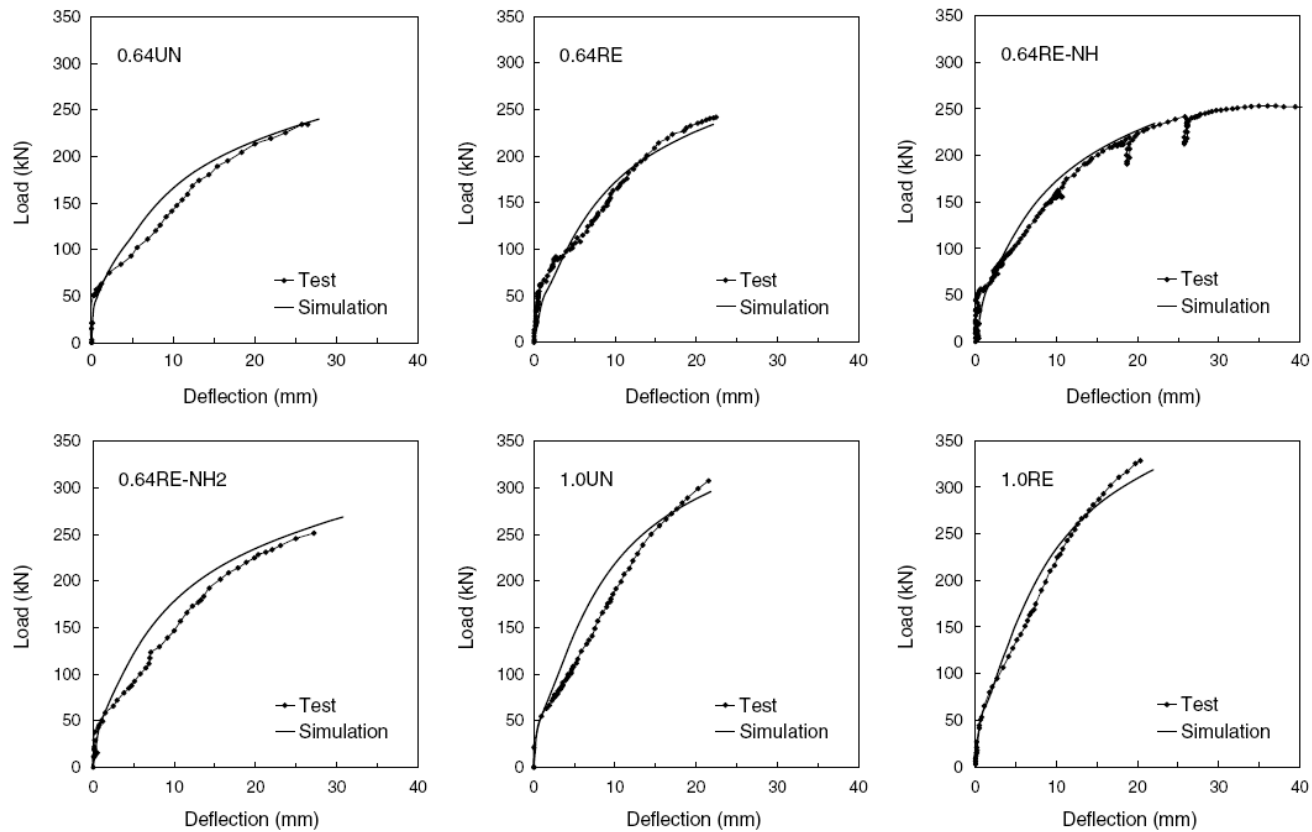

Figure 5-2 Load-deflection response predicted by macromodel versus test results (Peng et al.2017)

\subsection{Dynamic model modifications}

Originally, the simplified model was developed to accurately predict the punching shear capacity of slab-column connection subjected to static load conditions. However, dynamic isolated slab column specimens showed some differences in load-deflection behavior compared to the static test. Namely increased ductility with lower reinforcement ratios. Therefore, the model was modified to account for the effect of dynamic load on connection behavior. The connector properties were modified to account for the amount of enhancement in the concrete and steel material strength due to the strain rate effect. Modifying only the connector properties did not show significant differences in the numerical analysis between the static and dynamic simulations as shown in Figure 5-3.

In order to explain the differences in the experimental dynamic tests, a new failure criteria was defined to account for the effect of the dynamic load. Based on the detailed FE numerical and experimental results as shown in Figure 5-4, a regression analysis was 
implemented to modify the Muttoni failure criteria where the aggregate size effect term was multiplied by 12 instead of 15 . Equation (5-1) shows the modified Muttoni failure criteria.

$$
\frac{V_{u}}{b_{o} d \sqrt{f_{c}^{\prime}}}=\frac{3 / 4}{1+12 \frac{\psi_{u} d}{d_{g 0}+d_{g}}}
$$

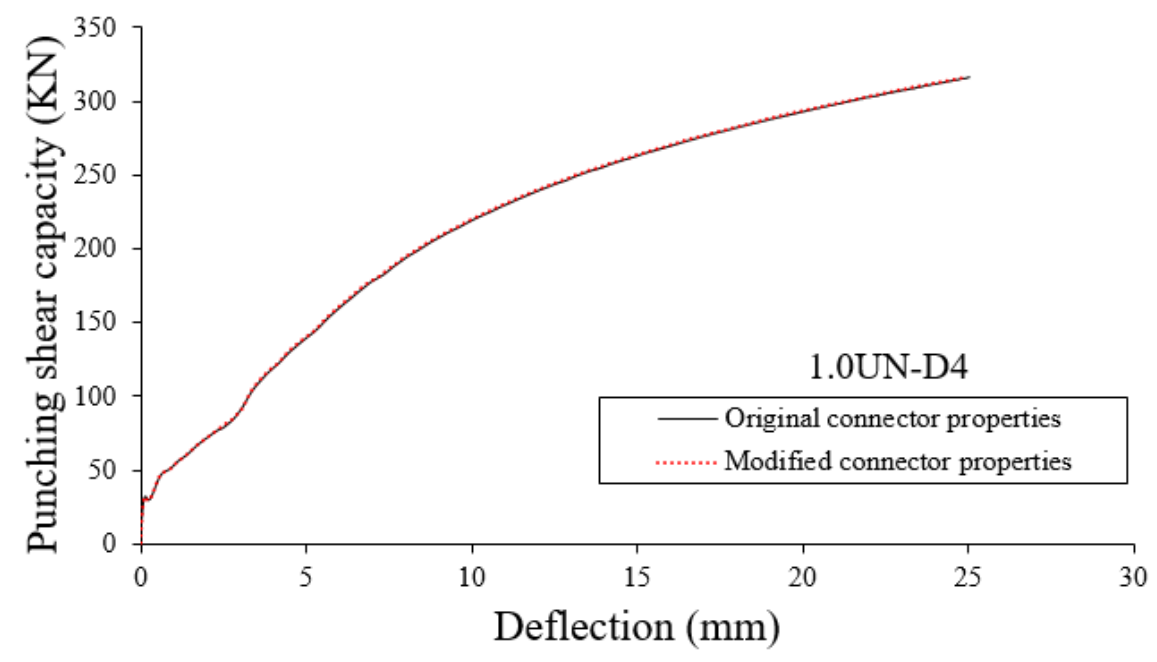

Figure 5-3 Load- Deflection curve of dynamic FE model of specimen 1.0UN-D4 based on original and modified connector properties 


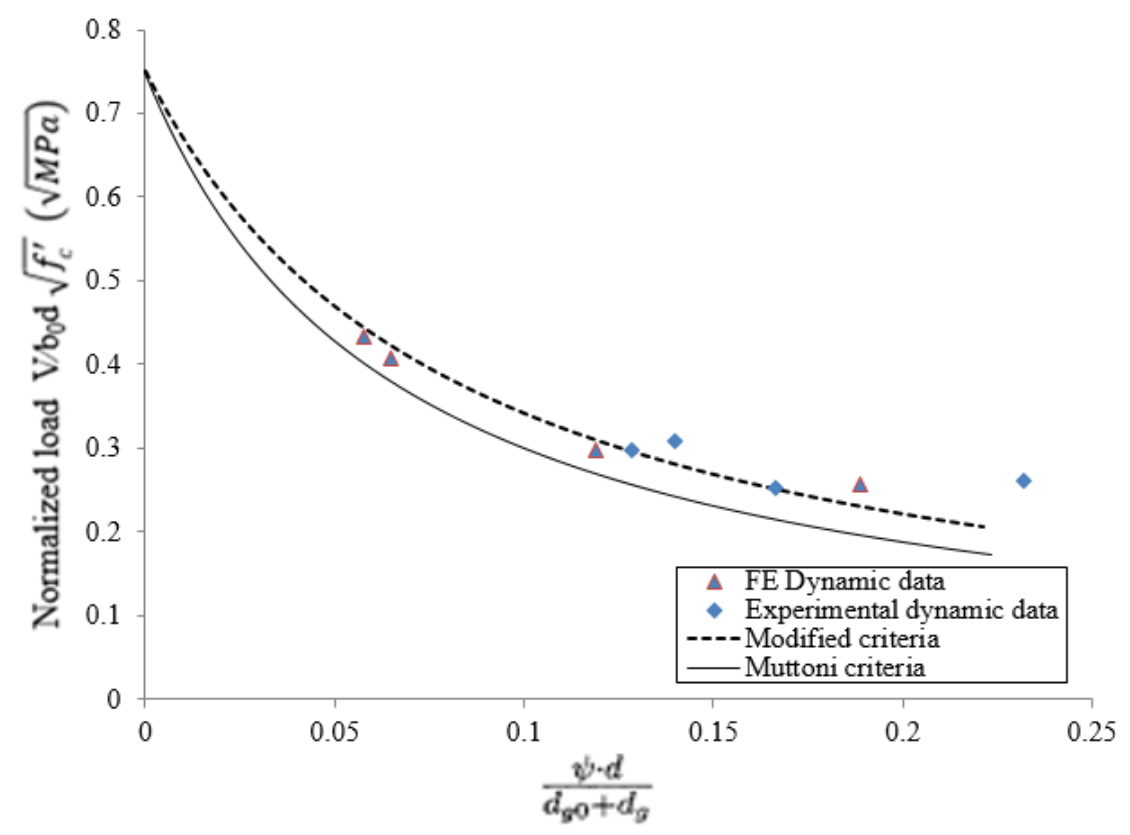

Figure 5-4 Muttoni failure criteria modification

\subsection{Simplified model validation of isolated slab-column connection}

The results of the modified simplified model are compared to the dynamic experimental tests and FE model until punching shear failure in order to validate the analysis method. The results for load vs. center deflection for all specimens are compared in Error! Reference source not found.. Despite some difference in stiffness after the first c rack of 1.0RE-D3 specimen, the other specimens showed a good agreement with the simulation model, especially specimen 0.64RE-D1. The overall response of load-deflection curve of slab column connection is captured in the simplified model up to punching shear failure. The numerical punching shear capacity of specimens 0.64RE-D1, 0.64RE-D2, and 1UN-D4 are $287 \mathrm{KN}, 265 \mathrm{KN}$, and $314.43 \mathrm{KN}$, respectively, and generally they are within $5 \%$ difference in comparison with the experimental tests and detailed FE simulation except 1.0RE-D3 which has 7\% difference comparing to the detailed FE model. However, there are some differences ranging from $3.8 \%$ to $4.5 \%$ in deflection at punching shear failure 
for all dynamic test except specimens 1RE-D3 and 0.64RE-D2 which had 17.16\% and 36.5\% more experimental deflection even within just $4 \%$ difference in simulation punching strength. This underestimating in deformation was captured again in specimen 0.64RE-D2 by knowing that the specimen 0.64RE-NH is almost having the same properties of specimen 0.64RE-D2 except the load condition.

The difference in the predictions of failure between the original and modified models are also shown in Figure 5-5. Because modifying the connector properties to account for the dynamic loading did not greatly alter the response of the specimens the curves for both models are nearly identical. However, the modified failure criteria greatly change the point of failure in each of the tests and brings that point closer to what was observed in the experiment. For specimens 0.64RE-D1, 0.64RE-D2, and 1.0UN-D4, the using the original criteria, the failure rotation was on average $21.4 \%$ of the experimental, while with the modified criteria, the failure rotation was within $7.6 \%$. Although the modified criteria need verification with specimens of different sizes and reinforcement ratios, the improved result show that accounting for the dynamic effect in slab-column connection can be done by simply modifying the failure criteria. 

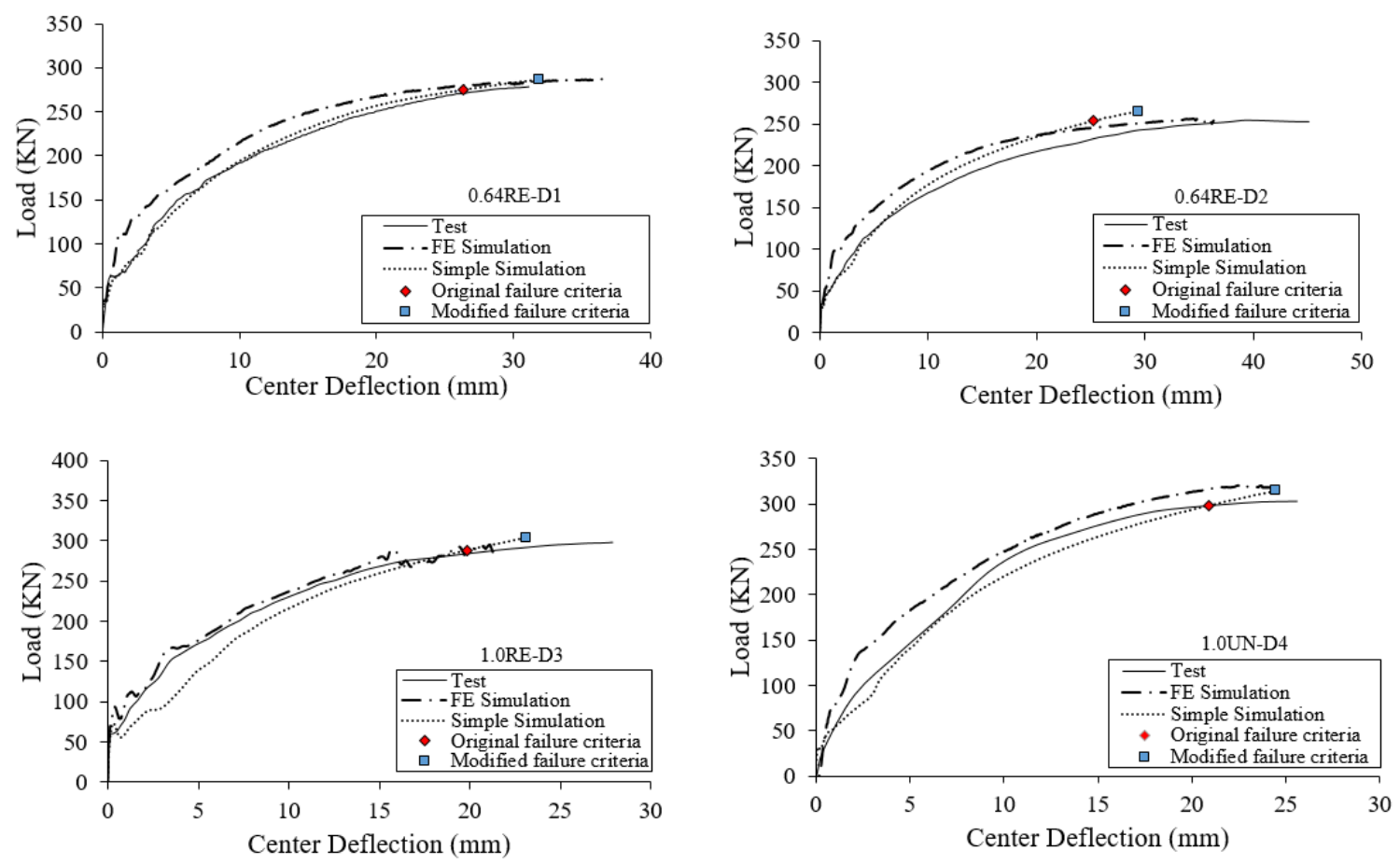

Figure 5-5 Load- Deflection curve of dynamic test and FE model of specimen

\subsection{Multipanel substructure}

In order to understand how the change in failure criteria under a dynamic load can change the response of a larger floor system, the criteria are used with a multi-panel system. A multi-panel substructure as shown in Figure 5-6 was tested by the dynamic removal of an interior column by Peng et al. (2018) to study the performance of flat-plat structure under collapse. The multi-panel specimen was a 0.4 scale of a prototype building which designed based on ACI 318-71(1971). No continuous bottom reinforcement was present in this specimen to represent the older flat-plate buildings design. Low reinforcement ratio ( $\rho=0.57 \%)$ of tensile reinforcement was used for the slab near the columns. Portions of a $152 \mathrm{~mm}$ square column were cast monolithically to support the specimen at a distance $2.44 \mathrm{~m}$ in either direction. HSS steel tubes were used at the lower part of square column to 
connect the specimen with the lab floor and measure the resulted axial force during the test. Three sides of the specimens were cantilevered at a distance $1 / 4$ of the span length to reflect the inflection point location, while the last side represented the exterior side of the prototype building. $5.55 \mathrm{kN} / \mathrm{m}^{2}$ uniform distributed load was applied on the interior slab by using soil bags and concrete blocks distributed uniformly on the slab panels in addition to the slab self-weight, $1.79 \mathrm{kN} / \mathrm{m}^{2}$, while the total applied load was increased to $15.51 \mathrm{kN} / \mathrm{m}^{2}$ on the exterior slab to reflect the effect of uncast portion of the slab at the perimeter area of specimen. More details on this test can be found in Peng et al. (2018). The specimen was tested by releasing the supporting load of the interior column B2 suddenly by using a collapsing jack. The results showed that the specimen experienced punching shear failure at four connections but the collapse was successfully resisted through post-punching capacity. The specimen survived a load $78 \%$ of its un-factored design load. The test showed that the punching shear failure at the adjacent connections of a lost column can happen at the load level less than the typical service design load of the building.

Peng et al. (2018) conducted additional isolated tests by cutting the slab around connections $\mathrm{A} 3$ and $\mathrm{C} 3$, which were not damaged in the dynamic test. The results of these tests were used later through the comparison between experimental and simulation results to define the critical rotation during the simulation analysis. 

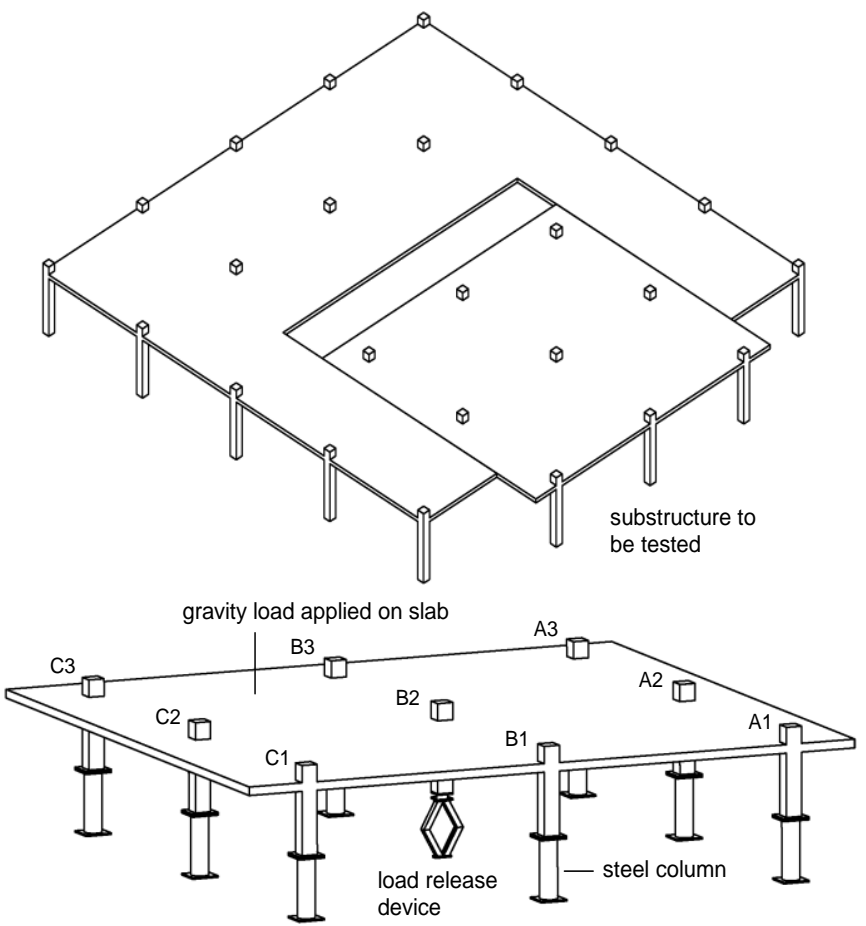

Figure 5-6 Schematic model of test specimen (Peng et al. 2018)

The macro-model for the multipanel substructure used the same technique of simulating as isolated slab-column specimens. The vertical displacement history at the removed column location B2 is shown in Figure 5-7 and the experimental and simulated results were compared until first punching failure at a connection. This figure shows that the measured and simulated results had the same behavior until $\delta_{\mathrm{B} 2}=20 \mathrm{~mm}$. Then, some discrepancy was observed. This discrepancy could be from the aberrations in the experimental set up or the modeling of defining the material properties such as concrete cracking. 


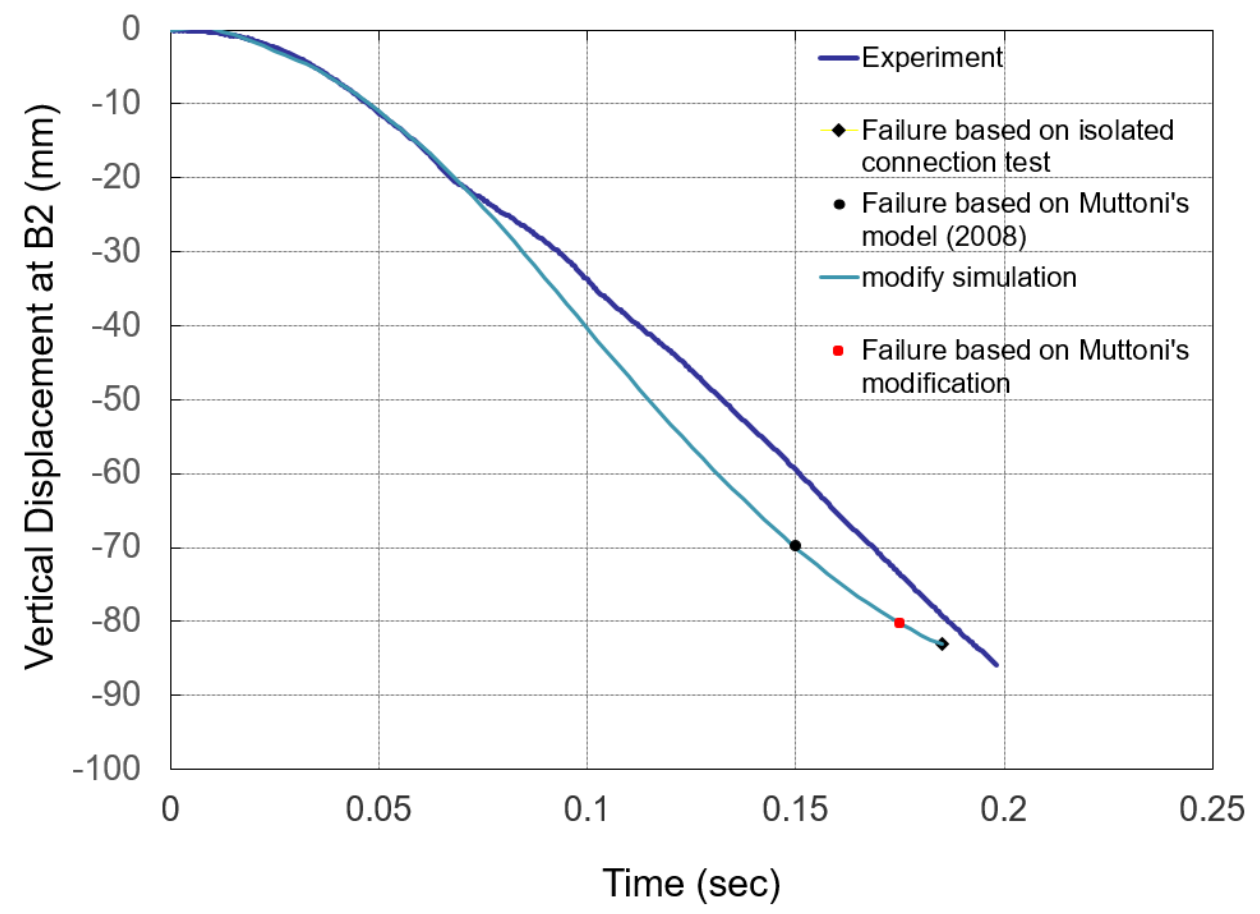

Figure 5-7 Experimental and simulation results for vertical displacement history at column B2

Muttoni failure criteria, modified failure criteria, and failure based on the tested isolated slab-column connection were applied to determine the failure point (defined by the slab column rotation at B1) for the simulation result. As can be seen in the figure, the rotations based on the modified Muttoni and isolated tests agree with the experimental result more closely.

Table 5-1 shows experimental and numerical rotation values at punching failure for various experiments and analysis. Both static and dynamic tests were conducted at the 0.73 scale at a reinforcement ratio of $0.64 \%$. The difference in rotation at failure in the dynamic test is $24 \%$ greater than the static test. At a 0.4 scale and a reinforcement ratio of $0.57 \%$ the predicted static rotational capacity of the connection using the original Muttoni failure criteria is $0.0353 \mathrm{rad}$ whereas the test of the connection yielded a rotation of $0.0418 \mathrm{rad}$, a difference of $18 \%$. This difference is reasonable due to the wide scatter of data used to 
formulate the Muttoni failure criteria. If the criteria are modified to account for the enhancement in ductility under dynamic loads (see section 5.3) then the predicted rotation capacity would be $0.0409 \mathrm{rad}$. This produces much closer estimate of the failure point as indicated by the red circular marker in Figure 5-7. If the \% difference in the experimental and theoretical results under static loading $(18 \%)$ is added on top of the theoretical dynamic capacity, then the estimated dynamic rotational capacity could be as much as 0.0484 rad. However, in the dynamic experimental multi-panel test the connections of the same design failed at rotations of 0.042 and $0.036 \mathrm{rad}$ for interior and exterior column removal respectively. Using the failure rotation of 0.042 produced the most accurate estimation in the behavior of the model as indicated by the diamond marker in Figure 5-7.

\section{Table 5-1 A comparison in rotation for different slab-column connections specimens}

\begin{tabular}{|l|l|l|c|c|c|}
\hline Description & Test type & \multicolumn{1}{|c|}{ Loading } & Scale & Reinforcement ratio & Rotation \\
\hline Muttoni original using static simulation of 0.4 scale & static & Concentric & 0.4 & 0.57 & 0.0353 \\
\hline Muttoni modification using static simulation of 0.4 scale & static & Concentric & 0.4 & 0.57 & 0.04092 \\
\hline Experimental test at 0.4 scale & static & Concentric & 0.4 & 0.57 & 0.0418 \\
\hline 0.64 experimental at 0.73 scale & static & Concentric & 0.73 & 0.64 & 0.0299 \\
\hline 0.64 experimental at 0.73 scale & dynamic & Concentric & 0.73 & 0.64 & 0.0372 \\
\hline multipanel experimental at scale 0.4 - interior & dynamic & Eccentric & 0.4 & 0.57 & 0.042 \\
\hline multipanel experimental at scale 0.4 - exterior & dynamic & Eccentric & 0.4 & 0.57 & 0.036 \\
\hline
\end{tabular}

\subsection{Summary}

A simplified model was developed to accurately predict collapse potential. The model was developed in the FE analysis program Abaqus. The model consisted of shell elements representing the slab and beam elements to represent the columns. The area within the punching cone perimeter modeled with connector elements as described in Liu et al. (2015). The failure criteria of the connector elements were modified to include the effect of the dynamic redistribution of the load. This modification in failure criteria showed 
a good agreement between the numerical and experimental results of slab-column connection subjected to dynamic loading rate with $4 \%$ difference in punching shear strength and $3.8 \%$ to $17.16 \%$ difference in deflection, except for specimen 0.64RE-D2. Also, this modified simplified model was used to predict the punching failure of a multipanel specimen and showed improved ability to predict the point of initiation of punching failure compared to an experimental test. 


\section{CHAPTER 6}

\section{CHAPTER 6: DYNAMIC DEBRIS LOADING IN FLAT-PLATE BUILDINGS}

\subsection{Introduction}

The robustness of a building, or the ability of that building to withstand collapse, is often analyzed in an alternate load path approach (GSA 2013, DoD 2016). In this approach a supporting element, such as a column, is suddenly removed and the ability of the building to withstand that removal is analyzed. Regardless of the cause of the removed column, generally, the progressive collapse event can be divided into two stages. The first stage analyzes the redistribution of load and if the members surrounding the failed column can support the redistributed load. If the surrounding members cannot support the redistributed load, the second stage of progressive collapse can happen. In this stage, there is falling debris from the failed members surrounding the removed column. This debris impacts the floor below and that floor must be able to withstand the dynamic impact to arrest progressive collapse. This work focuses on analysis of the impact loads from the falling debris and evaluation if the floor below would be able to withstand those loads.

In the past years, there has been some work in estimating the progressive collapse of floor systems in multi-story structures subjected to impact load due to falling slab or debris from the above floor. Vlassis et al. (2009) investigated the steel frame structures subjected to falling slab from the above floor. A simplified approach based on determining the kinetic energy of impacting floor that is transmitted to the impacted floor was used to examine two extreme impact events namely fully rigid and fully plastic impact. After that, 
the maximum dynamic deformation demands can be obtained by using the nonlinear static response of impacted floor by applying an energy balance concept without the need for detailed nonlinear dynamic analysis. More about this work is presented throughout this paper. Olmati et al. (2017) presented a framework for simplified reliability analysis for computing the probability of punching failure due to a slab falling from above. The analysis assumed an arbitrary portion of the impacting slab is in freefall and assumed to fail in three steps to induce some asymmetry to the impact. An FE model determined the demand at the slab column connection, and the capacity of the connection was assessed with Eurocode 2 and Critical Shear Crack Theory. The analysis showed that the demand quickly exceeded the punching shear capacity at the early stages of impact event and that a flat-plate building would be highly unlikely to survive the impact from a falling floor.

This chapter presents estimation of debris load using a simplified approach for a reinforced concrete (RC) flat-plate and compares it with a composite floor system which was considered previously by Vlassis et al. (2009). A theoretical determination of kinetic energy transmitted to the impacted floor was derived for two impact events (fully rigid and plastic impact). The mass of the impacting floor is varied and the required mass for survivability of the impacted floor determined. Since punching shear failure in flat-plate building dominates the response, a FE simulation model adopting the micromodel proposed by Liu et al. (2015) was used to investigate the nonlinear static response of slab column connection in a four-story building.

\subsection{Energy transferred during impact}

Generally, when an impacted body at rest is hit by a moving body (impacting body), the energy of the system will be dissipated through the impact, remain with impacting body, or be imparted to the impacted body. After the impact, the total of momentum of the system 
remains unchanged as the bodies move in velocity different than their initial velocities. To analyze impact problems two limit states: a fully plastic and a fully rigid impact scenario, can be assumed (Vlassis et al., 2009). The main characteristics of a fully plastic impact scenario is that the two bodies attach to each other and move together after the initial collision and part of the kinetic energy will be dissipated. To calculate the amount of energy transferred to the impacted body, the principle of conservation of momentum is employed. On the other hand, the fully rigid impact problems are more complicated than fully plastic impact. Due to the rigidity of impact bodies, several bounces of the impacting body on the impacted body are involved which leads to energy transmitted in various discrete points in time between two bodies. The principles of conversation of momentum and conservation of energy apply to calculate the percentage of transmitted energy to the impacted body. For both impact scenarios, a theoretical calculation of the energy transfer is presented next for two types of structures; RC flat-plate building, and a composite steel-concrete floor system which was analyzed earlier by Vlassis et al. (2009). The assumed impact response is based on the yield line theory of slab for RC flat-plate buildings and a plastic deformation in simply-supported beam for the composite floor system. The calculation assumes a kinematically admissible velocity field for the post-impact motion of the two colliding bodies. The shape of this field in each case is determined from the assumed static collapse profile, where consideration is given to a basic triangular failure mode.

\subsubsection{Fully plastic impact}

The energy transferred to the impacted body can be calculated for fully plastic impact event for both RC flat-plate and steel frame structures based on the assumed failure mechanism after impact. A reinforced concrete (RC) flat-plate building was analyzed using the same concept of Vlassis et al. (2009) by assuming a span panel length (L) of a square 
slab impacted by another panel falling from height $\mathrm{h}$ and travelling with initial velocity $v_{1}$ at time of impact. The initial velocity can be found by equating the total potential energy for the impacting panel to its kinetic energy just before impact; Equation (1). This velocity is calculated based on the assumption that the impacting panel falls at free-fall evenly throughout the story height. Rotation of the slab or other plastic deformations before freefall would reduce this velocity.

$$
v_{1}=\sqrt{2 g h}
$$

A yield line theory was applied to define the failure shape of the slab. Based on shape of failure as shown in Figure 6-1, assuming both panels have the same size and density $\rho$, assumed velocity field as shown in Figure 6-2(a), and symmetry about the rotation axis, the two-dimensional problem of conservation of angular momentum in Equation 2 is determined for a quarter slab panel.

$$
\int_{0}^{L / 2} \rho v_{1}\left(\frac{L}{2}-x\right) x d x=\int_{0}^{L / 2} 2 \rho v_{m c}\left(1-\frac{2}{L} x\right)\left(\frac{L}{2}-x\right) x d x
$$

By solving Equation 2, the value of $v_{m c}$ is:

$$
v_{m c}=\sqrt{2 g h}
$$

By calculating the ratio of the total kinetic energy for both slabs after impact to the initial kinetic energy of the impacting slab immediately before impact, Equation 6-4, the amount of energy which is transferred to the impacted floor is $33 \%$. 


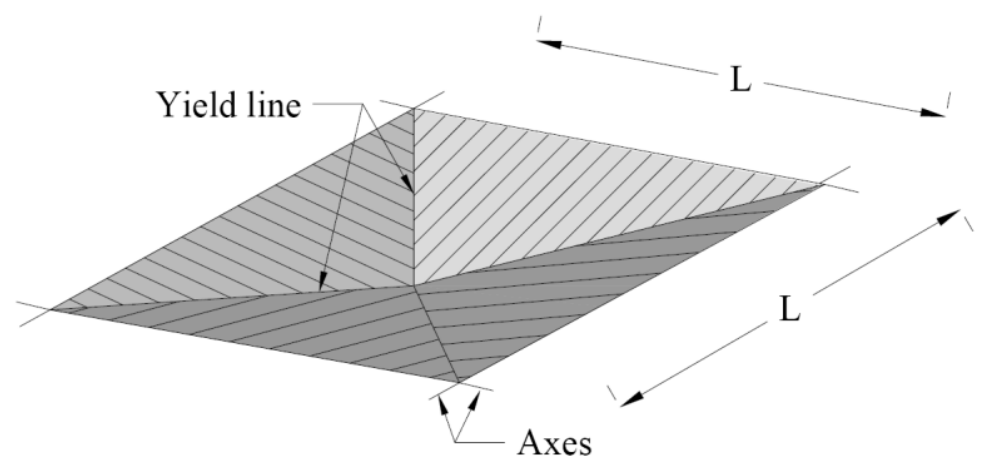

Figure 6-1 Assumed failure mechanism of RC panel based on yield line theory

$$
E=\frac{E_{2}}{E_{1}}=\frac{\int_{0}^{L / 2} \frac{1}{2}(2 \rho)\left[v_{m c}\left(1-\frac{2}{L} x\right)\right]^{2} x d x}{\int_{0}^{L / 2} \frac{1}{2} \rho v_{1}^{2} x d x}
$$

A composite steel-concrete floor was analyzed earlier by Vlassis et al. (2009) by assuming a span length (L) of a simply supported composite beam impacted by another beam falling from height $h$ with the same span length. By assuming a triangular rigidplastic failure mechanism for the combined beams after impact, a velocity field can be found for both beams based on Figure 6-2(a). Due to the symmetry in the system and assuming both beams have the same size and density $\rho$, a one-dimensional problem of conservation of angular momentum of one half of the two beams about the support can be applied to find the velocity field after impact. 


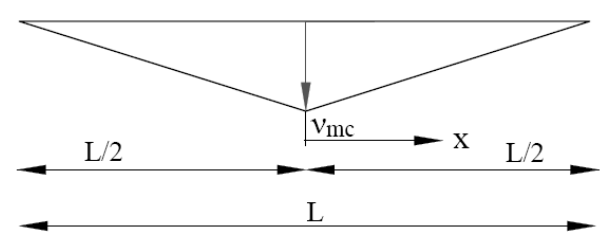

(a) Fully plastic impact

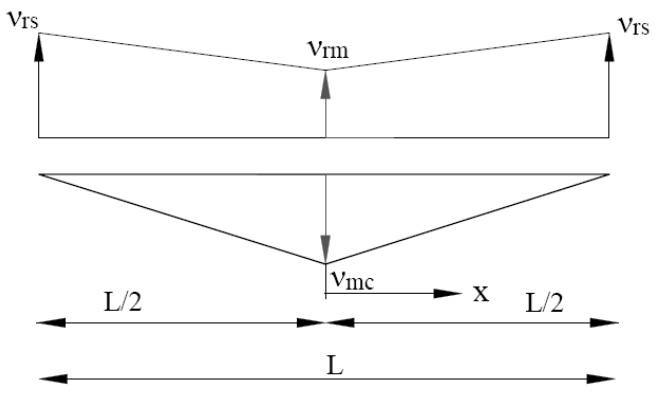

(b) Fully rigid impact

\section{Figure 6-2 Velocity profile for the two combined beams or slabs after fully plastic impact. Vlassis et al. (2009)}

The resulting amount of energy transfer to the impacted beam is $37.5 \%$ which means $62.5 \%$ of the initial kinetic energy of the impacting body is dissipated for steel framed buildings. More details can be found in Vlassis et al. (2009).

\subsubsection{Fully rigid impact}

The main assumption for fully rigid impact is that the two bodies do not remain in contact after colliding event and possess two independent velocity fields. Thus, there is no energy dissipation in this system. In this kind of impact, repeated bounces between two bodies are expected. Hence, for simplification purposes, only the transferred energy of the first bounce of the falling body is considered. The transferred energy at the end of impact events will be higher due to repeated bounces. The same two types of structures, RC flatplate buildings and composite beam are considered to find the relative transferred energy for a fully rigid impact scenario. For RC flat-plate structure, Figure 6-2(b) shows the assumed velocity field for the two bodies based on the yield line failure mechanism. The velocity at the center of the panel is assumed to be higher than the velocity of the ends at rotation axes. For two-dimensional problem and by taking the symmetry in consideration, the conservation of angular momentum about the rotation axes for the two bodies is: 


$$
\begin{aligned}
\int_{0}^{L / 2} \rho v_{1}\left(\frac{L}{2}-x\right) x d x= & \int_{0}^{L / 2} \rho v_{m}\left(1-\frac{2}{L} x\right)\left(\frac{L}{2}-x\right) x d x \\
& +\int_{0}^{L / 2} \rho\left(-v_{r m}-\left(\frac{2 v_{r s}-2 v_{r m}}{L} x\right)\right)\left(\frac{L}{2}-x\right) x d x
\end{aligned}
$$

Where, $v_{r m}$ and $v_{r s}$ are the rebound velocities of the upper slab at the center of panel and rotation axes. $v_{m}$ and $v_{1}$ are the panel center velocity of the lower slab and the uniform velocity of the falling slab immediately before impact respectively. To make sure that the exchange in momentum along the slab panel is compressive, the velocity of the lower slab $v_{m}$ should be positive. Moreover, the physical constrains $v_{r m} \geq-v_{m}$ and $v_{r s} \geq 0$ should be observed (Vlassis et al. 2007). By taking the integration of Equation 6-5:

$$
2 \sqrt{2 g h}=v_{m}-v_{r m}-v_{r s}
$$

To find the velocity field of the system, conservation of energy is applied by equating the kinetic energy immediately before and after impact events in Equation 6-7.

$$
\int_{0}^{L / 2} \frac{1}{2} \rho v_{1}^{2} d x=\int_{0}^{L / 2} \frac{1}{2} \rho\left[v_{m}\left(1-\frac{2}{L} x\right)\right]^{2} x d x+\int_{0}^{L / 2} \frac{1}{2} \rho\left(-v_{r m}-\frac{2 v_{r s}-2 v_{r m}}{L} x\right)^{2} x d x \text { (6-7) }
$$

By taking integration, Equation 7 can be rewritten in the following form:

$$
12 g h=v_{m}^{2}+v_{r m}^{2}+3 v_{r s}^{2}+2 v_{r m} v_{r s}
$$

By looking to Equations 6-6 and 6-8, there is not a unique solution to find the velocity field of the system. Therefore, the velocities of the panel center for upper and lower slab can be found in terms of the velocity at the panel end of upper panel $\left(v_{r m}\right)$ and the story height $(h)$ as follows:

$$
\begin{gathered}
v_{m 1,2}=\sqrt{2 g h} \pm \sqrt{4 g h-v_{r s}^{2}} \\
v_{r m 1,2}=-v_{r s}-\sqrt{2 g h} \pm \sqrt{4 g h-v_{r s}^{2}}
\end{gathered}
$$


By assuming the story height, Equations 6-9 and 6-10 can be solved to find the amount of energy transferred from the initial kinetic energy of impacting body to the impacted body for several values of $v_{r s}$, limited to the condition of the physical constrain $v_{r m} \geq-v_{m}$. For example, by assuming the story height for RC flat-plate is $3.05 \mathrm{~m}$, the maximum value for $v_{r s}$ would be $9.77 \mathrm{~m} / \mathrm{s}$. Hence, the percentage of the amount of energy transfer to the impacted slab for fully rigid impact scenario varies between $44 \%$ and $97 \%$ depending on the value of $v_{r s}$, as shown in Table 6-1.

A similar procedure was already conducted earlier by Vlassis et al. (2009) to find the amount of energy transferred to the impacted body. This study showed, for example, if the story height $h$ is $4 \mathrm{~m}$, the maximum value of $v_{r s}$ would be $12.97 \mathrm{~m} / \mathrm{s}$. Therefore, the amount of energy transfer to the impacted beam varies between $41 \%$ and $98 \%$ for the fully rigid impact scenario, as seen in Table 6-1.

Table 6-1 Energy transfer in a fully rigid impact for beam and slab construction elements

\begin{tabular}{ccccccc}
\hline \multirow{2}{*}{$v_{\mathrm{rs}}(\mathrm{m} / \mathrm{s})$} & \multicolumn{2}{c}{$v_{\mathrm{m}}(\mathrm{m} / \mathrm{s})$} & \multicolumn{2}{c}{$v_{\mathrm{rm}}(\mathrm{m} / \mathrm{s})$} & \multicolumn{2}{c}{ Relative energy transfer } \\
& $*$ Beam & †Slab & Beam & Slab & Beam & Slab \\
\hline 0.00 & 15.22 & 18.68 & 1.93 & 3.20 & 98.41 & 97.14 \\
4.00 & 14.86 & 17.92 & -0.42 & -1.55 & 93.85 & 89.42 \\
5.00 & 14.66 & 17.47 & -1.13 & -3.01 & 91.24 & 84.97 \\
6.00 & 14.40 & 16.88 & -1.89 & -4.59 & 88.01 & 79.39 \\
7.00 & 14.07 & 16.14 & -2.71 & -6.33 & 84.13 & 72.58 \\
9.77 & 12.79 & 12.66 & -5.38 & -12.58 & 69.50 & 44.64 \\
12.97 & 9.90 & & -9.87 & & 41.61 & - \\
\hline
\end{tabular}

*Assumed Steel- framed building $;\left(\mathrm{h}=4 \mathrm{~m}, \mathrm{~g}=9.81 \mathrm{~m} / \mathrm{s}^{2}, v_{1}=8.86 \mathrm{~m} / \mathrm{s}\right.$, initial kinetic energy $=19.62(\mathrm{~m} / \mathrm{s})^{2} / \mathrm{mL}$

${ }^{\dagger}$ Assumed RC flat-plate building; $;\left(\mathrm{h}=3.05 \mathrm{~m}, \mathrm{v}_{1}=7.74 \mathrm{~m} / \mathrm{s}\right.$, thickness $=0.19 \mathrm{~m}$, initial kinetic energy $=13.7 \mathrm{Kg}(\mathrm{m} / \mathrm{s})^{2} / \mathrm{m}^{2}$

\subsection{Assessment Methodology}

In progressive collapse scenarios, the falling debris from the upper floor can create a massive impulse of impact load on the lower floor and the structure's ability to withstand that impact load depends on the structural type. For RC flat-plate buildings, punching shear 
capacity of slab-column connection governs the ability resist the impact load. While for composite steel-concrete framed buildings with partial strength joints, the joint region capacity of impacted floor governs the ability resist the impact load. Based on the previous theoretical calculation of amount of transmitted kinetic energy to the impacted floor during impact events regardless of structure type, around $33 \%$ to $97 \%$ of the total kinetic energy can be transmitted to the impacted floor for fully plastic and fully rigid impact events respectively. This is a massive impact load on the impacted floor and it will be greater if more than one story impacts the below floor.

A simplified assessment approach used by Vlassis et al. (2009) is adopted to evaluate the impacted floor ability to withstand collapse. This approach was originally based on the framework developed by Izzuddin et al. (2007) for assessing the consequences of sudden column removal scenario. This approach contains three main steps: (i) calculation of nonlinear static response of impacted floor, (ii) simplified dynamic assessment, and (iii) ductility assessment.

The main platform of this approach is determination of nonlinear static response of impacted floor. Based on degree of sophistication and availability of analytical tools, the nonlinear static response can be determined. Once the static response is determined, the axes of this curve response $\left(P-u_{s}\right)$ should be shifted to dismiss the effect of initial response of gravity loads of the impacted floor prior the impact as Figure 6-3(a). Therefore, the resultant curve $\left(P^{\prime}-u_{s}^{\prime}\right)$ will be used in the next step of dynamic assessment calculation to find the ductility demands of the impacted floor as a result of impacting events of the upper floor. 
In the second step, the dynamic effect of the gravity load carried by the falling floor can be assessed without needing nonlinear dynamic analyses tools. An energy equilibrium approach is conducted to estimate the maximum dynamic deformation demands on the lower floor. Based on this approach, the point of stationary equilibrium following impact is achieved when the strain energy absorbed by impacted floor is equal to the summation of work done by the impacting floor gravity load and the kinetic energy transmitted to the impacted floor for assumed impact events and failure mechanism mode.

Generally, by assuming $P_{n}^{\prime}=\lambda_{n} P_{\circ}$, level of suddenly applied gravity loading that is imparted from the impacting floor, the external work $W_{n}^{\prime}$ done by this loading up to a dynamic displacement $u_{d, n}^{\prime}$ can be obtained from:

$$
W_{n}^{\prime}=\alpha \lambda_{n} P_{\circ} u_{d, n}^{\prime}
$$

The absorbed energy $U_{n}^{\prime}$ of the impacted floor following the impact is given by:

$$
U_{n}^{\prime}=\int_{0}^{u_{d, n}^{\prime}} \alpha P^{\prime} d u_{s}^{\prime}
$$

Based on the impact loading $P_{n}^{\prime}$ and impact scenario $i$, the transfer energy $E_{T, n, i}$ to the impacted floor can be obtained by:

$$
E_{T, n, i}=\gamma_{i} \lambda_{n} P_{\circ} h
$$

Where $\alpha$ is the non-dimensional weighting factor which depends on the assumed gravity load distribution on the floor components (Izzuddin et al. 2007,Izzudin et al. 2007, and Vlassis 2007), and $\gamma_{i}$ is a non-dimensional reduction factor related the percentage of the initial kinetic energy that is imported from the impacting floor to the impacted floor, and $h$ is the story height . Finally, by equating the difference of $U_{n}^{\prime}$ and $W_{n}^{\prime}$ to the $E_{T, n, i}$ and solving for $P_{n}^{\prime}=\lambda_{n} P_{\circ}$ : 


$$
P_{n}^{\prime}=\lambda_{n} P_{\circ}=\frac{\alpha \int_{0}^{u_{d, n}^{\prime}} P^{\prime} d u_{s}^{\prime}}{\alpha u_{d, n}^{\prime}+\gamma_{i} h}
$$

By using equation 15, the suddenly-applied gravity loading $P_{n}^{\prime}$ at each load level $n$ can be plotted with the corresponding maximum dynamic deformation $u_{d, n}^{\prime}$ as shown in Figure 6-3(b). This plot is called a modified pseudo-static response based on Vlassis (2009) and it will be used in the last step in the assessments.
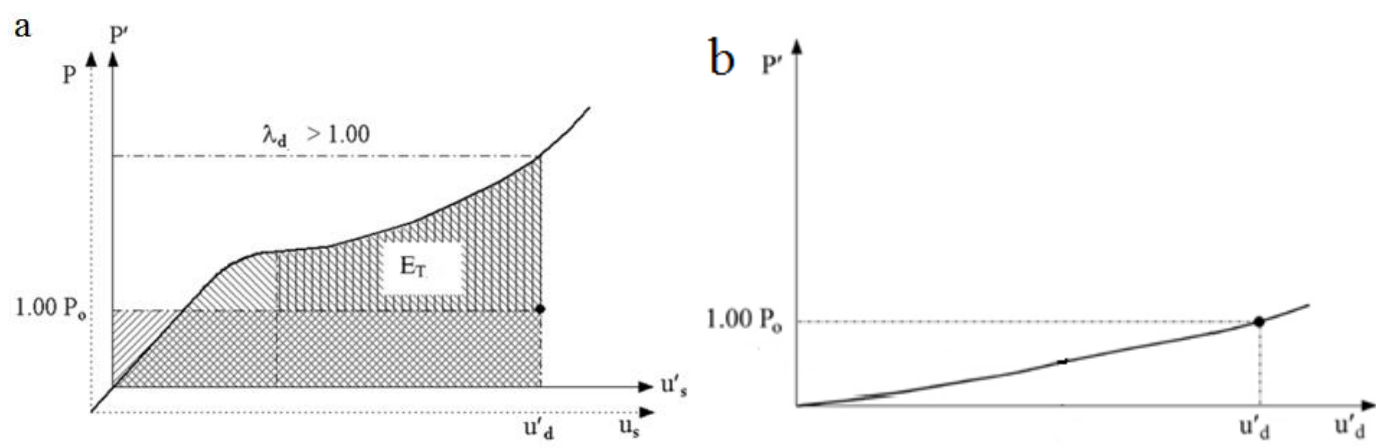

Figure 6-3 Simplified dynamic assessment and definition of modified pseudo-static response for impacted floor systems. (a) Dynamic response $P^{\prime}=1.00 P_{\circ}$; (b) modified pseudo-static response (modified from Vlassis et al. (2009))

In the last step, ductility demands on the impacted floor can be established based on the dynamic deformation demands which was created based on the modified pseudostatic response curve. To complete the assessment, the ductility demands can be compared with the available ductility of the impacted floor to assess the structure can resist the impact load to prevent progressive collapse. More details of this methodology can be found in Vlassis et al. (2009).

\subsection{Application Studies}

Two case studies were chosen to apply this proposed approach to investigate building withstanding progressive collapse. RC flat-plate building will be discussed in 
details, while a short summary will be given of the steel-concrete composite floor building from Vlassis et al. (2009).

\subsubsection{RC Flat-plate building}

The assessment approach on a RC flat-plate building was applied to study the building's ability to withstand progressive collapse due to falling debris. A theoretical existing RC flat-plate building designed with ACI 318-71 (ACI 1971) was used as a prototype. The prototype RC flat-plate structure is four story building having a $3.05 \mathrm{~m}$ story height and four bays with an equal length of $6.1 \mathrm{~m}$ span in each direction. The slab thickness was $190 \mathrm{~mm}$. Each floor was designed to carry a uniformly distributed 2.39 $\mathrm{KN} / \mathrm{m}^{2}$ live load and a superimposed $1.2 \mathrm{KN} / \mathrm{m}^{2}$ dead load. The compressive strength of concrete was $27.58 \mathrm{MPa}$ and yield strength of the steel of $414 \mathrm{~N} / \mathrm{mm}^{2}$. More details on this prototype building can be found in Peng et al. (2017). To establish a realistic assessment to the impacted floor, it is important to assume the failure mechanism of RC flat-plate structure. The falling floors evenly impacts the lower floor and the impacted floor will deform similar to yield line theory of the impacted floor and creating maximum deflection at the center(s) of the panel(s) as Figure 6-4. Failure of the floor will be controlled by the slab-column connection punching strength which is adopted as a state of building failure.

Punching shear capacity of slab-column connection can be determined by using either very sophisticated model analyses or simple methods. Finite element (FE) simulation by using ABAQUS (2011) was used in this study to simulate a portion of the prototype by adapting the macro-model proposed by Liu et al. (2015). The macro-model contains shell and connector elements jointed at column perimeter to simulate the nonlinear slab behavior. Punching shear perimeter position or connecter length was assumed based on the ACI 31814 (ACI 2014) at the distance of half slab effective depth. Thin shell elements contained 
rebar layers were selected to simulate the slab outside the punching shear perimeter. Concrete Damage Plasticity (Lubliner et al.1989, Lee and Fenves 1998) with tension stiffening behavior was adopted to model the concrete. Slab-column connection area was modeled as a rigid shell elements. Two connector beam elements in each side of punching shear perimeter were assumed with six degree of freedom at each node to represent the transfer forces from the slab to the column. Nonlinear behavior for primary bending moment and torsion was assumed, while shear force was assumed as a linear behavior. Punching shear failure is reached when the connecter beam element separate at a certain limit of failure criteria. Muttoni equation (2008) for punching strength was adopted as a failure criteria of connector beam element separation, Equation 6-15. More details of the macro-model can be found in Liu et al. (2015). Therefore, the load deflection behavior and maximum capacity of a slab column connection can be established and used in the assessment approach to assess the falling debris scenario.

$$
\frac{V_{u}}{b_{o} d \sqrt{f_{c}^{\prime}}}=\frac{3 / 4}{1+15 \frac{\psi_{u} d}{d_{g 0}+d_{g}}}
$$

Where $V_{u}$ is connection punching strength,$\psi_{u}$ is slab rotation relative to column at punching failure, $d_{g}$ is the maximum size of aggregate, and $d_{g} \mathrm{O}$ is a reference aggregate size equal to $16 \mathrm{~mm}$. 


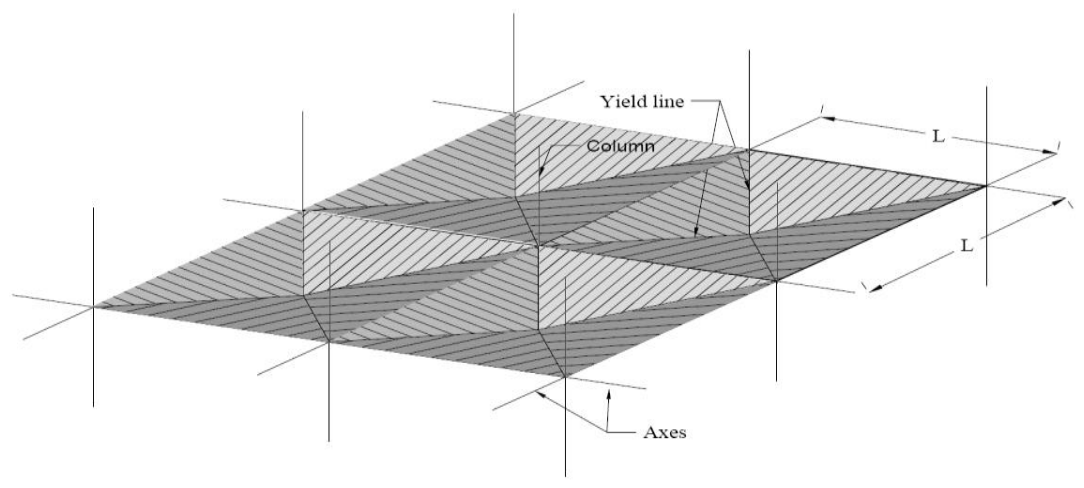

Figure 6-4 Assumed failure in four panels surrounding column in RC flat-plate structure based on yield line theory

The nonlinear response of the impacted floor was established as shown in Figure 6-5. The total gravity load (assuming $1.0 \mathrm{DL}+0.2 \mathrm{LL}$ ) at the assumed punching shear location failure is $143 \mathrm{KN}$ with a resulting $0.54 \mathrm{~mm}$ maximum displacement at the mid-panel. Therefore, the axes of $\left(P-u_{s}\right)$ curve shifts to establish $P^{\prime}-u_{s}^{\prime}$ to account this static response of service load on the impacted floor.

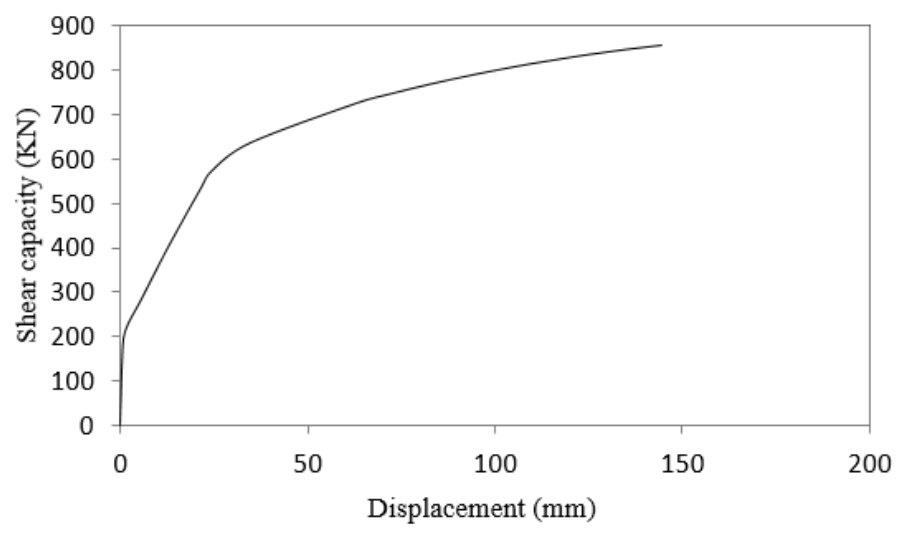

Figure 6-5 Static load-deflection curve for the RC flat-plate system

Furthermore, based on the failure mechanism and the failure shape in the impacted floor after impact as shown in Figure 6-1, the non-dimensional weighting factor $\alpha$ is 0.33 . As discussed earlier, to establish the modified pseudo-static response of the RC flat-plate structure, it is important to estimate the percentage of total kinetic energy transferred to the impacted floor. The theoretical analyses of RC flat-plate structures based on the assumed 
impact events and failure mechanism showed that $33 \%$ to $97 \%$ of total kinetic energy of falling floor will transfer to the impacted floor for fully plastic to fully rigid impact event, respectively. Hence, a range (20\% to $70 \%$ ) of non-dimensional energy reduction factor $\gamma_{i}$ was adopted to establish the modified pseudo-static curve as shown in Figure 6-6. It is obvious that even with the low kinetic energy transfer (20\%) the RC flat-plate structure can only resist $28 \%$ of the gravity loads on the impacted floor before the impact. This means that the impacted floor will survive impact only if the impacting floors mass (or weight) is $28 \%$ of the impacted floor mass. This may be true only for roofs or small areas of falling debris. Furthermore, higher transferred energy values to the impacted floor will reduce this value. This finding is consistent with the results from Olmati et al. (2017) which also indicated that flat-plate buildings are highly unlikely to withstand impact from falling debris.

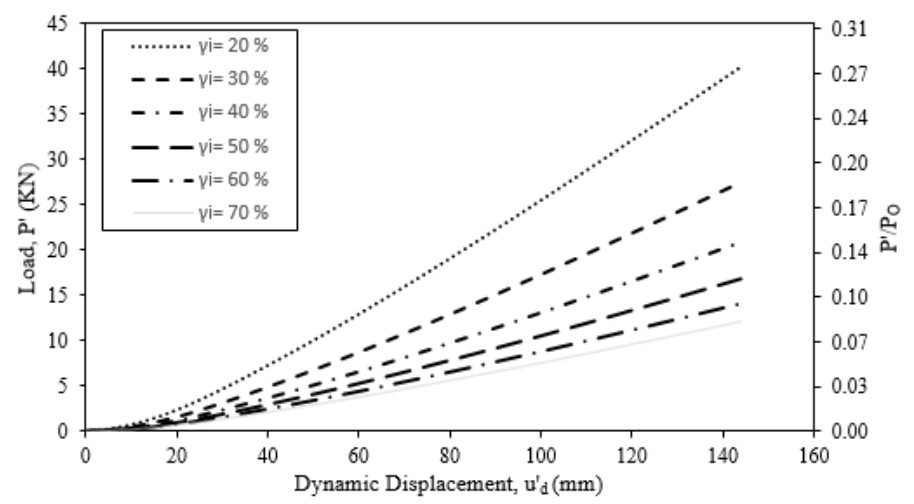

Figure 6-6 Modified pseudo-static load-deflection curve for the RC flat-plate system 6.4.1.1 Loading rate effect in RC Flat-plate

Most analysis of structures for collapse (GSA 2013, DoD 2016) use the static capacity of the surrounding members to determine if collapse will progress. However, as the loading is dynamic, this may introduce inaccuracy into the analysis. To account for dynamic loads the Muttoni failure criteria, Equation 6-15, is modified to take in 
consideration the loading rate effect, A series of four experimental test of isolated square $\mathrm{RC}$ slabs at a scale of 0.73 was conducted with two different longitudinal reinforcement ratios (1\% and $0.64 \%)$ and tested dynamically by using a dynamic hydraulic ram at a loading speed of $0.23 \mathrm{~m} / \mathrm{s}(9 \mathrm{in} / \mathrm{s})$. Furthermore, a numerical analysis was utilized to study the effect of tension reinforcement ratio, slab thickness, and grade of concrete compressive strength on the response of isolated RC flat-plate slab column connections and its failure criteria. The modified failure criteria are presented in Equation 6-16:

$$
\frac{V_{u}}{b_{o} d \sqrt{f_{c}^{\prime}}}=\frac{3 / 4}{1+12 \frac{\psi_{u} d}{d_{g 0}+d_{g}}}
$$

By applying Equation 17 to modify static response of slab-column connection, and assuming only $20 \%$ of transfer energy, the ability of RC flat-plate structure to withstand falling debris is enhanced from $28 \%$ to $34 \%$ of the gravity loads on the impacted floor which is still very low to withstand collapse.

\subsubsection{Composite steel -concrete floor building}

A typical composite steel-concrete floor building was analyzed by Vlassis et al. (2009) to investigate its ability to resist progressive collapse due to falling debris by applying the proposed methodology assessment. Analytical tools and geometry details can be found in more detail in Vlassis et al. (2009). In summary, a seven-story composite floor building with identical floors and story to story height of $3.5 \mathrm{~m}$ was used as a prototype. Each floor was designed to carry an unfactored uniformly distributed dead and imposed loads of $4.2 \mathrm{KN} / \mathrm{m}^{2}$ and $5 \mathrm{KN} / \mathrm{m}^{2}$ respectively. A grillage-type approximation is conducted to create the nonlinear static response of impacted floor. Failure of a single support joint in one of the grillage components is adopted as the limit state of the grillage floor system. By 
using static analysis performed by ADAPTIC (Izzuddin 1991), initial static response of gravity load on the impacted floor prior the impact was determined and resulted in a total static load capacity of $P_{\circ}=585 \mathrm{KN}$ and mid span deflection $14 \mathrm{~mm}$ based on a load combination of 1.0DL+0.25LL. Moreover, the nonlinear static response of grillage system representing a peripheral and an internal floor plate was determined.

By applying the methodology assessment, it is noticed that even with a very small amount of transferred energy (20\%), the structure will survive only if the impacting floor has $26 \%$ of the gravity load of the impacted floor. This value decreases as the amount of transfer energy increases. More details can be found in Vlassis et al. (2009).

\subsection{Summary}

This research adapted a simplified assessment methodology, based on the amount of transferred kinetic energy to the impacted floor, to investigate the withstanding progressive collapse due to falling debris for two types of construction; reinforced concrete flat-plate structure, and composite steel-concrete floor structure. A theoretical calculation has been done for two scenarios of impacting events (fully plastic impact, and fully rigid impact) to estimate the amount of transfer energy to the impacted floor. The conclusions can be drawn as follows:

1. Fully plastic events with the assumed failure shape showed that $37.5 \%$ and $33 \%$ of the initial kinetic energy of impacting floor immediately prior the impact transferred to the impacted floor for composite floor and RC flat-plate structures, respectively. While, approximately $44 \%$ to $97 \%$ of initial kinetic energy transfers to the impacted floor in case of fully rigid impact events. 
2. The RC flat-plate building showed low percentage of survivability to withstand progressive collapse due to falling debris. For very low amount of transferred energy (20\%), the structure will survive only if the impacting floor as $28 \%$ of the mass of the impacted floor. Moreover, with enhancing the strength and ductility of slab-column connection due to the effect of loading rate, the mass of the impacting floor can increase from $28 \%$ to $34 \%$.

3. The composite floor building presented is highly unlikely to withstand the impact due to falling debris. Even with only $20 \%$ of transferred energy, the impacted floor can only survive the impact if the impacting floor has $26 \%$ of the impacted floor's gravity load.

This analysis assumes that the impacting floor falls at freefall throughout the story height. While this may be true for flat-plate buildings where punching failure occurs brittle and the impacting slab falls freely, for framed building the rotation and bending of beams may significantly slow the impacting floor and reduce the energy at impact. More research needs to be done to determine the velocity of the falling debris before impact. 


\section{CHAPTER 7}

\section{CHAPTER 7: CONCLUSIONS AND FUTURE WORK}

\subsection{Summary}

During the initial stages of a collapse, failure of the initiating member (i.e. column loss) can cause a dynamic load redistribution in the surrounding members. The ability of the structure to withstand these dynamically redistributed loads will determine if the building is susceptible to collapse. If the surrounding members cannot support the redistributed load, the second stage of progressive collapse can happen. In this stage, there is falling debris from the failed members surrounding the removed column and dynamic impact on the floors below. Furthermore, while the behavior of $\mathrm{RC}$ members under static and high-rate (blast) loads are well researched, there is less information about the response under medium rate loads that occur during collapse. This research looked specifically at flat-plate slab column connections to study the effect of collapse loading rate on the slab column connection behavior and how that behavior changes the collapse potential of the building. Second, the effect of falling debris load on the lower floors of flat-plate buildings during the collapse was investigated.

The objective of this research was to experimentally and analytically investigate the difference in behavior of flat-plate slab column connections under static and dynamic loading rates (collapse loading rate) and its effect on the collapse process. The research implements improvements to a simplified model (similar to what would be available in design office) to account for the dynamic response of the connection. Furthermore, the 
research analyzes the impact loads from the falling debris and evaluates if the floor below would be able to withstand those loads.

\subsection{Conclusions}

The following conclusions can be drawn from this study:

\subsubsection{Experimental investigation of loading rate effects on RC slab-column connection}

- The experimental results show a significant increase in ductility in dynamically tested connections compared to static tests with no significant change in punching shear capacity. The increase in ductility could be from the difference in rate enhancement of shear and flexural capacity of the member due to stain rate effect on materials strength. The lack of increase in punching capacity could be due to a counteracting dynamic strain amplification in the dynamic tests.

- All the experimental tests showed increased energy absorption of column-slab connections with increasing loading rate especially for $0.64 \%$ reinforcement ratio specimens which absorbed more energy compared to $1.0 \%$ reinforcement ratio. This may improve the ability of a building to resist progressive punching failures.

\subsubsection{Numerical investigation of loading rate effects on RC slab-column connection}

- A 3D FE model was developed using LS DYNA and ANSYS was used to assess the punching shear strength and ductility of isolated slab-column connection under dynamic and static loading rate. The overall response of load-deflection curve of slab column connection is captured in FE model up to punching shear failure. Also, the FE study showed that at increased loading rates, the punching capacity is enhanced to a greater extent than the flexural capacity. This could allow for more 
flexural deformation in the slab before final punching failure as explanation of having more ductility for specimens tested dynamically than the static tests.

- A parametric study was investigated numerically. The parameters include the effect of tension reinforcement ratio, slab thickness, and grade of concrete compressive strength on the response of isolated RC flat-plate slab column connections under static and dynamic loading rate. The parametric study showed more ductility for lower tensile reinforcement, smaller slab thickness, and reduced concrete strength in compression under dynamic loading rates while the strength of the connection remained relatively unchanged.

\subsubsection{Simplified simulation of loading rate effect on RC slab-column connection}

- The failure criteria of the connector elements in a simplified model were modified to include the effect of the dynamic redistribution of the load. This modification in failure criteria showed an improved agreement between the numerical and experimental results of slab-column connection subjected to dynamic loading rate with $4 \%$ difference in punching shear strength and $3.8 \%$ to $17.16 \%$ difference in deflection, except for specimen 0.64RE-D2. Also, this modified simplified model was used to predict the punching failure of a multi-panel specimen and showed improved ability to predict the point of initiation of punching failure compared to an experimental test.

\subsubsection{Dynamic debris loading in flat-plate buildings}

- Fully plastic events with the assumed failure shape showed that $37.5 \%$ and $33 \%$ of the initial kinetic energy of impacting floor immediately prior the impact transferred to the impacted floor for composite floor and RC flat-plate structures, 
respectively. While, approximately $44 \%$ to $97 \%$ of initial kinetic energy transfers to the impacted floor in case of fully rigid impact events.

- The RC flat-plate building showed low percentage of survivability to withstand progressive collapse due to falling debris. For very low amount of transferred energy (20\%), the structure will survive only if the impacting floor as $28 \%$ of the mass of the impacted floor. Moreover, with enhancing the strength and ductility of slab-column connection due to the effect of loading rate, the mass of the impacting floor can increase from $28 \%$ to $34 \%$.

- The composite floor building presented is highly unlikely to withstand the impact due to falling debris. Even with only $20 \%$ of transferred energy, the impacted floor can only survive the impact if the impacting floor has $26 \%$ of the impacted floor's gravity load.

\subsection{Future work}

Future work in the area of collapse if flat-plate buildings needs to be conducted in:

- Verification of connection and slab behavior using full-scale tests. Almost all multi-panel specimens have been conducted at a reduced scale, however due to size effects (especially important in the compressive membrane phase) the behavior of scaled specimens may not capture full scale behavior.

- Investigation of effect of different reinforcement ratios on the dynamic slabcolumn connection response. Tests and analysis were only conducted at two reinforcement ratios. Tests at more ratios are needed to fully understand the dynamic response of slab-column connections. 
- Additional tests at different loading rates. While these tests tried to simulate the collapse loading rate, additional tests are needed to determine the point at which the behavior of the system changes.

- Experimental investigation into the impact of falling debris. Many simplifying assumptions (impact velocity, distribution, energy) were made in the analysis and more experimental and analytical investigations are needed to clarify these parameters. 


\section{REFERENCES}

ACI Committee 318. (1971). Building Code Requirements for Reinforced Concrete and Commentary (ACI 318-71). American Concrete Institute, Farmington Hills, MI, 1971.

Adhikary, S. D., Li, B., \& Fujikake, K. (2015). "Parametric study of RC beams under a wide range of loading rates". Proceedings of the Institution of Civil Engineers-Structures and Buildings, 168(10), 729-746.

Adhikary, S. D., Li, B., \& Fujikake, K. (2014). "Effects of high loading rate on reinforced concrete beams". ACI Structural Journal, 111(3), 651.

American Concrete Institute (ACI). (2014). "Building code requirements for structural concrete and commentary.” ACI 318-14 and 318R-14, Farmington Hills, Mich.

ANSYS, (2015). Release 16, ANSYS User's Manual.

Bažant, Z. P., Adley, M. D., Carol, I., Jirásek, M., Akers, S. A., Rohani, B., ... \& Caner, F. C. (2000a). Large-strain generalization of microplane model for concrete and application. Journal of engineering mechanics, 126(9), 971-980.

Bažant, Z. P., Caner, F. C., Adley, M. D., \& Akers, S. A. (2000b). Fracturing rate effect and creep in microplane model for dynamics. Journal of Engineering Mechanics, 126(9), 962-970.

Belytschko, T., \& Bindeman, L. P. (1993). “Assumed strain stabilization of the eight-node hexahedral element”. Computer Methods in Applied Mechanics and Engineering, 105(2), $225-260$. 
Broms, C. E. (1990). "Punching of flat-plates: a question of concrete properties in biaxial compression and size effect”. ACI Structural Journal, 87(3), 292-304.

CEN Comité Européen de Normalisation.(2004). EN 1992-1-1: design of concrete structures - Part 1-1: general rules and rules for buildings. Brussels, Belgium.

Chopra, A. K. (2012). Dynamics of structures: Theory and applications to Earthquake Engineering.

Criswell, M. E. (1974). "Static and dynamic response of reinforced concrete slab-column connections". Special Publication, 42, 721-746.

Comité Euro-International du Béton, CEB-FIP Model Code 1990, Redwood Books, Trowbridge, Wiltshire, UK, 1993.

Dassault Systèmes Simulia Corp. (2011). Abaqus analysis user’s manual ,2011

DoD (Department of Defense). (2016). "Design of buildings to resist progressive collapse." UFC 4-023-03, Washington, DC.

Fujikake, K., Mori, K., Uebayashi, K., Ohno, T., \& Mizuncr, J. (2000). Dynamic properties of concrete materials with high rates of tri-axial compressive loads. WIT Transactions on The Built Environment, 48.

Ghali, A., Elmarsri, M. Z., \& Dilger, W. (1976, October). "Punching of Flat-plates Under Static and Dynamic Horizontal Farces". In Journal Proceedings (Vol. 73, No. 10, pp. 566572). 
GSA, U. (2013). Progressive collapse analysis and design guidelines for new federal office buildings and major modernization projects. Washington, DC.

Isaac, P., Darby, A., Ibell, T., \& Evernden, M. (2013). Influence of loading rate on failure mode of reinforced concrete members. Proceedings of the Institution of Civil EngineersEngineering and Computational Mechanics, 166(4), 194-203.

Iwai, S., Yoshida, N., Nakamura, T., \& Wakabayashi, M. (1972). Effects of loading rate on the performance of structural elements. Transactions of Architectural Institute of Japan(AIJ), 102-111.

Izzuddin, B. A. (1990). Nonlinear dynamic analysis of framed structures (Doctoral dissertation, Imperial College London (University of London)).

Izzuddin, B. A., Vlassis, A. G., Elghazouli, A. Y., \& Nethercot, D. A. (2007). Progressive collapse of multi-storey buildings due to sudden column loss—Part I: Simplified assessment framework. Engineering structures, 30(5), 1308-1318.

Izzuddin, B. A., Vlassis, A. G., Elghazouli, A. Y., \& Nethercot, D. A. (2007). Assessment of progressive collapse in multi-storey buildings.

Kulkarni, S. M., \& Shah, S. P. (1998). "Response of reinforced concrete beams at high strain rates”. Structural Journal, 95(6), 705-715.

Lee, J., and Fenves, G.L. (1998). Plastic-Damage Model for Cyclic Loading of Concrete Structures. ASCE Journal of Engineering Mechanics, 124(8), 892-900. 
Liu, J., Tian, Y., Orton, S. L., \& Said, A. M. (2015). Resistance of flat-plate buildings against progressive collapse. I: Modeling of slab-column connections. Journal of Structural Engineering, 141(12), 04015053.

Liu, J., Tian, Y., \& Orton, S. L. (2013). "Vulnerability of disproportionate collapse in older flat-plate buildings subjected to sudden removal of a bearing column”. In Structures Congress 2013: Bridging Your Passion with Your Profession (pp. 2814-2823).

Lubliner, J., Oliver, J., Oller, S. and Oñate, E. (1989). A Plastic-Damage Model for Concrete. International Journal of Solids Structures, 25(3), 299-329.

Kinnunen, S., \& Nylander, H. (1960). Punching of concrete slabs without shear reinforcement (p. 112). Elander.

LSTC, (2016). (LS-DYNA R8.1.0; LSTC, Livermore, CA, USA).

Malvar, L. J. (1998). "Review of static and dynamic properties of steel reinforcing bars". Materials Journal, 95(5), 609-616.

Malvar, L. J., \& Ross, C. A. (1998). "Review of strain rate effects for concrete in tension”. Materials Journal, 95(6), 735-739.

Mihashi, H., \& Wittmann, F. H. (1980). Stochastic approach to study the influence of rate of loading on strength of concrete. Stevin-Laboratory of the Department of Civil Engineering of the Delft University of Technology. 
Mohamed, O. A. (2006). Progressive collapse of structures: annotated bibliography and comparison of codes and standards. Journal of Performance of Constructed Facilities, 20(4), 418-425.

Muttoni, A., \& Schwartz, J. (1991). Behavior of beams and punching in slabs without shear reinforcement. In IABSE colloquium (Vol. 62, No. EPFL-CONF-111612, pp. 703-708). IABSE Colloquium.

Muttoni, A. (2008). Punching shear strength of reinforced concrete slabs without transverse reinforcement. ACI structural Journal, 105(EPFL-ARTICLE-116123), 440-450.

Murray, Y. D. (2007). “User's manual for LS-DYNA concrete material model 159 (No. FHWA-HRT-05-062)".

Mutsuyoshi, H., \& Machida, A. (1985). "Behavior of reinforced concrete members subjected to dynamic loading”. Doboku Gakkai Ronbunshu, 1985(354), 81-90.

Olmati, P., Sagaseta, J., Cormie, D., \& Jones, A. E. K. (2017). Simplified reliability analysis of punching in reinforced concrete flat slab buildings under accidental actions. Engineering Structures, 130, 83-98.

Peng, Z. (2015). Experimental and Analytical Evaluation of Disproportionate Collapse in Flat-Plate Buildings (Doctoral dissertation, University of Missouri-Columbia).

Peng, Z., Orton, S. L., Liu, J., \& Tian, Y. (2017a). Effects of In-Plane Restraint on Progression of Collapse in Flat-Plate Structures. Journal of Performance of Constructed Facilities, 04016112. 
Peng, Z., Orton, S. L., Liu, J., \& Tian, Y. (2017b). Experimental Study of Dynamic Progressive Collapse in Flat-Plate Buildings Subjected to Exterior Column Removal. Journal of Structural Engineering, 143(9), 04017125

Peng, Z., Orton, S. L., Liu, J., \& Tian, Y. (2018). Experimental Study of Dynamic Progressive Collapse in Flat-Plate Buildings Subjected to Interior Column Removal. Journal of Structural Engineering, Accepted

Reinhardt, H. W., \& Weerheijm, J. (1991). Tensile fracture of concrete at high loading rates taking account of inertia and crack velocity effects. International Journal of Fracture, $51(1), 31-42$.

Shah, S. P., Fafitis, A., \& Arnold, R. (1983). "Cyclic loading of spirally reinforced concrete". Journal of Structural Engineering, 109(7), 1695-1710.

Simo, J. C., \& Ju, J. W. (1987). "Strain-and stress-based continuum damage models-II. Computational aspects". International journal of solids and structures, 23(7), 841-869.

Soroushian, P., \& Choi, K. B. (1987). Steel mechanical properties at different strain rates. Journal of Structural Engineering, 113(4), 663-672.

Vlassis, A. G. (2007). Progressive collapse assessment of tall buildings (Doctoral dissertation, Imperial College London (University of London)).

Vlassis, A. G., Izzuddin, B. A., Elghazouli, A. Y., \& Nethercot, D. A. (2007). Progressive collapse of multi-storey buildings due to sudden column loss-Part II: Application. Engineering Structures, 30(5), 1424-1438. 
Vlassis, A. G., Izzuddin, B. A., Elghazouli, A. Y., \& Nethercot, D. A. (2009). Progressive collapse of multi-storey buildings due to failed floor impact. Engineering Structures, 31(7), $1522-1534$.

Vos, E., \& Reinhardt, H. W. (1982). "Influence of loading rate on bond behaviour of reinforcing steel and prestressing strands”. Matériaux et Construction, 15(1), 3-10.

Wakabayashi, M., Nakamura, T., Yoshida, N., Iwai, S., \& Watanabe, Y. (1980). Dynamic loading effects on the structural performance of concrete and steel materials and beams. In Proc., 7th World Conf. on Earthquake Engineering (Vol. 6, pp. 271-278). Turkish National Committee on Earthquake Engineering.

Weathersby, J. H. (2003). "Investigation of bond slip between concrete and steel reinforcement under dynamic loading conditions" (Doctoral dissertation, Mississippi State University).

Xiao, S., Li, H., \& Monteiro, P. J. M. (2010). Influence of strain rates and load histories on the tensile damage behaviour of concrete. Magazine of Concrete Research, 62(12), 887894.

Xiao, Y., Li, B., \& Fujikake, K. (2016). “Experimental Study of Reinforced Concrete Slabs under Different Loading Rates”. ACI Structural Journal, 113(1), 157.

Xiao, Y., Li, B., \& Fujikake, K. (2017). Behavior of Reinforced Concrete Slabs under LowVelocity Impact. ACI Structural Journal, 114(3), 643. 
Yan, C. (1992). Bond between reinforcing bars and concrete under impact loading (Doctoral dissertation, University of British Columbia).

Yan, D. M., \& Chen, G. D. (2012). "Effect of loading rate on the bonding strength between rebar and concrete”. In Advanced Materials Research (Vol. 450, pp. 122-125). Trans Tech Publications. 


\section{VITA}

The author Aamer Jawdhari was born in Al-Qassim County, Babylon Province, Iraq in 1976. He attended the University of Technology, Baghdad, Iraq from October 1994 to June 1999 and received Bachelor of Science in Building and Construction Engineering. He then continued graduate school at the same university, in October 1999 and graduated with his Master of Science degree in February 2002. He worked as a site engineer in the Makhool Dam Project in October 2002 until March 2003, then he worked at the main office

as a chief engineer in the General Commission for Maintenance of Irrigation and Drainage Projects -Ministry of Water Resources in Iraq from March 2004 until 2013. He began work toward his Ph.D. in Structural Engineering at the University of MissouriColumbia, Missouri, USA in August 2014 and will graduate with his Ph.D. in Civil Engineering in July 2018 and will work with the Ministry of Water Resources in Iraq. 